\title{
ESTABLISHMENT OF THE FFTF VERTICAL CORE REFERENCE CONCEPT
}

\section{AEC RESEARCH \& DEVELOPMENT REPORT}




\section{LEGAL NOTICE}

This report was prepared as an account of work sponsored by the United States Government. Neither the United States nor the United States Atomic Energy Commission, nor any of their employees, nor any of their contractors, subcontractors, or their employees, makes any warranty, express or implied, or assumes any legal liability ar responsibility for the accuracy, completeness or usefulness of any information, apparatus, product or process disclosed, or represents that its use would not infringe privately owned rights.

\section{PACIFIC NORTHWEST LABORATORY \\ RICHLAND, WASHINGTON \\ operated by}

BATTELLE MEMORIAL. INSTITUTE

for the

UNITED STATES ATOMIC ENERGY COMMISSION UNDER CONTRACT AT(45-1)-1830 
BNWL- 1165

33679000615189

UC-80, Reactor

Technology

\section{ESTABLISHMENT OF THE FFTF VERTICAL CORE \\ REFERENCE CONCEPT $(a)$}

Report compiled by

C. P. Cabe11(b)

September 1970

BATTELLE MEMORIAL INSTITUTE

PACIFIC NORTHWEST LABORATORIES

RICHLAND, WASHINGTON 99352

(a) Work performed during the period July 1967-December 1968.

(b) Now employed by WADCO Corp., a Subsidiary of Westinghouse Electric Corp., under AEC Contract No. AT(45-1)-2170 
BNWL- 1165

Printed in the United States of America

A zilable from

Clearinghouse for Federal Scientific and Technical Information National Bureau of Sta lards, U.S. Department of Commerce

Springfi ld, Virginia 22151

Price: Printed spy $\$ 3.00 ;$ Microfiche $\$ 0.65$ 
$\underline{\text { PRINCIPAL CONTRIBUTORS }}$

**E. R. Astley
A. J. Anthony
*S. O. Arneson
K. L. Berrett
D. E. Bloomfield
C. L. Boyd
D. C. Boyd
W. L. Bunch
W. E. Cawley
*. L. Condotta
R. R. Cone
K. O. Creek
W. H. Dayenport
W.
L. M. Finch
E. E. Garrett
J. W. Hagan
G. A. Halseth
R. J. Hennig
*P. L. Hofmann
R. J. Jackson
W. U. Jackson
M. T. Jakub
R. N. Johnson
*E. M. Johnston
J. W. Kolb
H. D. Lenkersdorfer
A. F. Lille
W. W. Little
C. E. Love

**E. R. Astley

. Anthony

K. I. Berrett

D. E. Bloomfield

C. L. Boyd

D. C. Boyd

W. L. Bunch

D. L. Condotta

R. R. Cone

K. 0. Creek

- H. Dayenport

L. M. Finch

E. E. Garrett

J. W. Hagan

G. A. Halseth

R. J. Hennig

P. L. Hofmann

R. J. Jackson

W. U. Jackson

M. T. Jakub

J. W. Kolb

H. D. Lenkersdorfer

W. W. Little

C. E. Love
J. F. Lubeck

L. L. Maas

C. A. Mansius

D. Marinos

*W. B. McDonald

J. E. Mills

C. L. Mohr

R. A. Moen

C. A. Munro

C. R. Nash

J. C. Noakes

C. L. Peckinpaugh

R. E. Peterson

R. B. Rothrock

H. C. F. Ripfel

E. J. Ruane

G. H. Salzano

D. P. Schively

D. E. Simpson

R. G. Smith

D. D. Stepnewski

E. G. Stevens

G. H. Strong

M. A. Vogel

R. C. Walker

G. R. Waymire

J. H. Westsik

J. F. Wett

M. F. Wiitala

T. W. Withers

The assistance of technical personnel from Westinghouse Electric Corporation, Atomics International, Bechtel Corporation, Aerojet-General, and the AEC is acknowledged with thanks.

\footnotetext{
*Task Force leaders

**Work Described Herein was directed by ER Astley.
} 


\section{ESTABLISHMENT OF THE FFTF VERTICAL CORE REFERENCE CONCEPT \\ ABSTRACT}

This report was prepared by Battelle-Northwest under Contract No. AT(45-1)-1830 for the Atomic Energy Commission, Division of Reactor Development and Technology, to summarize the studies which led to the establishment in December 1968, of the FFTF Vertical Core Reference Concept.

This report supersedes BNWL-470, FFTF split Conical Core Reference Concept. 


\section{TABLE OF CONTENTS}

Page No.

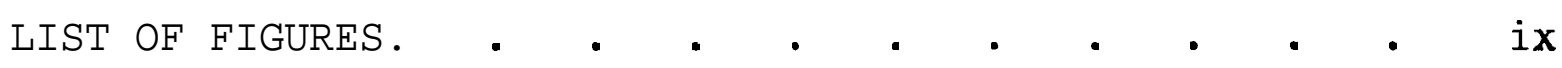

I. INTRODUCTION AND SUMMARY . . . . • • • 1

A. Introduction

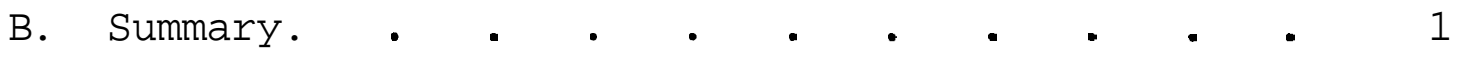

1. General Method of Investigation 1

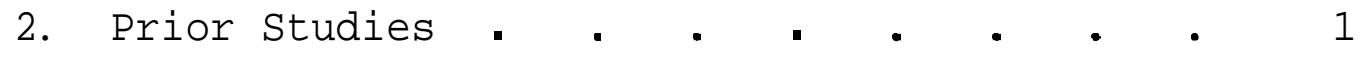

3. Summary of Results Presented in This Report. 3

EXHIBIT A - EVALUATION OF THE SPLIT CONICAL CORE REFERENCE CONCEPT. • • • • • • • • • • • A-1

1. Summary Description of Concept . . A-1

2. July-December 1967 Evaluation . . A-5

3. January-March 1968 Evaluaiton . A-9

4. April-June 1968 Evaluation . . A-11

EXHIBIT B - FY-69 ALTERNATES EVALUATED IN DEVELOPMENT OF THE VERTICAL CORE REFERENCE CONCEPT . . B-1

1. Summary Descriptions of Alternate Concepts Evaluated : • • • • • . . . . B-1

2. BNW Review of Concept I . • • • • . B-11

3. BNW Review of Concept II . $B-12$

4. BNW Review of Concept III. $B-13$

5. BNW Review of Concept IV . . . . • . B-14

6. Study Team Reviews of Concepts I, II, II I,

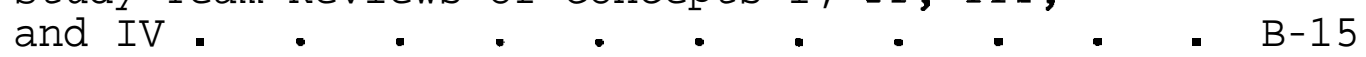

7. Management Reviews of Concepts I, II, III, . B-16

8. Review of Concept V . . . . . . . B-16

EXHIBIT C - FFTF VERTICAL CORE REFERECE CONCEPT
DESCRIPTION.

1. Summary Concept Description. - . . • . C-1

2. Summary of Principal Concept Characteristics

3. Drawings . • . • . . . . • . C-13

4. Reactor Core Description . - C-47

5. Reactor Vessel and Head Description. - C-55 
BNWL -1165

6. Reactor Nuclear Control Description and Operation . . . . . . . . . . . C 59

7. Reactor Refueling System Description . . . C-63

8. Irradiation Test Facilities . . . . . C-69

9. Reactor Instrumentation . . . . . . C-73

10. Containment . . . . . . . . . C -87 


\section{LIST OF FIGURES}

Page No.

2.1. Vertical Core Reference Concept Elevation 5

2.2 Vertical Core Reference Concept Core Map 6

A-1 Split Conical Core Reference Concept

A -2

A-2 Schematic Drawing of FTR Split Core in X-Y Geometry

A- 6

A-3 Baseline Core Geometry

A -10

A-4 Gap Utilization - Theoretical Study

$A-12$

B-1 Concept I Elevation

$B-2$

B-2 Concept II Elevation

B- 4

B-3 Concept III Elevation

$B-7$

B-4 Concept Iv Elevation

B- 9

B-5 Concept V Core Map and Cover Arrangement

B -10 


\section{ESTABLISHMENT OF THE FFTF \\ VERTICAL CORE REFERENCE CONCEPT}

\section{INTRODUCTION AND SUMMARY}

\section{A. INTRODUCTION}

This report presents a summary of FY-67, FY-68 and FY-69 conceptual design studies which led to the establishment in December 1968 of the FFTF vertical core reference concept. This concept superseded the split conical core FFTF concept. (1)

\section{B. SUMMARY}

1. General Method of Investigation

During the period April 1965 through December 1968, Battelle-Northwest managed for the USABC Division of Reactor Development and Technology under Contract AT(45-1)-1830 a series of studies to establish a conceptual design for the Fast Flux Test Facility. At appropriate points in the study program, three so-called "reference concepts" were identified and evaluated; each reference concept was a self-consistent design representative of one of the broad general types of reactor design being considered for the FFTF.

\section{Prior Studies}

a. Interim Reference Concept

The first concept established was a so-called "interim" reference concept ${ }^{(2)}$ wherein all reactor channels (including a 11 test channels) diverged approximately 4 to $5^{\circ}$ from true. vertical. The interim reference concept for the FFTF was designed to provide a maximum hard neutron flux (approximately $70 \%$ above $0.1 \mathrm{MeV}$ ) of about $1.35 \times 10^{16} \mathrm{n} / \mathrm{cm}^{2}-\mathrm{sec}$. $\mathrm{PuO}_{2}$-SS cermet fuel was employed in a $6001 \mathrm{iter}$ sodium-cooled tubed-core. 
b. Establishment of Split Conical Core Reference Concept

After submission of the interim reference concept, BNW continued conceptual design studies at the request of AEC-DRDT. A major goal was a design providing "plumb vertical" closed loop tubes in the reactor, while at the same time retaining sufficient physical dispersion of coolant piping to permit convenient handling of test specimens and adequate instrumentation of test positions.

A $\mathrm{PuO}_{2}-\mathrm{UO}_{2}$ ceramic fuel was selected ${ }^{(3)}$ for development as the reference concept driver fuel. Total peak neutron flux requirements were concurrently reduced to $0.7 \times 10^{16} \mathrm{n} / \mathrm{cm}^{2}-\mathrm{sec}$.

Conceptual design studies were performed by BNW, Atomics International, General Electric, Phillips Petroleum, and Westinghouse. A total of seven conceptual designs so generated were evaluated by BNW. (4) These included three variations of the skewed design of the interim reference concept, three variations of a vertical-tube core, and a split core design which provided five vertical closed loops and slightly inclined driver tubes. Desired flux in the split core was defined as $7 \times 10^{15} \mathrm{n} / \mathrm{cm}^{2}-\mathrm{sec}$. However, flux levels provided by the split core design were uncertain since available computation models could not fully describe such a split core reactor with a large fuel-void volume at the center.

Through agreement with the AEC, it was determined that the "split core concept" (see Exhibit A) appeared to be a suitable reference concept choice for the reactor provided that required flux levels could be obtained and mechanical design problems could be solved. Hence the split conical core reference concept (',') was established as a basis for further design studies.

The flux level problem was the primary concern, and was defined ${ }^{(1)}$ as follows: 
"One would expect that the central test region-which contains little fissile fuel--would significantly affect the FTR nuclear performance. To assess this effect, the critical mass and center point flux were computed for a wide range of central gap volumes and driver volumes. The composition of the central gap was estimated using representative FBR fuel in the five test loops. The results show clearly that large central gaps significantly increase the critical mass, and, for a given total power, depress the central flux."

c. Initiation of Vertical Core Backup Study

In view of the uncertainties associated with the reference concept, BNW sponsored conceptual design work for a vertical "backup core." This work, performed by General Electric Company, ${ }^{(6)}$ was initiated early in FY-68.

It was recognized that a true vertical core FTR concept would have important advantages, including high flux level. Closed test loops would be exposed to a test environment fully representative of nuclear and thermal conditions expected in future fast breeder reactors. Other reactor fuel channels would be exposed to the same conditions and could be used for fully representative tests of fuels and materials. Furthermore, the reactor itself (except for irradiation test features) would be prototypic of future LMFBR designs and, thus, could serve as a valuable test installation for fuel ducts, control rods, core restraint mechanisms, instrumentation and other equipment.

3. Summary of Results Presented in This Report

a. Evaluation of Split Conical Core Reference Concept

During FY-68, BNW conducted extensive studies on the split conical core reference concept. As a result of these studies, 
it was determined that the split conical core concept did not offer reasonable potential for meeting the criteria of providing five independently cooled test positions exposed to flux of $0.7 \times 10^{16} \mathrm{n} / \mathrm{cm}^{2}-\mathrm{sec}$. These studies are described in Exhibit A.

b. Development of FFTF Vertical Core Reference Concept

During the first half of FY-69, comprehensive studies were made by BNW, Westinghouse, AEC/DRDT and Atomic International on variations of the split-core and dispersed core concepts, and on a number of potential vertical concepts.

As described in Exhibit B, these concepts consisted of two new split-core designs, ${ }^{(7)}$ one open-top-loading vertical design( (8) similar to the backup core, (6) and three fixed-head vertical reactor designs.

A fixed-head vertical reactor concept was selected as the FFTF vertical core reference concept. $(9,10)$ Figure 2.1 gives the elevation of the concept and Figure 2.2 gives the core map. This concept employs two cooled, shielded fuel handling machines operating in an air atmosphere outside the reactor vessel, plus three in-vessel fuel handling machines.

Driver refueling is accomplished by use of an in-reactor grapple assembly which transfers driver fuel under sodium to finned pots located at the core elevation but radially outside the core. Driver fuel is transferred into and out of the reactor vessel through transfer ports utilizing the finned pots and a shielded out-of-vessel cask.

Refueling of closed and open loop test facilities is accomplished by means of a shielded, sodium-cooled, fuel handling machine.

Approximately three scram-assisted safety rods and six scram-assisted control rods are located within the core. These are supplemented by approximately 15 gravity-drop control rods 
BNWL -1165

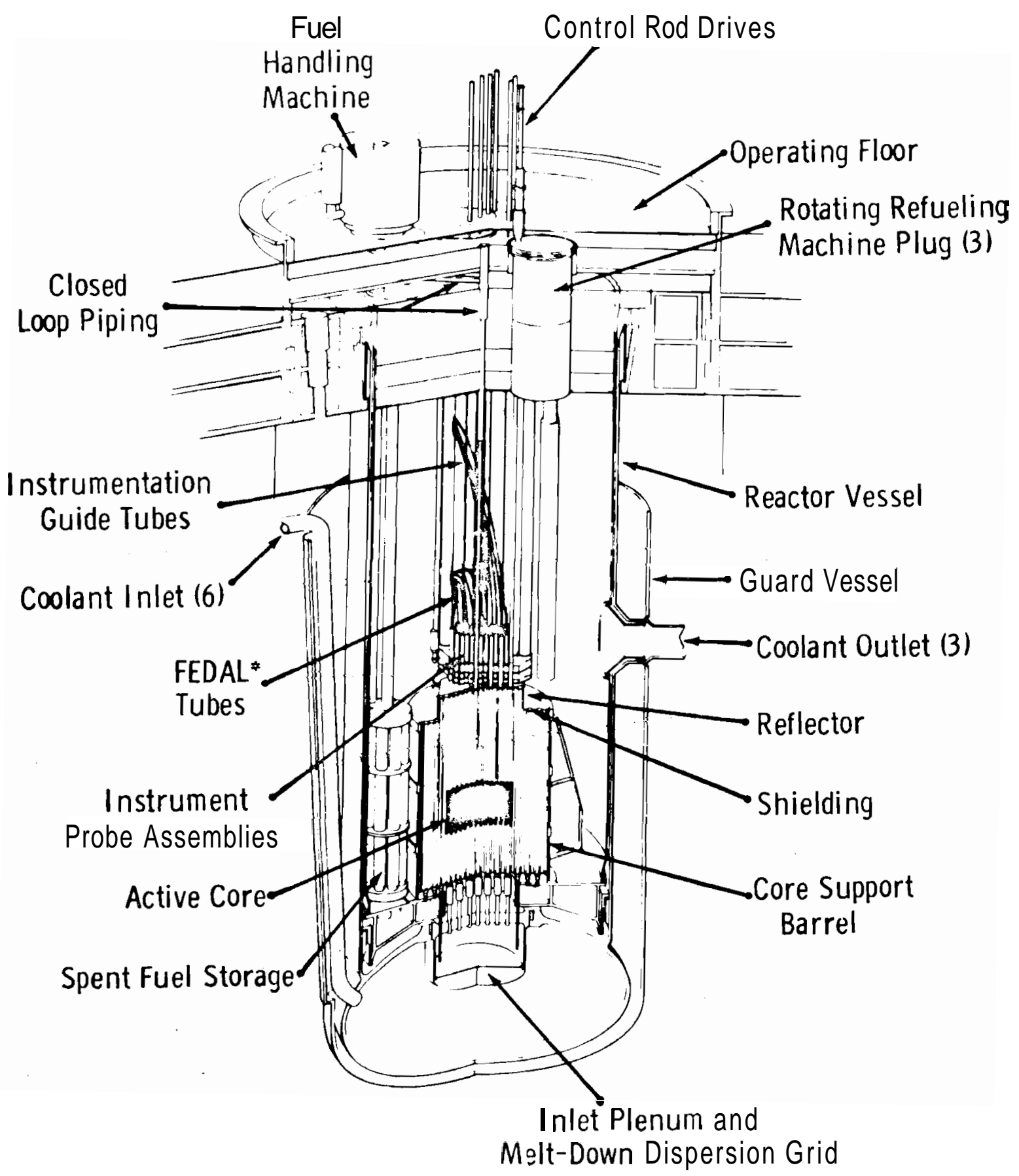

${ }^{*}$ Failed Element Detection and Location

FIGURE 2.1. Vertical Core Reference Concept Elevation 


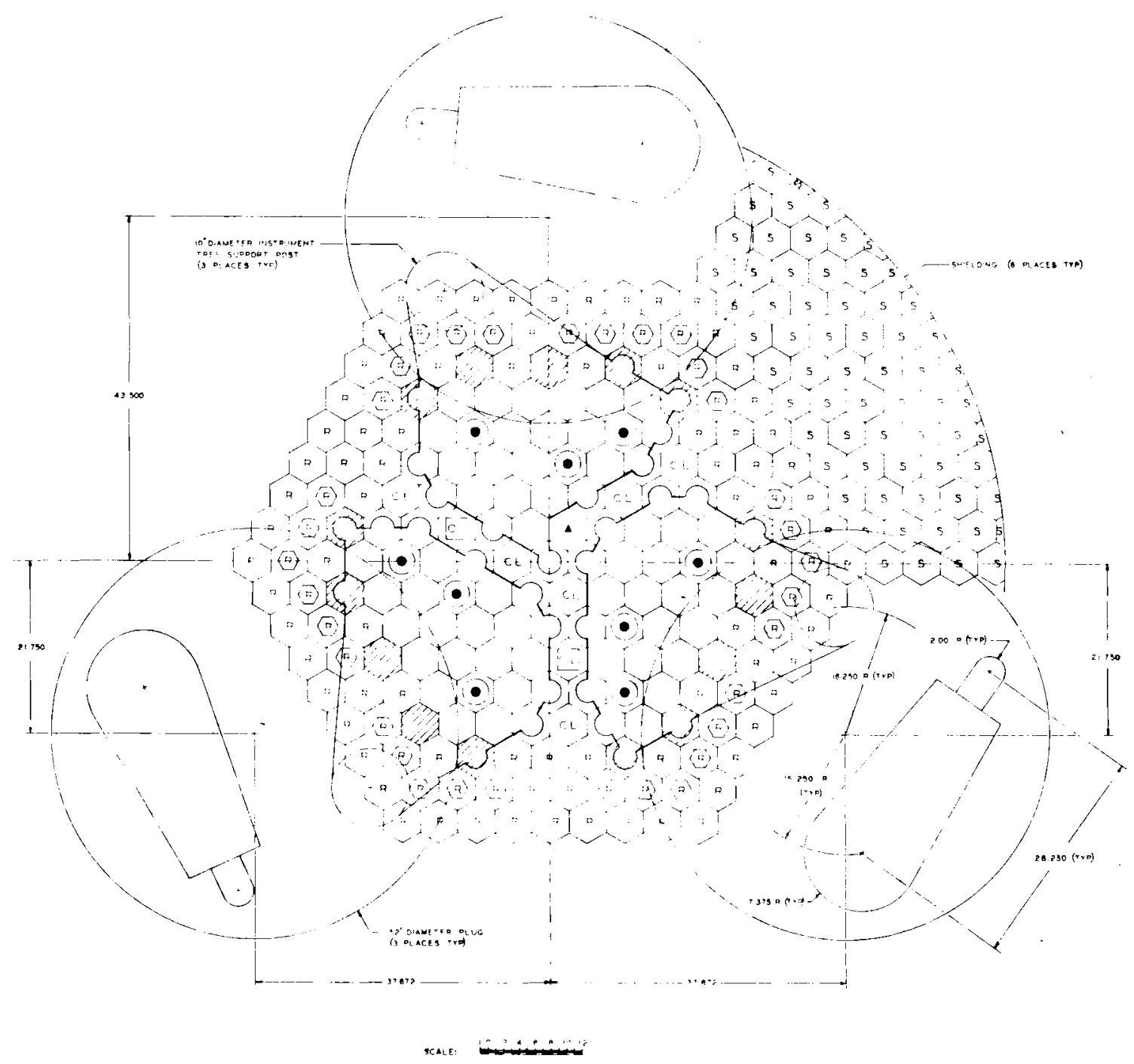

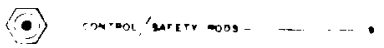
(ब) Den
(60) orem toons .......... - -
(v) custe mes ..... .

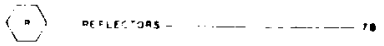
引

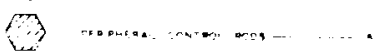

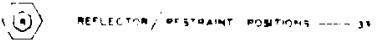
(3) MMIELow: 
located in the first of the three reflector rows. The reactor core is a hexagonal array of hexagonal assemblies. The 73 driver fuel assemblies employ mixed $\mathrm{PuO}_{2}-\mathrm{UO}_{2}$ fuel cladding in 0.230-in diameter Type 316 SS pins arranged in a 217-pin array.

A 11 driver fuel positions are instrumented for outlet temperature, flow and failure location utilizing three instrument plate assemblies, each assembly supported by a rotating plug located in the refueling port for the reactor sector. Further details are given in Exhibit $C$.

Testing Capabilities. Six sodium-cooled closed loops are provided. Two closed loops are located essentially at the core center, one is located at mid-radius of the core, and three are located at the periphery of the driver fuel zone.

Two fully-instrumented open loops are provided at the mid-radius of the driver core. One special proximityinstrumented open loop position is located essentially at the core center. This position can also be utilized for a variety of special test assemblies such as reduced diameter open loops, capsules, or materials tests.

\section{REFERENCES}

1. E. R. Astley. Progress Report FFTF Reference Concept, BNWL-470. Battelle-Northwest, RichZand, Washington, August 1967.

2. C. P. Cabezz. Progress Report FFTF Interim Reference Concept, BNWL-CC-400 REV. Battelle-Northwest, Richland, Washington, February 1, 1970.

3. FFTF Summary Technical Report, January-December, 1966, BNWL-325."Battelle-Northwest, Richland, Washington.

4. FFTF Quarterly Technical Report, January, February, March, 1967, BNWL-501. Battelie-Northwest, Richland, Washington.

5. E. R. Astley. The Conceptual Evaluation of a Fast Flux Test Facility, BNWL-SA-978. BattelZe-Northwest, Richland, Washington. Presented at the National Topical Meeting on Fast Reactors. San Francisco, California, April 10-12, 1967. 
6. Final FFTF Backup Design Summary, GEAP-5722. General Electric Company, Schnectady, New York, January 1969.

7. FFTF Quarterly Technical Report, April, May, June, 1968, BNWL-880. BattelZe-Northwest, Richland, Washington, pp. $3.1-3.49$.

8. FFTF Quarterly Technical Report, April, May, June, 1968, BNWL-880. BattelZe-Northwest, Richland, Washington, pp. 3.50-3.73.

9. R. C. Walker and W. B. McDonald. Unpublished Data. BatteZZe-Northwest, Richland, Washington, January 1969. (FFTF Reference Concept Summary Description).

10. E. R. Astley and J. C. R. Kelly, Jr. "FFTF - Fast Flux Test Facility for Developing Breeder Reactor Technology" Westinghouse, Eng., November 2969. 
BNWL - 1165

EXHIBIT A

EVALUATION OF THE SPLIT CONICAL CORE REFERENCE CONCEPT 


\section{EXHIBIT A \\ EVALUATION OF THE SPLIT \\ CONICAL CORE REFERENCE CONCEPT \\ (BNWL-470 Concept) (I)}

\section{SUMMARY DESCRIPTION OF CONCEPT}

The concept is based on a dispersed, split conical core reactor (Figure A-1). The core is formed by a hexagonal array of fuel subassemblies situated near the region of convergence in a split truncated cone. The subassemblies are tilted to provide space, in a vertical plane across the center of the core, for closed loop installation.. The core has 94 hexagonal lattice positions with a lattice spacing of $\sim 4.3 \mathrm{in}$.

The FTR core, consisting of driver and test regions, has a roughly conical shape. The nominal driver volume is 21000 liters; the central gap (test region) volume is 150 liters. The core is surrounded (radially) by a 30 am Inconel reflector. The flux objective is $7 \times 10^{15} \mathrm{n} / \mathrm{cm}^{2}-\mathrm{sec}$, but achievement of this objective was uncertain."

The core, the reflector, the experimental facilities, and various 'support structures (along with hydraulic components) are housed in a stainless steel vessel with a cover providing access to the driver and experimental positions through individual nozzles. These nozzles provide access for refueling and for instrument connections.

Reactor refueling operations are accomplished in a shielded enclosure (hot cell) above the reactor. This enclosure normally has an air atmosphere, but it can be flooded with inert gas for special operations requiring an oxygen-free atmosphere. The fuel handling equipment in the hot cell is independently cooled and is capable of maintaining fuel temperatures at required levels during transit to and from the reactor.

See paragraph I.B.2.b., page 2. 
BNWL- 1165

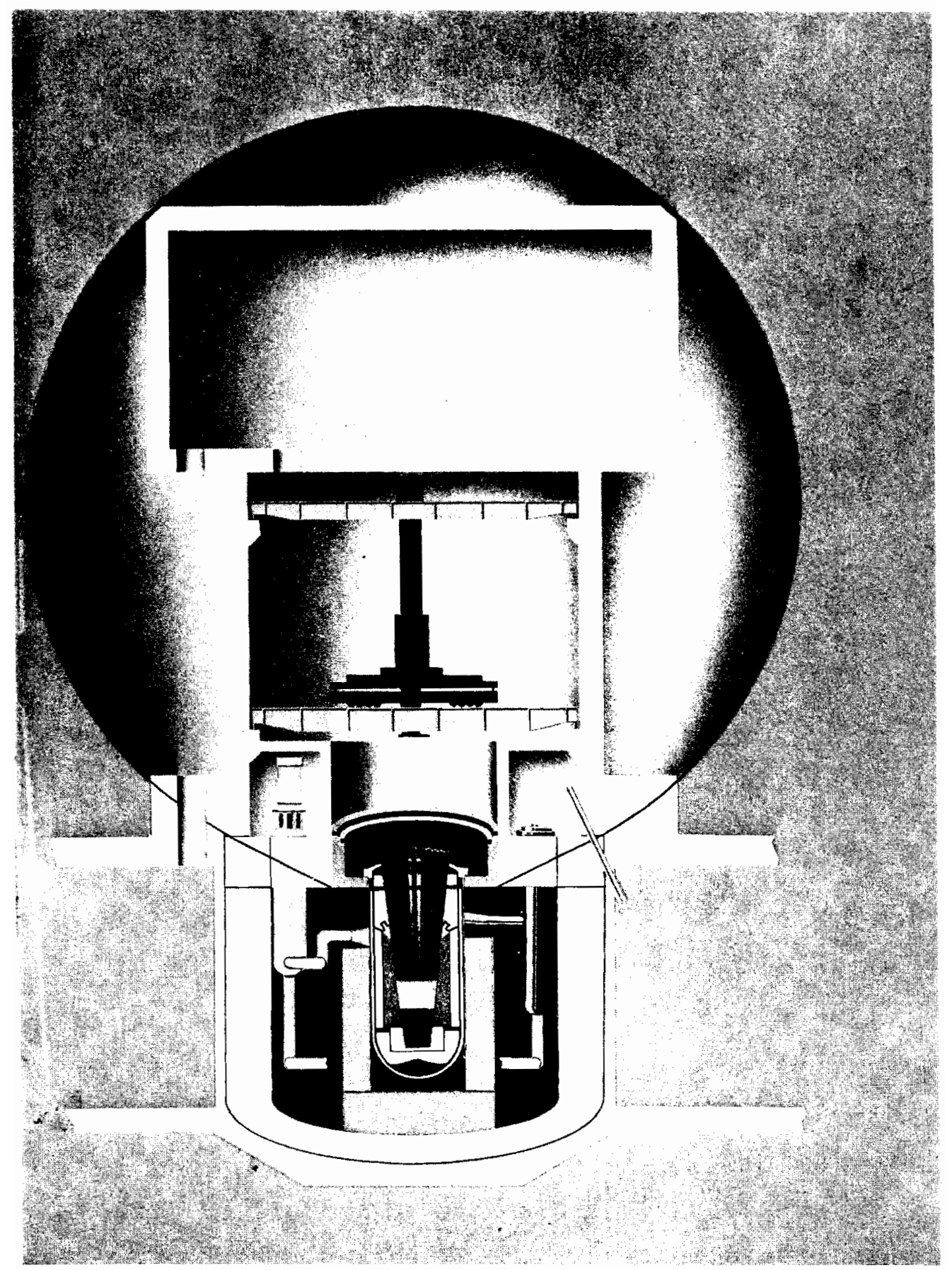

FIGURE A-1. Split Conical Core Reference Concept 
The coolant for the core is sodium. The heat transport system includes four independent parallel circuits each consisting of a primary and secondary sodium loop and a modular air heat dump. The primary sodium from the reactor outlet passes through shell and tube intermediate heat exchangers and is pumped back to the reactor inlet by free surface centrifugal pumps. The secondary sodium receives the thermal energy in the IHX's. The hot leg sodium is pumped through the forced a ir heat dumps and back to the IHX by the secondary pumps. At the design point of $900^{\circ} \mathrm{F}$ the full reactor power may be rejected through three of the four circuits providing one redundant circuit for improved plant availability.

The reactor safety system is designed to respond to signals from flow and temperature sensors in the primary cooling loop, from flow sensors in individual fuel channels, and from neutronic instrumentation. Signals exceeding preset limits cause the control system to take corrective action through insertion of control rods.

As shown in Table A-1, the design will initially provide three closed test loops and 13 open test loops. Ultimately, a total of five closed loops can be provided. 
TABLE A-1. FFTF Irradiation Test Facilities $\underline{\text { In-Core Test Facilities }}$

\begin{tabular}{|c|c|c|c|}
\hline & \multirow{2}{*}{$\begin{array}{l}\text { Maximum Test Cross } \\
\text { Section, in. } \\
\end{array}$} & \multicolumn{2}{|c|}{ Number } \\
\hline Test Facility & & Initial & Ultimate \\
\hline Closed Loop Fuel Tests & 4 & 1 & 1 \\
\hline Closed Loop Fuel Tests & $31 / 2$ & 2 & 2 \\
\hline Closed Loop Fuel Tests & 3 & 0 & 1 \\
\hline Closed Loop Fuel Tests & $21 / 2$ & 0 & 1 \\
\hline $\begin{array}{l}\text { Packaged Loop Materials } \\
\text { Tests }\end{array}$ & $21 / 2$ & 1 & * \\
\hline Open Test Positions & $4 \& 5$ & 13 & \\
\hline Control Rod Nosepieces & $31 / 2$ & 10 & Undecided \\
\hline Driver End Reflectors & & * * & * \\
\hline$\underline{\operatorname{Ref}}$ & ctor Test Faci & & \\
\hline Tect & Maximum Test & Num & er \\
\hline Hot tactity & 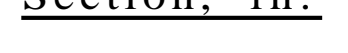 & & vilimate \\
\hline $\begin{array}{l}\text { Packaged Loop Materials } \\
\text { Tests }\end{array}$ & 2 & 1 & * \\
\hline Control Rod Nosepieces & $31 / 2$ & Undecided & Undecided \\
\hline Short Term Test Facilit & & 1 & 2 \\
\hline Reflector Test Holes & 4 & 38 & Undecided \\
\hline
\end{tabular}

* Large number possible. Packaged Zoops and/or open Zoops may be instazled $i$ n any lattice position.

* * Any number up to the number of driver fuel assemblies can be provided. 


\section{JULY-DECEMBER 1967 EVALUATION}

Evaluation of the flux possibilities was carried out in the period July-December 1967 and reported ${ }^{(2)}$ as follows:

"Physics Statics Calculations for the FTR Sp1it Core

A model of the FTR split core in X-Y geometry was developed for use in physics statics calculations (Figure A-2). The model is a representation of a transverse cut at the core midplane. The 2DF transport theory computer code employing this $X-Y$ model was used to calculate critical mass, control rod worths, fluxes, and fission rates in the FTR. A four energy group cross section set derived from the PNL 26-group fast reactor cross section library was used for all calculations. The cross sections include an axial leakage correction.

"Table A-I1 lists the characteristics of the FTR for a core with a uniform driver fuel and for a core with two equal-volume driver fuel zones. It is to be noted that the calculated flux levels are significantly below the goal of $0.7 \times 10^{15} \mathrm{n} / \mathrm{cm}^{2}-\mathrm{sec}$. "Core and Fuel Design for PNL Split Conical Array

Several sets of design data were generated for the fuel and core for the split core reactor concept. The design effort, based on considerations of flux, testing volume, and safety, was directed toward an optimized split conical array.

"Table A-I1 1 lists key parameters used in this study and the target or constraint of each. 
BNWL - 1165

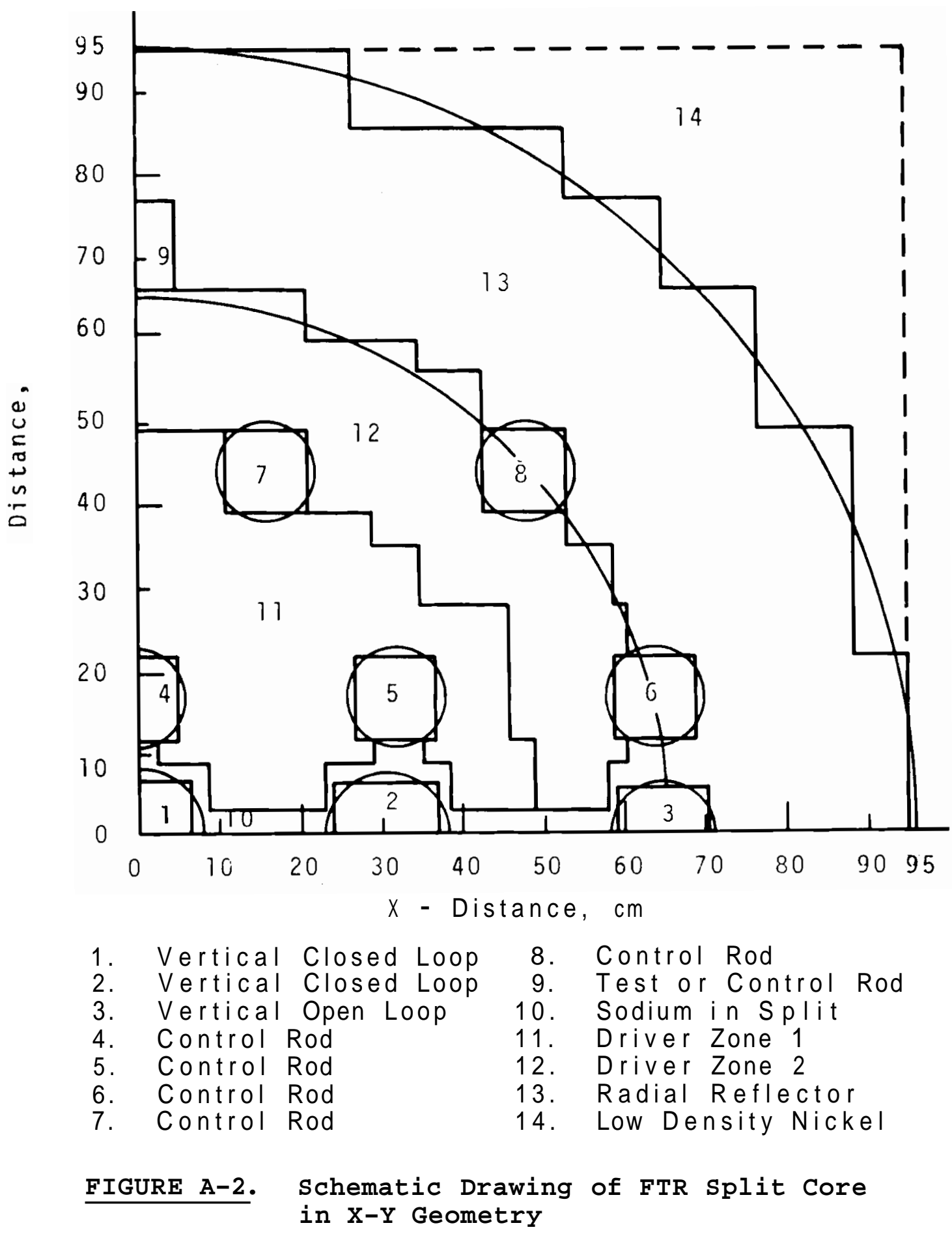


TABLE A-11. Comparison of One- and Two-Zoned

FTR Split Cores

Zoned

$\underline{\text { Unzoned }} \underline{\text { Zone } 1} \quad \underline{\text { Zone } 2}$

Vol. Frac. $\mathrm{PuO}_{2}(\rho=11.46)$

$\begin{array}{cccc}(90 / 10,239 \mathrm{Pu} / 240 \mathrm{Pu}) & 0.0743 & 0.0695 & 0.0834 \\ 238 \mathrm{UO}_{2}(\rho=10.96) & 0.2687 & 0.2645 & 0.2686 \\ \text { Void } & 0.0610 & 0.0590 & 0.0620 \\ \text { Stainless Steel } & 0.2510 & 0.2560 & 0.2460 \\ \text { Sodium } & 0.3450 & 0.3510 & 0.3400\end{array}$

Spl it Vol ume, 1iters

$\begin{array}{lll}\text { (includes test volume) } 154.0 & 154.0\end{array}$

$\begin{array}{lll}\text { Test Volume, 1iters } & 65.0 & 65.0\end{array}$

Core Volume, liters $\quad 1000.0 \quad 500.0 \quad 500.0$

Driver + 4 Open Loops 912.8447 .7

Control Rods $\quad 87.2 \quad 52.3$

34.9

Core Length, cm

85.0

85.0

Total Reflector Savings, cm 22.0

22.0

keff

1.04

1.04

${ }^{239}$ Pu Critical Mass, kg

$616.7 \quad 282.9$

352.7

${ }^{239} \mathrm{Pu}$ Test Mass, kg

15.9

15.9

Total ${ }^{239} \mathrm{Pu}$ Mass, $\mathrm{kg}$

632.6

651.5

${ }^{238} \mathrm{U} /{ }^{239} \mathrm{Pu}$ Ratio

3.859

4.061

3.436

Center Point Flux,
$\frac{\mathrm{n}}{\mathrm{cm}^{2}-\sec }$
$5.920 \times 10^{15}$
$5.461 \times 10^{15}$ 
BNWL - 1165

\section{TABLE A-111. Key Parameters}

Centerpoint flux

Fertile-to-fissile ratio

Core volume, including central test channels

Maximum power

Core AP

Core axial AT

Pin spacing $\geq 7 \times 10^{15}$

$\geq 4.0$

$\sim 1000$ 1iters

$400 \mathrm{MW}$

60 to $90 \mathrm{psi}$

300 to $400{ }^{\circ} \mathrm{F}$

$1.16 \frac{\mathrm{c} / \mathrm{c} \text { spacing }}{\text { Pin OD }}$

"The major impediment to achieving the desired design conditions is the requirement for approximately $10 \%$ more fuel in the split core conical array than for a compact core of the same effective volume. The peak flux in this 1000 liter core is substantially less than $7 \times 10^{15}$ at 410 MW (including 10 MW from the closed loops). The increased fuel loading requires tight fuel packing (c/c spacing/pin OD 21.12 ) within the subassembly in order to achieve a fertile-to-fissile ratio near 4:1. The 4:1 fertile-to-fissile ratio may be required for an adequate Doppler coefficient, $\frac{\mathrm{Tdk}}{\mathrm{dT}}=-0.004$.

"Baseline Concept for the Split Core

A concept was defined and subsequently adopted with minor revisions as the 'Baseline Concept' to serve as the basis for formal evaluation. Table A-IV lists the major features and Figure A-3 shows the baseline core geometry. Flux attained in this concept is less than $0.7 \times 10^{16} \mathrm{n} / \mathrm{cm}^{2}-\mathrm{sec} . "$ 
TABLE A-IV. Baseline Concept

$\begin{array}{ll}\text { Subassembly Size } & 4.52 \mathrm{in.} \\ \text { Pins Per Subassembly } & 217 \\ \text { Pin Diameter } & 0.250 \mathrm{in} . \\ \text { Minimum Pin Spacing } & 0.030 \\ \text { Pitch/Diameter } & 1.12 \\ \mathrm{PuO}_{2} \text { Fraction } & 0.225 \\ \text { Fissile/Fertile Ratio }_{\text {Core AT }} & 3.9: 1 \\ \text { Core Inlet } & 350{ }^{\circ} \mathrm{F} \\ \text { Pin Bundle } \triangle \mathrm{P} & 550{ }^{\circ} \mathrm{F} \\ & 60 \mathrm{psi}\end{array}$

* Hexagonal across flats

3. JANUARY-MARCH 1968 EVALUATION

The evaluation of the split conical core reference concept was continued in 1968. The first-quarter report(3) concluded:

"Problems in obtaining flux levels of $0.7 \times 10^{16} \mathrm{n} / \mathrm{cm}^{2}-\mathrm{sec}$ were previously reported. Continuing studies performed during this reporting period concluded that all design parameters significantly affecting the achievable flux level for the first core were limited by constraints of practical technology, safety, testing capability requirements, or economics. Significant flux improvements in the basic bisected conical core geometries appear virtually impossible without utilizing odd-sized subassemblies to fill the split gaps. However, maintaining a single driver subassembly design to avoid additional complexities in the core and refueling procedures was considered preferable." 
BNWL - 1165
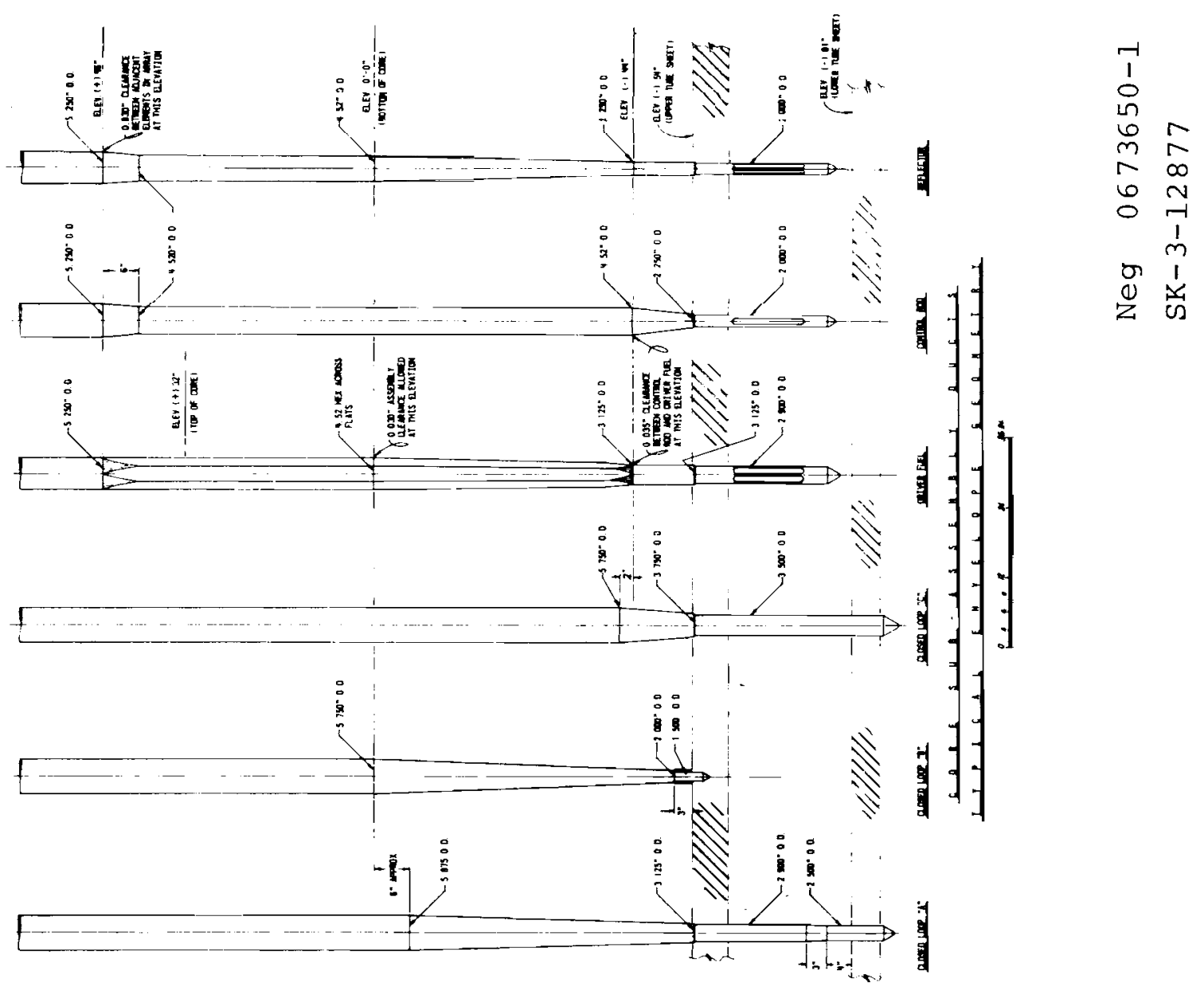

2
+1
0
0
0
0
0
0
0
0
0
0
0
0
-1
-1
0
0
0
0
0

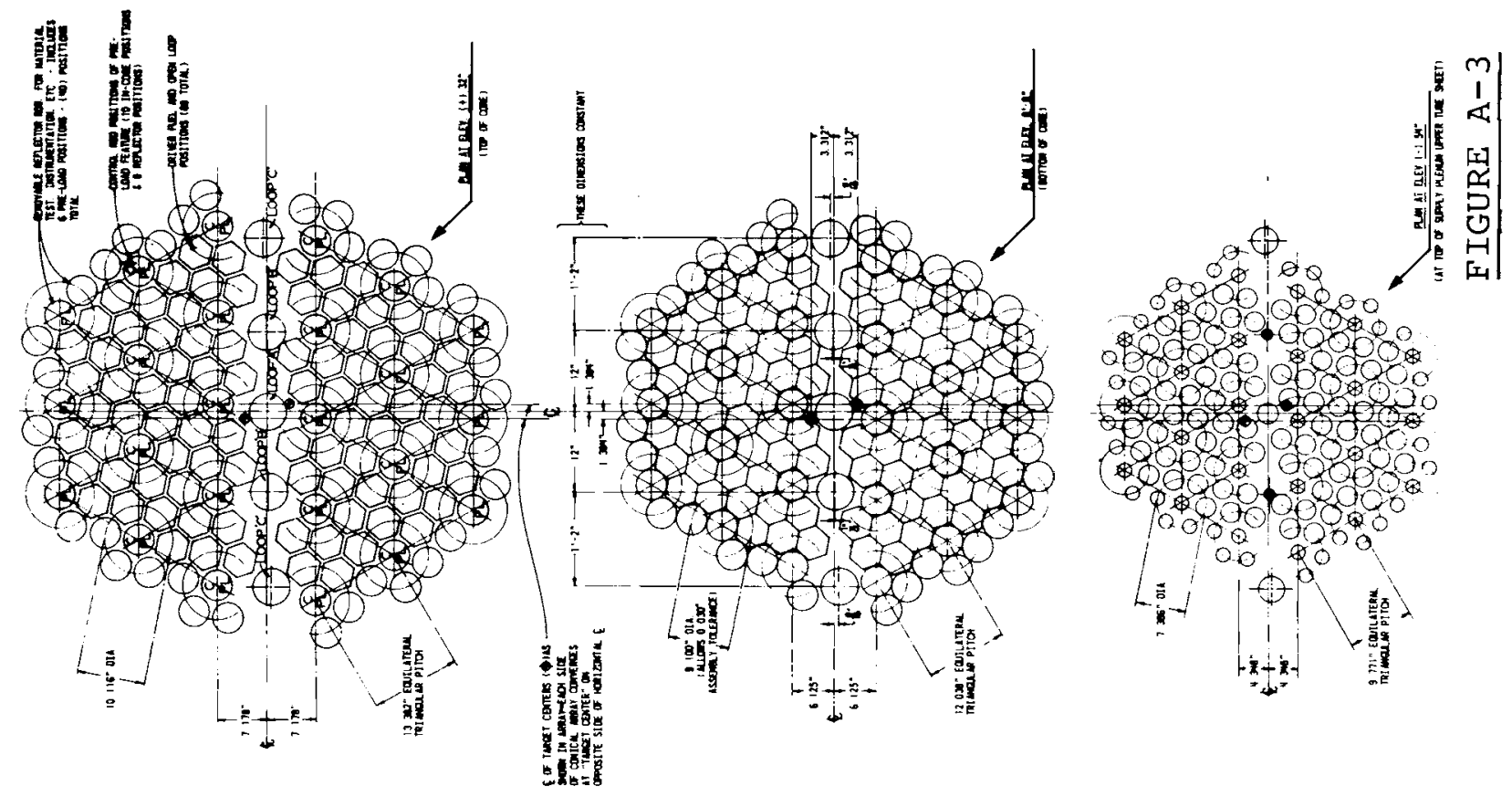




\section{APRIL-JUNE 1968 EVALUATION}

The evaluation of the split conical core reference concept was concluded in the second quarter of CY-1968. The terminal report ${ }^{(4)}$ stated:

"To achieve a core packing consistent with the minimum total flux goal of $0.7 \times 10^{16} \mathrm{n} / \mathrm{cm}^{2}-\mathrm{sec}$, 'the packing efficiency' for the split core must be significantly increased. The opportunity for improvement lies in the utilization of the large gap around the vertical closed loops. Two major options exist for utilizing this gap as follows:

Rearrange the core. Erect a minimum of three vertical loops and place fueled positions around these vertical positions.

- Decrease the gap width: Utilize the reference concept and attempt to reduce the split width, utilizing the criteria changes noted.

"Core Rearrangement. Earlier parametric studies(5) indicated that the greatest improvement in centerpoint flux is obtained by utilizing the central gap for driver fuel. Before arriving at a feasible design, the maximum theoretical potential for flux improvement by core rearrangement was investigated utilizing the above observation as a starting point. To evaluate a practical degree of gap utilization against the theoretical potential, a brief investigation was performed on how to construct fueled positions practically. The study was then completed in two phases.

"The first phase was an analysis for the central flux assuming the gap was filled with fuel to an equivalent density consistent with the 0.03 in. spaced reference fuel design. As shown in Figure A-4, if the gap could be 
BNWL - 1165
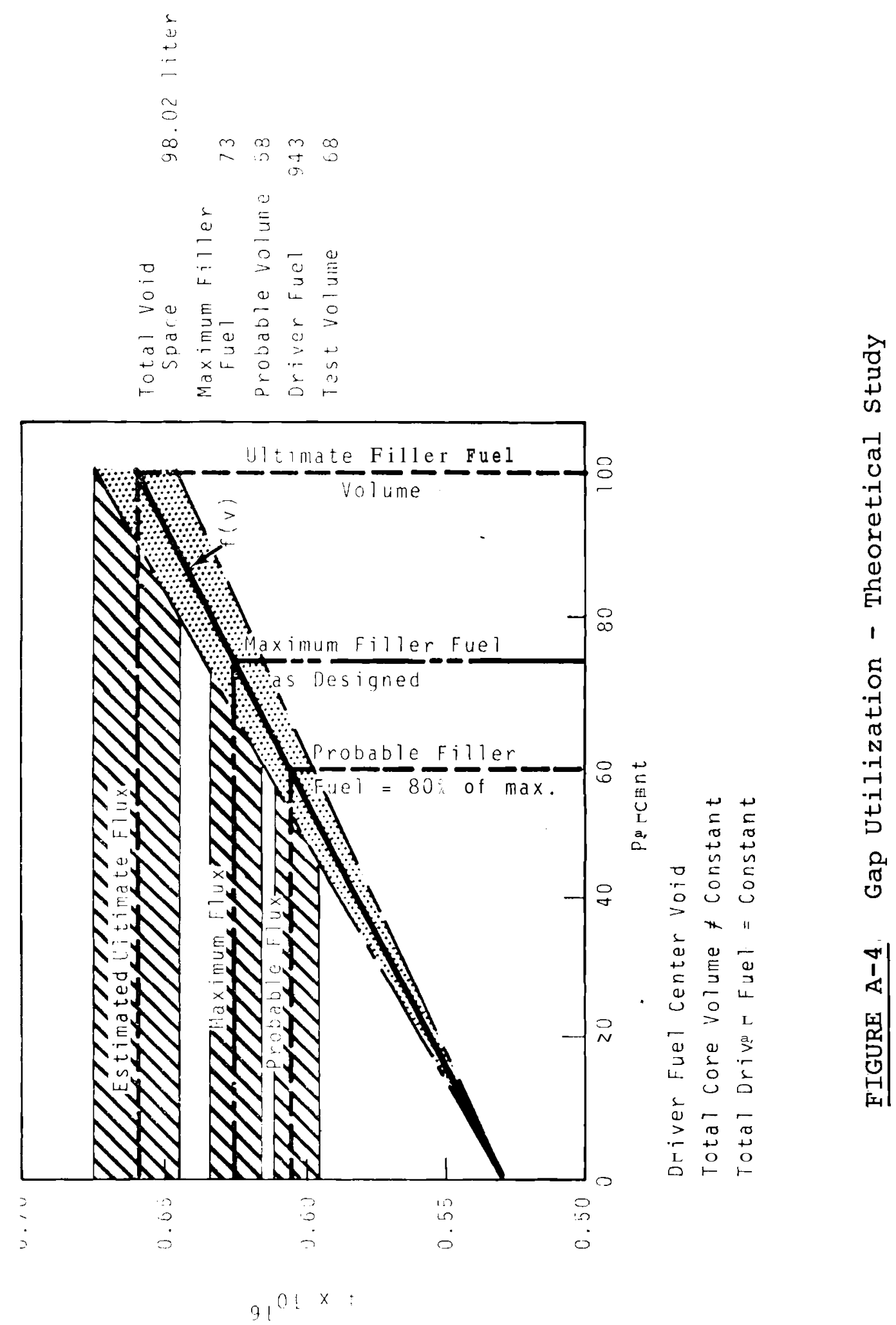
filled, the central flux would increase from about $0.53 \times 10^{16}$ to about $0.66 \times 10^{16} \mathrm{n} / \mathrm{cm}^{2}-\mathrm{sec}$. As a matter of practical design, however, an $80 \%$ utilization appeared to be a maximum value, with $60 \%$ being a more realistic design.

"For the second phase, design layouts were constructed to determine precisely what theoretical fuel density could be achieved with a 0.04 in. fuel pin spacing. These layouts indicated that about 1140 pins could be placed in the defined envelope of the split zone, or the equivalent of 5.25 additional driver assemblies. These added assemblies which were assumed to replace lower worth positions in the core periphery, gave a maximum theoretical flux of $0.56 \times 10^{16} \mathrm{n} / \mathrm{cm}^{2}-\mathrm{sec}$. Since the theoretical maximum utilization fell short of the required miniumum flux requirement $\left(0.7 \times 10^{16} \mathrm{n} / \mathrm{cm}^{2}-\mathrm{sec}\right)$ by $20 \%$, further efforts in rearrangement of the split core were curtailed.

"Gap Closure. This study involved moving the two conical halves of the core inward until a mechanical interference developed. Core components were altered to correct this interference and split zone closure continued until another interference developed. The study was initiated with the five vertical loop reference design. With this design, interference occurs first at the reactor cover between the intermediate loops and adjacent driver fuels. Average core gap at this point has increased by $1 / 4 \mathrm{in}$. Elimination of the two vertical intermediate loops fulfills the minimum vertical position criteria and allows the gap closure to continue.

"Continued movement of the core halves results in an interference at the two outer vertical positions. -Since the minimum number of vertical loops has now 
been reached, further closure requires outward radial shifting of these outboard vertical positions. Lateral movement continues until two adjacent drivers contact. To avoid interference during insertion of positions, the projections of nonvertical drivers have forced the outer vertical loops into the radial reflector region.

"As a result of this gap closure exercise, the resulting core has only one vertical loop with a flux improvement of about $10 \%$.

"Conclusions. The best potential for improving the bisected core involves more efficient utilization of the gap region in the core. The largest flux improvement results when the split region is utlized for driver fuel. A maximum flux (with 0.04 in. spacing) of $0.56 \times 10^{16} \mathrm{n} / \mathrm{cm}^{2}-\mathrm{sec}$ may be attained by practically utilizing a major portion of the gap packed with fuel at a density equivalent to a driver position. Since this value is $20 \%$ below the required minimum, it may be concluded that it is virtually impossible to achieve the flux minimum requirement with the bisected core. Even with 0.03 in. spacing, the maximum flux is $11 \%$ below the required minimum."

\section{REFERENCES}

1. E. R. Astley. Progress Report FFTF Reference Concept, BNWL-470. BatteZle-Northwest, Richland, Washington, August 1967.

2. $\quad$ FFTF Periodic Technical Report July-December 1967, BNWL-567, Battelle-Northwest, Richland, Washington.

3. FFTF Quarterly Technical Report, January, February, and March 1968, BNWL-660. Battelle-Northwest, Richland Washington.

4. FFTF Quarterly Technical Report. April. May and June 1968, BNWL-880. Batte Zle-Northwest, Richland, Washington.

5. L. M. Finch, R. E. Peterson, and G. R. Waymire. Geometry Problems Encountered in Design of the FFTF Split Conical Core., BNWL-SA-1323. Battelle-Northwest, Richland, Washington, November 1967. 
EXHIBIT B

FY-69 ALTERNATES EVALUATED IN DEVELOPMENT OF THE VERTICAL CORE REFERENCE CONCEPT 
EXHIBIT B

FY- 69 ALTERNATES EVALUATED IN DEVELOPMENT

OF THE VERTICAL CORE REFERENCE CONCEPT

1. SUMMARY DESCRIPTIONS OF ALTERNATE CONCEPTS EVALUATED

a. Concept I - Skewed Split Annular Core

Description of Concept

Pertinent features of Concept I consist of (1) a reactor core whose elements are dispersed in an annular skewed geometry, (2) a gamma shield over the reactor cover, (3) nozzle access through the reactor cover to each core position from the top face, (4) refueling, test and core component handling by a fully shielded machine operating through the gamma shield, and (5) an optional hot cell over the reactor containing an air atmosphere. A sketch of the concept arrangement is shown in Figure $B-1$.

Core performance is based on a power of $400 \mathrm{MW}_{t}$ in a total core volume of 942 liters, yielding a peak flux to the central loops of $0.7 \times 10^{16} \mathrm{n} / \mathrm{cm}^{2}-\mathrm{sec}$. First core operation is based on system temperatures of $550{ }^{\circ} \mathrm{F}$ inlet and $900{ }^{\circ} \mathrm{F}$ bulk outlet in a fully orificed core maintaining a core AT of $350^{\circ} \mathrm{F}$.

\section{Testing Capabilities}

The core design is an annular skew accommodating 68 driver subassemblies, 6 in-core control rods, 8 open test positions, and 5 closed loops (of which $\mathbf{3}$ are plumb vertical). The three vertical closed loops are located at the core center surrounded by the remainder of the core positions in a tightly packed annulus. The dispersion angle of inclination is $1^{\circ} 44^{\prime}$ per row, giving a maximum tilt angle $6^{\circ} 56^{\prime}$ to the outer fueled row.

Closed loops are of the reentrant type in which a useful test diameter of about 2.6 in. can be achieved. Open test 


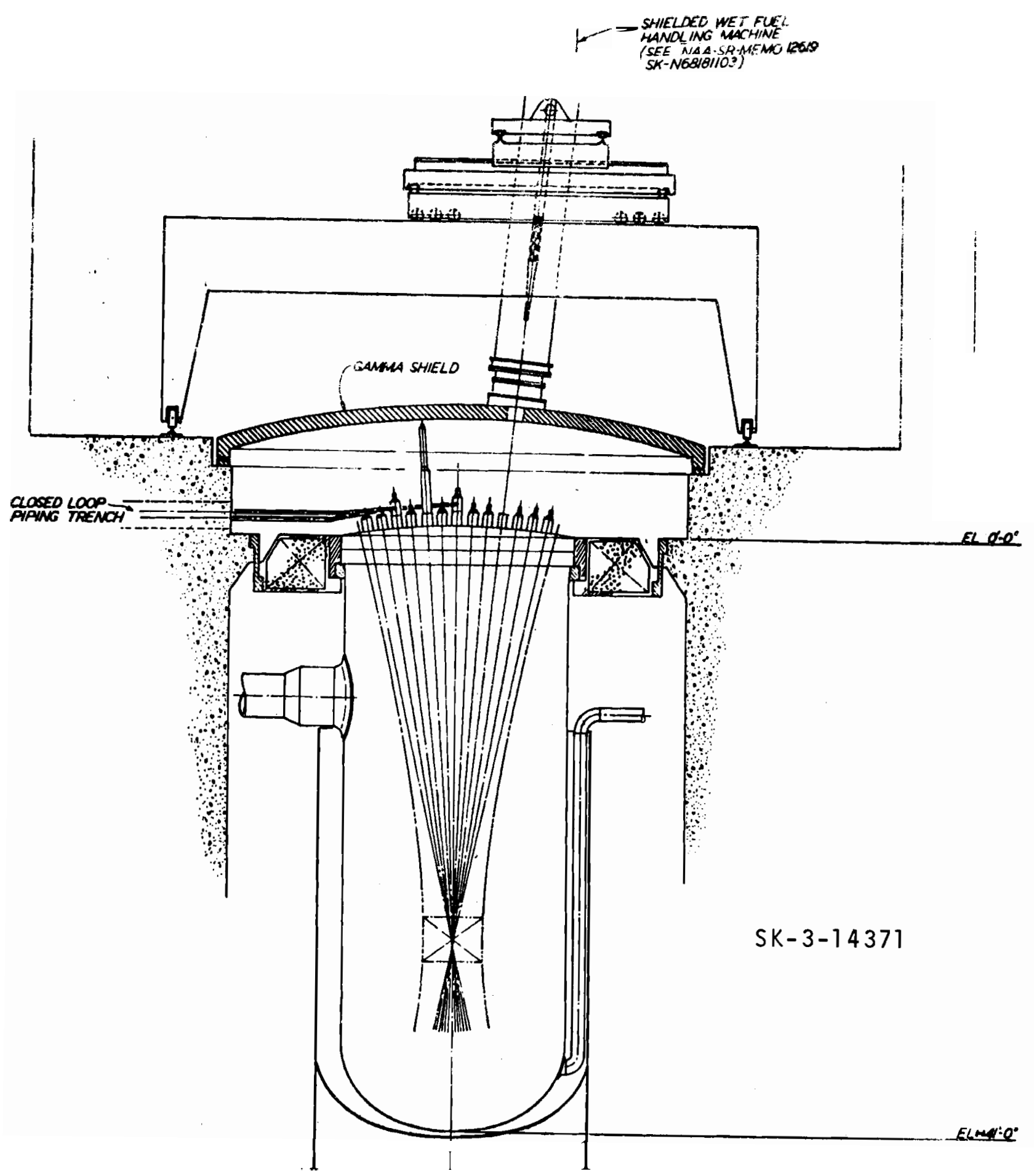

FIGURE B-1. Concept I Elevation 
positions can accommodate test diameters up to driver fuel diameter. Although 13 test positions are shown in the core, this is a representative case and a substantially greater number can be used within neutronics and thermal limitations.

Cross arm or branch piping for closed loops is brought out between nozzles over the top of the cover under the gamma shield.

b. Concept II - Sp1it Conical Core

Description of Concept

Concept II provides (1) a dispersed core of an annular design, (2) nozzle access through the reactor cover to each core position, (3) refueling, test and core component handling using a remotely operated unshielded fuel handling machine, and (4) a hot cell containing an inert atmosphere. A sketch showing the concept arrangement in elevation is presented in Figure B-2.

Dispersion is achieved at the reactor nozzles in this concept by using an annular conical core design. The core is subdivided to provide 71 driver fuel assemblies, 6 in-core control rods, 8 open test positions, and 5 closed loop positions ( 3 of which are plumb vertical). The three center loop positions are surrounded by the remainder of the core in a tightly packed annulus. Inclination of core positions from the vertical is $0^{\circ} 56^{\prime}$ per row, yielding a maximum tilt angle at the outer fueled row of $3^{\circ} 44^{\prime}$. The core is surrounded by nickel reflector assemblies and 24 peripheral control rods.

Performance is based on a total core power of $400 \mathrm{MW}_{\mathrm{t}}$ in a total volume of 1064 liters. The resulting power density yields a peak neutron flux to the central loops of $0.7 \times 10^{16} \mathrm{n} / \mathrm{cm}^{2}-\mathrm{sec}$. First core operations is based on a 550 and $900^{\circ} \mathrm{F}$ bulk sodium outlet temperature. The core is fully orificed to maintain a $350^{\circ} \mathrm{F}$ A t across the channels. 
BNWL - 1165

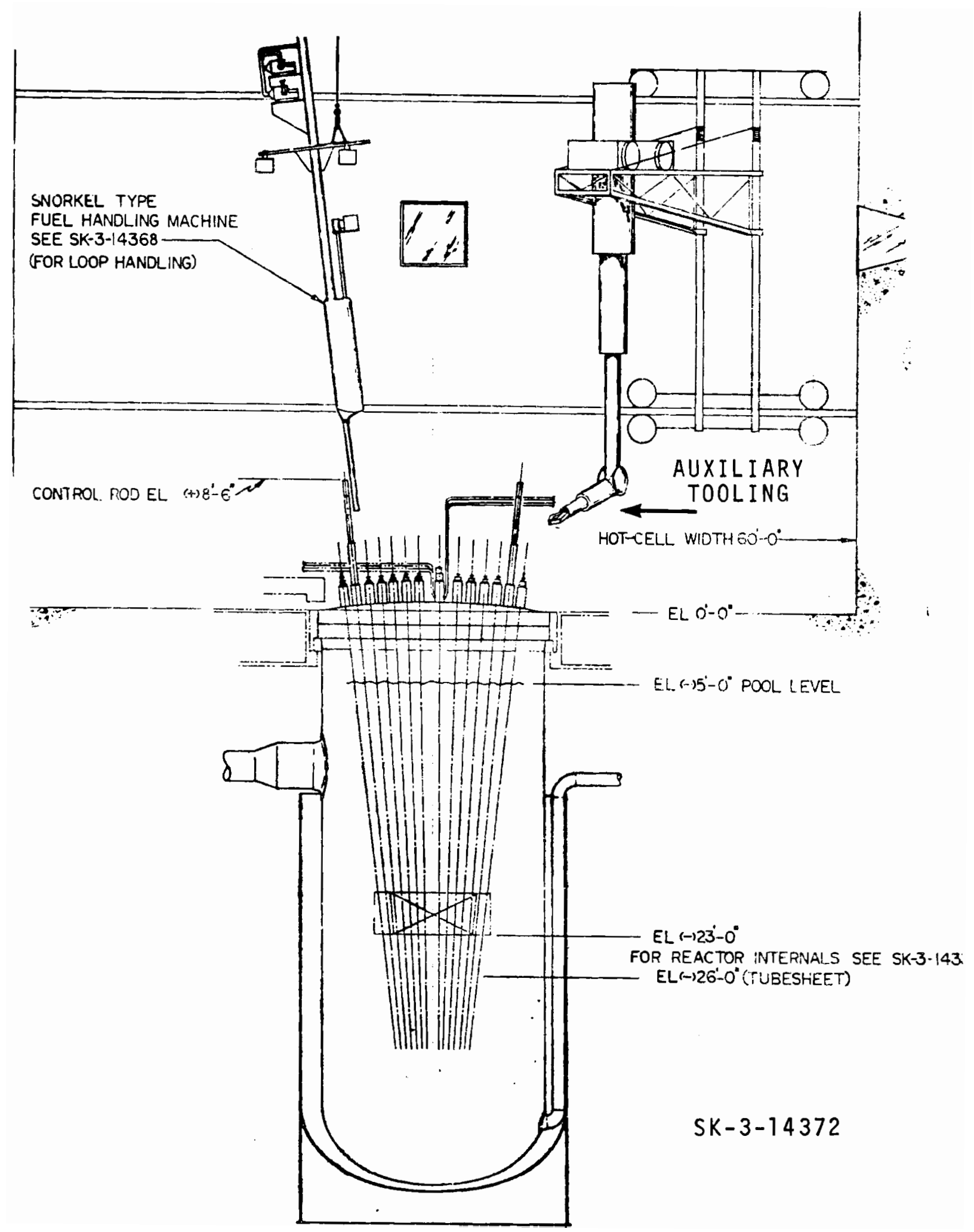

FIGURE B-2. Concept II Elevation 
Instrumentation is provided for each core position to sense channel outlet temperature, flow and failed fuel. Instrument leads extend upward from the instrument package containing the sensors through the instrument section to a mating plug and leadout mounted in the nozzle. Leads from each nozzle cap are directed outward radially between and slightly above the nozzles. At the periphery of the vessel cover, leads are harnessed and grouped in instrument troughs that are pivoted and can be moved for convenience when connectors at both ends are detached.

\section{Testing Capabilities}

Closed loops are of the reentrant type in which a useful test diameter of about 2.6 in. can be achieved. Open test positions can accommodate test diameters up to driver fuel diameter. Although 8 open test positions and 5 closed loops (including 3 vertical loops) are shown in the core, this is a representative case. A substantially greater number of either can be used within neutronics and thermal limitations, but six closed loop cells are envisioned as a maximum because of containment and facility space limitations.

Additional test holes are available in reflector positions for nonfuel tests compatible with the primary sodium or shortterm irradiations. Other specialized test facilities such as axial positioners or package loops can be introduced in any core position.

Origins of Concept II

Concept II was developed ${ }^{(1)}$ as an "Improved Dispersed Core Reference Concept" by a BNW task force. 


\section{c. Concept III - Vertical Core with Open-Top Refueling Description of Concept}

As shown in Figure B-3, Concept III is based on use of a vertical core, with open-reactor fuel handling, cooled by a "piped" heat transport system. The core is comprised of 127 lattice positions consisting of 105 driver fuel assemblies, 3 safety rod positions, 6 closed loop positions, and 12 open loop positions. Control is accomplished using 38 reflector shim-regulating rod assemblies.

The two-zone core, rated at $400 \mathrm{MW}_{\mathrm{t}}$ with a $300{ }^{\circ} \mathrm{F}$ core $\mathrm{AT}$, produces a peak total flux of about $1 \times 10^{16} \mathrm{n} / \mathrm{cm}^{2}$. First core operation will be with a 500 to $600{ }^{\circ} \mathrm{F}$ coolant inlet temperature and an 800 to $900{ }^{\circ} \mathrm{F}$ core outlet temperature. Each driver fuel position is orificed to maintain the required $300{ }^{\circ} \mathrm{F}$ core $\mathrm{AT}$ at mid-cycle conditions. Overall core volume is about 745 liters.

\section{Testing Capabilities}

Twelve open loops and six closed loops are presently envisaged for testing facilities although upwards of about 20 open loops could be used with the core geometry. Both the open loop and closed loop positions allow contact instruments to the test specimens.

One of the closed loops is a hairpin, or U-tube, type of facility with a usable test diameter of 2.75 in., located at the center of the core. The remaining five closed loops are of the reentrant type, with usable test diameters of 2.25 in. and are located at approximately the mid-radius of the core. 
BNWL - 1165

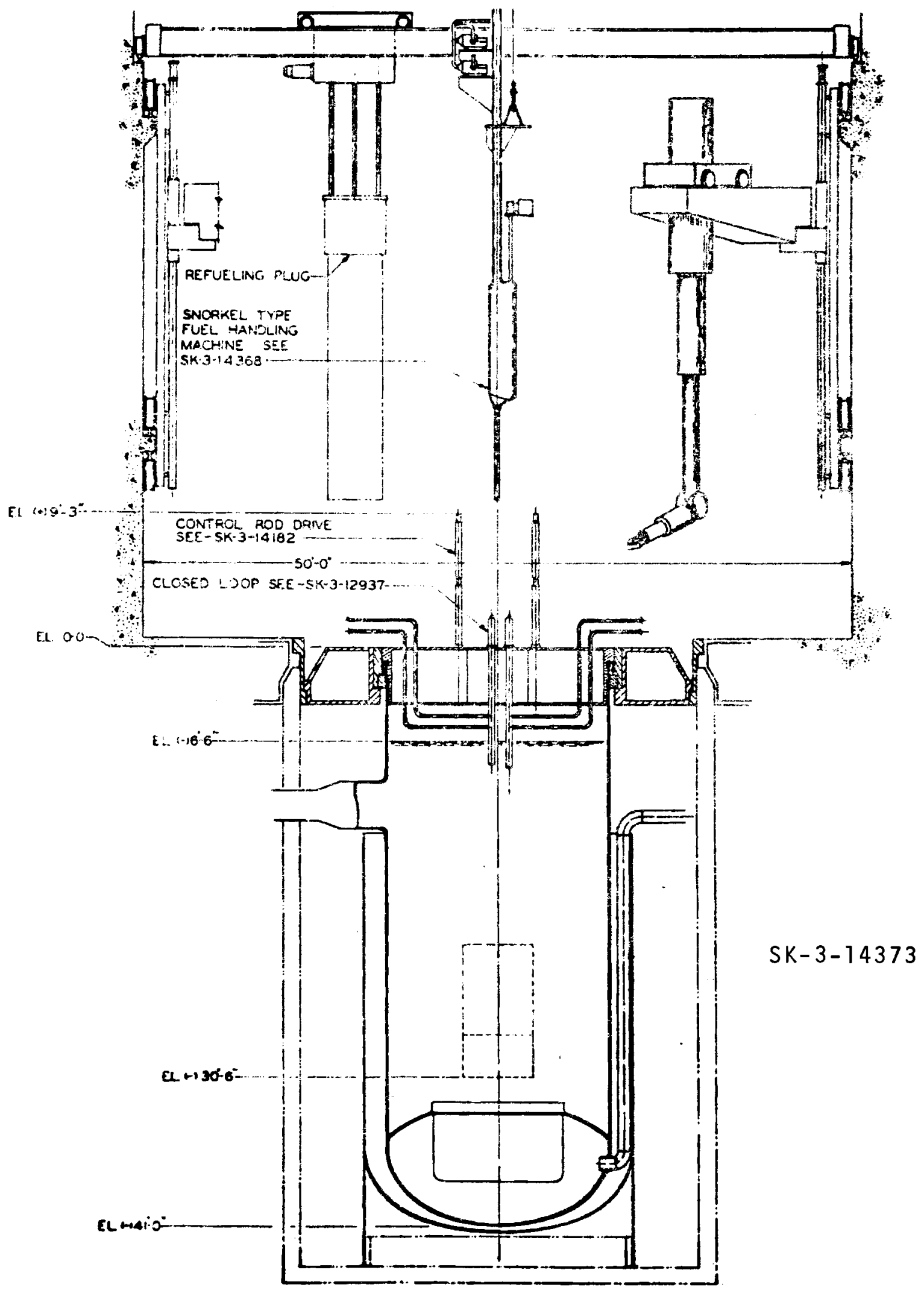

FIGURE B-3. Concept III Elevation 
BNWL -1165

Sources of Concept III

Concept III was developed from the "FFTF Backup Core Design"(2) by a BNWL "Improved Vertical Core Task Force". (3)

d. Concept IV - Vertical Core with In-Vessel Fuel Handling Description of Concept

Concept IV provides a vertical core with under-cover fuel manipulation (see Figure B-4). Closed-loop test fuel is handled in a hot cell above the reactor.

Testing Capabilities

The closed loop testing capability for this concept consists of three (3) plumb vertical loops located in the center of the core and up to three additional vertical closed loop positions located in selected positions toward the core periphery. (The design of the loops in the core periphery must accommodate plug rotation for refueling.)

There are eight (8) contact instrumented open test positions in the core lattice. These are restricted to the centrally located lattice positions.

e. Concept V - Vertical Core with Multiple Cover Ports

Description of Concept

Concept $V$ employs a total of 14 cover ports, each 16 in. in diameter (see Figure B-5). The 16-in. diameter core access port plugs are handled by a double barrel machine which removes the plug and insets the lower portion of the fuel handling machine (FHM). The upper portion of the FHM is a wet machine having sufficient storage and handling capacity for performing all charge-discharge and shuffling functions at any given port. 


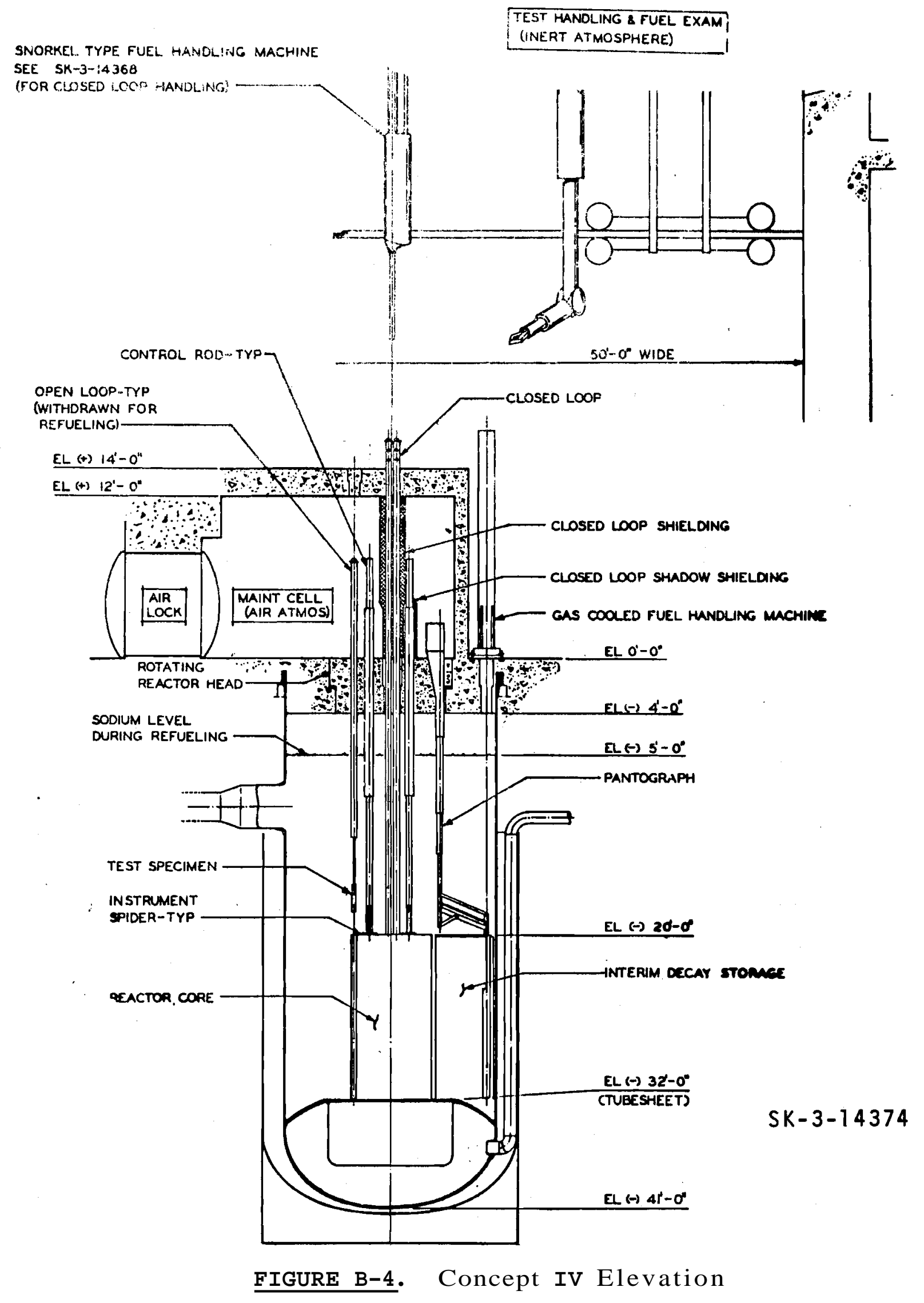


BNWL - 1165
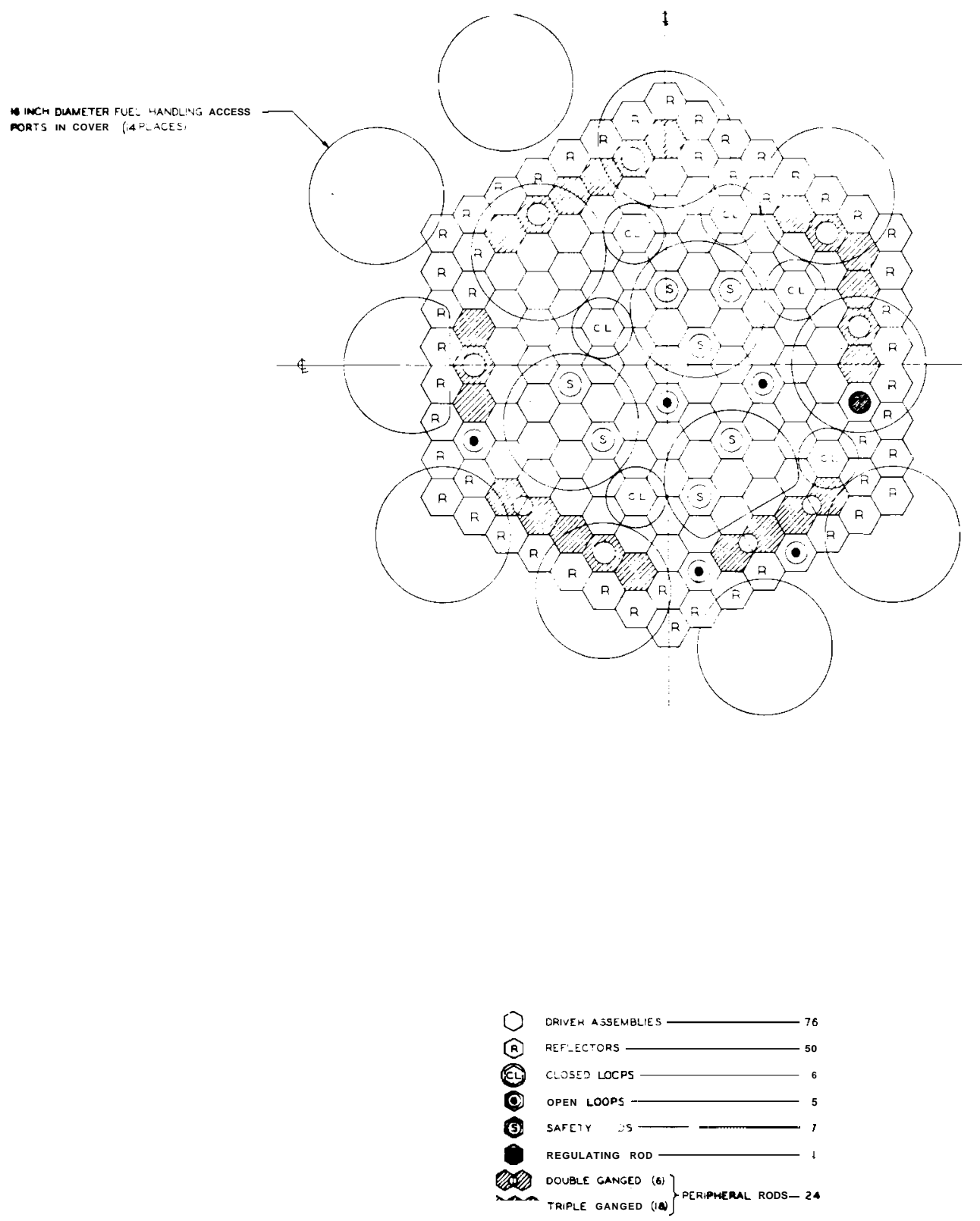

SK-3-14421

FIGURE B-5. Concept V Core Map and Cover Arrangement 
The core includes 76 driver assemblies, 102 reflector assemblies, 8 in-core control rods and 18 peripheral control rods. Drives for in-core rods are removed for refueling. The peripheral rod drives are mounted below the operating deck and do not require removal for the refueling operation. Cross-arm piping and instrument leads for the closed loops are below the operating deck and are not affected by core refueling.

Testing Capabilities

The concept provides six fully instrumented closed loops, two fully instrumented open loops, and four open loops without test fuel instrumentation.

2. BNW REVIEW OF CONCEPT I (4)

BNW review of Concept I yielded a number of advantages and disadvantages which are summarized below.

Advantaees

Full instrumentation capability extends to each core position.

- Interchangeability of test positions offers a wide range of environment and facilities.

- Tests or their instrumentation are not perturbed by refueling operations.

Disadvantages

- Test positions other than the three central loops depart from plumb vertical orientation.

- Interim examination of tests or core components is not easily accomplished in the hot cell area.

- Core dispersion decreases the neutron flux to test positions.

- Dispersion introduces complexities into the core mechanical design. 
- Not prototype of planned LMFBR's.

Refueling and servicing is off-vertical and non-prototypic of planned LMFBR ${ }^{1}$ s.

- Design of gamma shield and penetrations difficult.

- FHM tends to be large and heavy.

- Nozzle preparation procedures penalize refueling time.

3. BNW REV IEW OF CONCEPT II (4)

BNW review of Concept II has led to identification of advantages and disadvantages which are summarized below.

\section{Advantages}

- Full instrumentation capability extends to each core position.

- Interchangeability of test positions offers a wide range of environment and facilities.

- Tests or test instrumentation not perturbed by refueling operations.

Disadvantanes

- Test positions other than the three central loops depart from plumb vertical orientation.

- Core dispersion decreases the neutron flux to test positions.

- Dispersion introduces complexities into the core mechanical design.

- Not prototypic of planned LMFBR's.

- Refueling and servicing is off-vertical and non-prototypic of planned LMFBR ${ }^{1}$ s.

- Operational costs tend to be high because of remote operations.

- Nozzle preparation procedures penalize refueling time. 
4. BNW REVIEW OF CONCEPT III (4)

BNW review of Concept III is summarized below.

Advantages

Performance - The vertical core will produce the maximum peak neutron flux of any concept being considered, approaching $1 \times 10^{16} \mathrm{n} / \mathrm{cm}^{2}-\mathrm{sec}$ for the initial core loading.

- Testing Capabilities - The incorporation of six plumb vertical closed loops represents no problems in the Concept III configuration. More than the desired number of open loop positions, namely, 12 , can also be accommodated with the configuration. The Concept III configuration allows plumb verticality in all positions.

- Core Access - Concept III provides complete, routine access to the reactor core region.

- Current Technology - Fast reactors built to date and those presently planned are vertical core reactors. The technology developed by existing reactors and currently being used in the design of planned reactors is directly applicable to the Concept III configuration.

Disadvantages

- Inflexibility of Test Loop Positions - While driver fuel can be installed in any vacant closed loop position, the mechanical arrangement of Concept III makes it unreasonable to install a closed loop in any driver fuel position.

Such interchangeability would require extensive rework of the reactor cover and core instrumentation arrangement. A similar situation exists for open loop test positions.

- Instrumentation Limitations - The design may not allow individual channel fuel failure detection for all core positions. 
BNW REVIEW OF CONCEPT IV (4)

BNW review of Concept IV is summarized below.

\section{Advantages}

- Can achieve high test flux.

- Test loops are vertical.

- In-vessel storage allows under-sodium transfer of high power elements. Subsequent decay in storage results in very low heat loads during ex-vessel (out of sodium) transfer.

- Is a direct application of and would contribute to LMFBR fuel handling technology.

- Refueling reactivity checks may be made without serious lost time.

- Use of an instrument "spider" for sensor support and location provides a standard, remotely removable, 7-group unit .

- Handling of test loops does not interfere with driver fuel handling, therefore increasing potential for high plant availability.

- Permits simultaneous performance of core component handling and maintenance operations.

- Potential for high plant availability.

\section{Disadvantages}

- Limited core location interchangeability of components, i.e.,

(a) test loops and driver elements

(b) control rods and driver elements

- May result in selection of fewer than six closed loop test locations, or might result in complicated peripheral closed loop designs, depending on concept. 
- Requires additional fuel handling machine(s), i.e., in-vessel driver fuel handling machine and possibly an auxiliary machine to raise instrumentation or test loops during refueling to avoid interference with the in-vessel machine.

- Employs only proximity instrumentation on driver elements.

- Rupture detection by sodium sampling presents problems of routing sampling tubes in the shield plug.

- Provision of suitable clearance for unobstructed movement of the refueling pantograph may present a problem especially with the refueling channels near the core center. Removal of interfering control rod or closed loop may be required to open a path.

6. STUDY TEAM REVIEWS OF CONCEPTS I, II, II I AND I V

Following the BNW reviews of Concepts I, II, III and IV, further reviews were made by joint BNW-Westinghouse-RDT study teams. $(5-11)$

Some of the more significant findings of the study teams are summarized below:

- Mechanical design and fabrication problems are not significantly different between the four concepts.

A 11 concepts would meet containment requirements.

- For refueling, modifications of Concepts I and IV were preferred.

- Studies on instrumentation capabilities indicated a good possibility that much of the needed instrumentation could be provided in vertical cores, except that little interchangeability could be provided between driver fuel and closed loop positions and between driver fuel and open loop positions. 
7. MANAGEMENT REVIEWS OF CONCEPTS I, II, II I AND IV

Comprehensive reviews of the evaluations of Concepts I, II, III and IV were made by BNW, Westinghouse and AEC/DRDT management.

Conclusions and agreements were reached and placed in the form of guidelines for continuing concept selection effort. Typical guidelines were

(1) Design concepts which are based on use of a sealed hot cell (one in which all operations for the life of the reactor are assumed to be carried out remotely in an inert atmosphere) are not acceptable. A routine capability must be provided for contact maintenance in an air atmosphere-in the reactor head area during shutdown.

(2) The reactor head plug shall be fixed.

(3) The fuel assemblies must be vertical within the reactor core.

(4) Concept design efforts shall have flexibility in locating open and closed loops within the core.

8. REVIEW OF CONCEPT V

After intensive evaluation it was concluded in joint meetings between BNW, Westinghouse, A-I and RDT that Concept V was unattractive and further work was suspended in November 1968. Typical problems are listed below:

- Test Facilities

With the multiple plug arrangement, the closed loops must be located near the periphery of the core to allow piping access without interfering with other vertical elements. This arrangement would not provide desired flux levels for the closed loops. The arrangement also created mechanical problems in design at the control rod drives. 
- Fuel Handling

(a) The number and size of machines required is undesirably large. The need for a holddown foot and the plug size are contributing factors.

(b) Removal of any driver fuel or test assembly from the core requires clearing the entire top head area because of the size and design of the floor valve.

- Instrumentation

Number of individual seals required due to the present need to rotate and translate individual instrument modules is excessive. The reliability of seals as shown is questionable.

- Availability

A Study team report ${ }^{(12)}$ on Concept $V$ availability showed lower availability for Concept $V$ than for Concepts II, III and IV.

\section{REFERENCES}

1. FFTF Quarterly Progress Report, April, May, and June, 1968 , BNWL-880, pp. 3.1-3.49. Battelle-Northwest, Richland, Washington.

2. Final Fast Flux Test Facility Backup Design Summary Report. GEAP-5722. GE Company, Schnectady, New York. January 1969

3. FFTF Quarterly Technical Report, April, May, and June, 2968. Washington.

4. S. O. Arneson, R. E. Peterson, A. F. Lillie, C. R. Nash, et al. Unpublished Data. Battelle-Northwest, Richland, Washington, August 1968. (Preliminary Integrated Concept Summary)

5. L. M. Finch, E. E. Purvis (AEC), A. SeZz (W-), and A. W. Kramer (W). Unpublished Data.

September 13, 2968 . (Mechanical Problems of Skewed Cores and Core Restraint Methods for the FTR) 
6. D. C. Boyd, J. D. Sutherland (W), W. C. Ritz (W) and C. J. Heltemes, Jr. (AEC). Unpublished Data.

September 1968. (Practicalities of Inert Cells During Normal Operations)

7. D. E. Simpson, T. Beresovski (AEC) and P. Fox (W). Unpublished Data. September 16, 1968. (Report-of Fact Finding Team on DBA Containment Considerations for FFTF Concept Selection)

8. T. Withers, C. E. Boyd, D. Riley (AEC) and W. E. Gunson (W). Unpublished Data. September 13, 1968. (Report on ReZative Availability of Four FFTF Concepts)

9. C. A. Halpine $(A E C)$, W. E. Cawley, H. D. Lenkersdorfer and E. E. Wade (W). unpublished Data. September 12, 2968. (FFTF Fue 2 Handling Machine - Design, Evaluation and Technical Critique)

10. N. E. Todreas (AEC), C. R. Nash, K. O. Creek, W. DaZos and E. Paxson (W). Unpublished Data. September 13, 1968. (Instrumentation Capabilities of Vertical Cores)

11. J. E. Mills, R. L. Flurry (W), H. E. Rehnborg (W) and L. M. Welshans (AEC). Unpüblished Data.

September 13, 1968. (Reactor Top Access Requirements for Maintenance and Repair)

12. C. E. Love and W. E. Gunson (W). Unpublished Data. November 18, 1968. (Relative Avaizabizity of FFTF Concept V) 
BNWL- 1165

\author{
EXHIBIT $C^{*}$ \\ FFTF VERTICAL CORE \\ REFERENCE CONCEPT DESCRIPTION
}

* This exhibit presents extracts from an informal document prepared by R. C. Walker, W. B. McDonald, et al. in December 1968. The document summarized work by an FFTF integrated Reactor Task Force composed at BNW, Westinghouse and Atomics International personnel. 


\section{EXHIBIT C \\ FFTF VERTICAL CORE \\ REFERENCE CONCEPT DESCRIPTION}

\section{SECTION 1. SUMMARY CONCEPT DESCRIPTION}

The FFTF Concept (Figures 2.1 and 2.2, pages 5 and 6) is a fixed reactor head, vertical core design with individual nozzle access primary testing facilities. The design features location of closed loops and open test positions along three near-radii of the core at 120-degree intervals. Driver fuel assemblies are installed and removed utilizing three major circular ports located in the trisected regions between the test facility rows. The reactor is located below the operating floor level within a containment structure which contains an air atmosphere in normal operating areas. An air-filled machinery dome is installed over the reactor.

The reactor core is made up of hexagonal assemblies in a 91-site array. The driver fuel assemblies feature mixed $\mathrm{PuO}_{2}$ $\mathrm{UO}_{2}$ fuel cladding in 0.230-in. diameter, Type 316 stainless steel arranged in a 217-pin array. The driver fuel assemblies are $14 \mathrm{ft}$ long including approximately $2 \mathrm{ft}$ of length to accommodate fuel pins which require fission gas plenums longer than those of initial core driver fuel. Approximately three scramassisted safety rods and six scram-assisted control rods are located within the core. These are supplemented by approximately 15 gravity-drop control'rods located in the first of the three reflector rows. All control rods utilize enriched $\mathrm{B}_{4} \mathrm{C}$ as the neutron absorber. All control rods in the concept are driven by in-line, top mounted drives.

Six sodium cooled closed loops and two contact instrumented, subassembly size, open test positions are located along. the three test position radii. Further study will be necessary to ensure means for accommodating the trail cable type short-term test facility. An axial positioner is provided for selected tests in an open test position as well as one axial positioner for a closed loop. Two closed loops are located at essentially 
BNWL-1165

the core center, one closed loop and two open test positions are located at approximately core mid-radius and three closed loops are positioned at the core periphery. Closed loop positions can accommodate open tests or driver fuel and additional flexibility for relocation of closed loops into open test positions is provided.

In the event that driver fuel is located in any of these test positions, instrumentation and backup hold-down is provided utilizing a special assembly inserted through the test position nozzle. One special proximity-instrumented open test position is provided at essentially the core center. This position can also be utilized for a variety of special test assemblies such as reduced diameter open loops, capsules or materials tests.

All driver fuel positions are instrumented for outlet temperature, flow and failure location utilizing an instrument plate assembly which also provides a mechanical backup to the full hydraulic balance hold-down. The instrument plate assembly in the reference concept arrangement also is utilized to radially position driver fuel assemblies prior to actuation of the radial core restraint system. Instrumentation package sensors (thermocouples and flowmeter) are located in the instrument plate; these instruments are installed in a module which can be replaced from the top of the support column for the instrument plate. Passive instrumentation components (flow conditioning components for temperature, flow and FEDAL measurements) are also located in the instrument plate.

The instrument plate assembly is supported by a rotating plug located in the approximately 4-ft diameter refueling port for each reactor sector. For the reference concept arrangement, the rotating plug also contains the in-vessel driver fuel handling machine. The lower end of the instrumentation plate support column is guided in a socket which also serves as the connection plug for the sodium sampling FEDAL system. Driver refueling is accomplished by use of a fixed-length arm grapple 
assembly positioned by means of rotation of a plug located in the refueling port. This fuel handling machine transfers driver fuel under sodium to finned pots located at the core elevation but radially outside the core. In the reference reactor arrangement, in-vessel storage of driver fuel is provided utilizing a lazy susan. Driver fuel is transferred into and out of the reactor vessel through transfer ports utilizing the finned pots and a shielded out-of-vessel fuel handling machine.

Refueling of closed loop and open test facilities is accomplished by means of a shielded, sodium-cooled fuel handling machine to ensure safe transfer of experiments without damage and to ensure maximized plant availability due to test facility refueling.

The concept employs a three-loop primary heat transport system with hot leg pumps to supply coolant to the reactor. The reactor vessel may be either of the piped downcomer or annular design; this concept feature is not yet established. 


\section{SECTION 2. SUMMARY OF PRINCIPAL CONCEPT CHARACTERISTICS AND DATA}

A. GENERAL PLANT DATA

1. Core arrangement

\begin{tabular}{|c|c|c|}
\hline Units & Values & $\underline{\text { Status* }}$ \\
\hline & vertical & 1 \\
\hline year & 20 & 1 \\
\hline $\mathrm{n} / \mathrm{cm}^{2} / \mathrm{sec}$ & $7.3 \times 1015$ & 2 \\
\hline \multirow[t]{2}{*}{$\mathrm{MW}_{\mathrm{t}}$} & 400 & 1 \\
\hline & sodium & 1 \\
\hline 1 iter & 1025 & 2 \\
\hline $1 \mathrm{~b} / \mathrm{hr}$ & $1.5 \times 10^{7}$ & 2 \\
\hline psi & 100 & 2 \\
\hline
\end{tabular}

9. Reactor bulk inlet temp. initial core
design maximum

$\begin{array}{ll}{ }^{\circ} \mathrm{F} & 600 \\ { }^{\circ} \mathrm{F} & 900\end{array}$

2. Design 1 if e

3. Peak flux

4. Total power

5. Reactor coolant

6. Core volume

7. Reactor coolant flow

8. Reactor pressure drop design maximum Reactor bulk outlet temp.

$$
\begin{aligned}
& \text { initial core } \\
& \text { designmaximum }
\end{aligned}
$$

${ }^{\circ \mathrm{F}}$

900

1200

11. Core temperature rise avg.

$$
\begin{aligned}
& \text { in itial } \\
& \text { designmaximum }
\end{aligned}
$$

${ }^{\circ} \mathrm{F}$

300

400

12. Reactor cover gas

argon

1

B. REACTOR VESSEL
1. Diameter
$f t$
$\sim 18$
2
2. Height
f t
$\sim 51$
2
3. Wall thickness
in.
2
2
4. Wall fluence, total
$\mathrm{nvt}$
$10^{21}$
2

1 means the firm requirement or definite concept characteristic 2 means the current reference design value 
5. Material

c. CORE DESIGN

1. Number of core lattice positions

2. Number of driver fuel subassemblies

3. Number of closed loops

4. Number of contact instrumented in-core open test positions

5. Number of proximity instrumented open test positions

6. Number of in-core safety rods

7. Number of in-core control rods

8. Number of peripheral control rods

9. Equívalent core diameter

in.

10. Active core height

in.

36

2

11. Reflector material

12. Reflector thickness

$$
\text { radial }
$$

13. Fuel pin heat transfer area

14. Core coolant velocity, maximum

15. Direction of coolant flow in.

rows

$f t^{2}$

$\mathrm{ft} / \mathrm{sec}$
2800

2

6

3

1

2

upward 
D. DRIVER FUEL

1. Fuel composition

2. Cladding Material

3. Linear heat generation rate, average

4. Overpower factor

5. Engineering hot channel factor

6. Peak linear heat generation at overpower

7. Target burnup, average

8. Cladding heat transfer coefficient

9. Maximum fuel temperature

10. Fuel assembly length

11. Fuel geometry

12. Pin diameter

13. Spacer wire diameter

14. Number of pins per assembly
Units

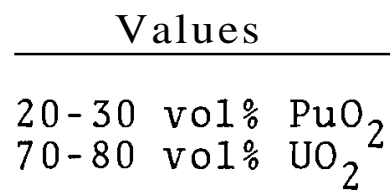

Type 316 SS
Status

1

$\mathrm{kW} / \mathrm{ft}$

7.85

2

1.25

2

1.13 to 1.25

2

$\mathrm{kW} / \mathrm{ft}$

18.0

2

MWd/tonne 45,000

(metal)

$$
\underset{\mathrm{ftu}}{\mathrm{Bt}} \mathrm{t}^{2} / \mathrm{hr}-{ }^{\circ} \mathrm{F} \quad 40,000
$$

${ }^{\circ} \mathrm{F}$

4200

2

f t

14

Hexagonal pin cluster

1

in.

0.230

in.

0.056

15. Subassembly cross section outside dimension (across flats )

in .

4.615

2

16. Lattice spacing in.

4.715

17. Duct wall thickness 
E. PHYSICS DATA

Units

Values

$\underline{\text { Status }}$

1. Delayed neutron

fraction

0.003

2

2. Neutron lifetime

sec

$\mathrm{T}\left(\frac{\mathrm{dk}}{\mathrm{dt}}\right)$

$3.5 \times 10^{-7}$

2

3. Doppler

MW/1iter

$-0.004$

2

4. Power density

0.4

5. Power distribution (peak

per average)

radial

1.35

2

axial

1.24

2

total

1.68

2

F. TEST FACILITIES

1. Closed loops

-number

6

2

-location

2 adjacent to

core center

2

1 @ mid-radius 2

3 e core

periphery

2

-power handling capability

MW

$\mathrm{ga} 1 / \mathrm{min}$

4

1

- test flow rate

- test section outlet temp.

${ }^{\circ} \mathrm{F}$

$30-300$

1

- test section length

in .

1400 (bypass

flow permitted)

1

- test section diameter

in.

36

2

-pumping headprimary

1b/in. ${ }^{2}$

2.5

1

- test section pressure drop, maximum

1b/in. ${ }^{2} 90$

2

-material (incore tube)

Type 316 SS

1 
BNWL- 1165

Units Values

2. In-core open test positions

-number

$\begin{aligned} & \text { with contact } \\ & \text { instrumentation }\end{aligned}$
$\begin{aligned} & \text { with proximity } \\ & \text { instrumentation(a) }\end{aligned}$
-power
-coolant flow rate
-test assembly length
-test assembly cross
$\begin{aligned} & \text { section } \\ & \text {-coolant }\end{aligned}$

3. Short term irradiation facility

-type

trail cable 1

-number

-1ocation

1

core periphery

2

2

-minimum irradia-

tion time at constant flux min

1

2

-sample length in.

24

2

-sample cross section, maximum

in.

2.0

2

G. HEAT TRANSPORT SYSTEM

1. Primary loops

- number

-primary loop

material

-primary loop

flow (per loop) $\mathrm{lb} / \mathrm{hr}$
3

Type 304 SS

$5.0 \times 10^{6}$
1

1

2

a. One proximity instrumented test position wizl have superior instrumentation accessibility. Driver fuel positions can be used as open test positions with standard driver instrumentation. 
2. Primary pumps

-number

3

1

-design pump head

ft

500

2

-net positive suction head

ft

43

2

-design

temperature

${ }^{\circ} \mathrm{F}$

1050

(a)

1

-speed control

wound rotor motor with liquid rheostat

-motor power

brake

hp

1665

2

rated

hp

3000

2

3. Intermediate heat exchangers

-number

3

1

-type

vertical shell and tube

- LMTD

$$
\begin{aligned}
& \text { initial } \\
& \text { ultimate } \\
& \text {-capacity } \\
& \text { initial } \\
& \text { ultimate }
\end{aligned}
$$

$\begin{array}{lll}{ }^{\circ} \mathrm{F} & 75 & 2 \\ { }^{\circ} \mathrm{F} & 100 & 2 \\ & & \\ \mathrm{MW} & 133 & 2 \\ \mathrm{MW} & 177 & 2\end{array}$

H. SHIELDING

1. Within reactor vessel

-material

- configuration

-thickness

$\begin{array}{ll} & \text { stainless steel } \\ & \text { hexagonal } \\ & \text { assemblies } \\ \text { in. } \quad & \mathbf{2 4}(5 \text { concentric } \\ & \text { rows })\end{array}$

a. Pump tank wizl be designed for $1200^{\circ} \mathrm{F}$ 
BNWL- 1165

Units

Values

Status

2. Cover shield

-material

-thickness

ft

low alloy steel 2

- coolant

4

2

argon, helium or 2 sodium

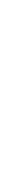


SECTION 3. DRAWINGS

No.

SK $-3-14400$

SK - $3-14425$

SK - 3- 14426

SK - 3-14456

SK - 3- 14457

SK $-3-14458$

SK $-3-14459$

SK $-3-14495$

SK - $3-14496$

SK $-3-14497$

SK $-3-14501$

SK $-3-14502$

SK $-3-14503$

SK - 3- 14504

SK - 3-14513

SK $-3-14514$

SK-3-14515

SK $-3-14519$

SK $-3-14529$

SK - 3- 14530

SK - 3- 14531

SK $-3-14532$

SK $-3-14533$

SK - $3-14540$

SK - 3-14541
Title

Page

No.

Flexing Grid Plate Assembly, Hydraulic Balanced

C -15

$\mathrm{C}-16$

$\mathrm{C}-17$

$\mathrm{C}-18$

Sheet 2 - Closed Loop, Double Containment and Encapsulation System

C -19

Closed Loop Spool Piece Assembly, Welded Closure

$C-20$

Open Loop Spool Piece Assembly, Welded

Closure

$\mathrm{C}-21$

$\mathrm{C}-22$

$\mathrm{C}-23$

$\mathrm{C}-24$

$\mathrm{C}-25$

$\mathrm{C}-26$

Core Restraint System, Cam Actuated

C-27

Core Restraint System, Toggle Actuated

C-28

Core Restraint System, Leaf Spring

C-29

Core Restraint System, Cam Actuated; Elev.

C-30

Open and Closed Loop Tests and Control Rod Integuments

C -31

Open Test Loop-Immersed Section

$\mathrm{C}-32$

C -33

Reactor Cover Assembly

$\mathrm{C}-34$

Poison Tip Section Control/Safety Rods

C-35

Rod Hanger Shaft and Gripper Assembly

C-36

Control/Safety Rod Driver Mechanism

$\mathrm{C}-37$

Control/Safety Rod Head Arrangement

$\mathrm{C}-38$

Driver Fuel Assembly

C -39

Reactor Arrangement

C-40 
BNWL -1165

No.

SK-3-14546

SK-3-14547

SK-3-14538

SK-3-14567

SK-3-14568
Title

Open and Closed Loop Instrument Connector

Open and Closed Loop Instrument Connector

FEDAL Location System Arrangement for Drivers

Reference Core Map

Primary Loading Beam, Radial Restraint
Page

No.

C- 41

C- 42

C- 43

C - 44

C- 45 


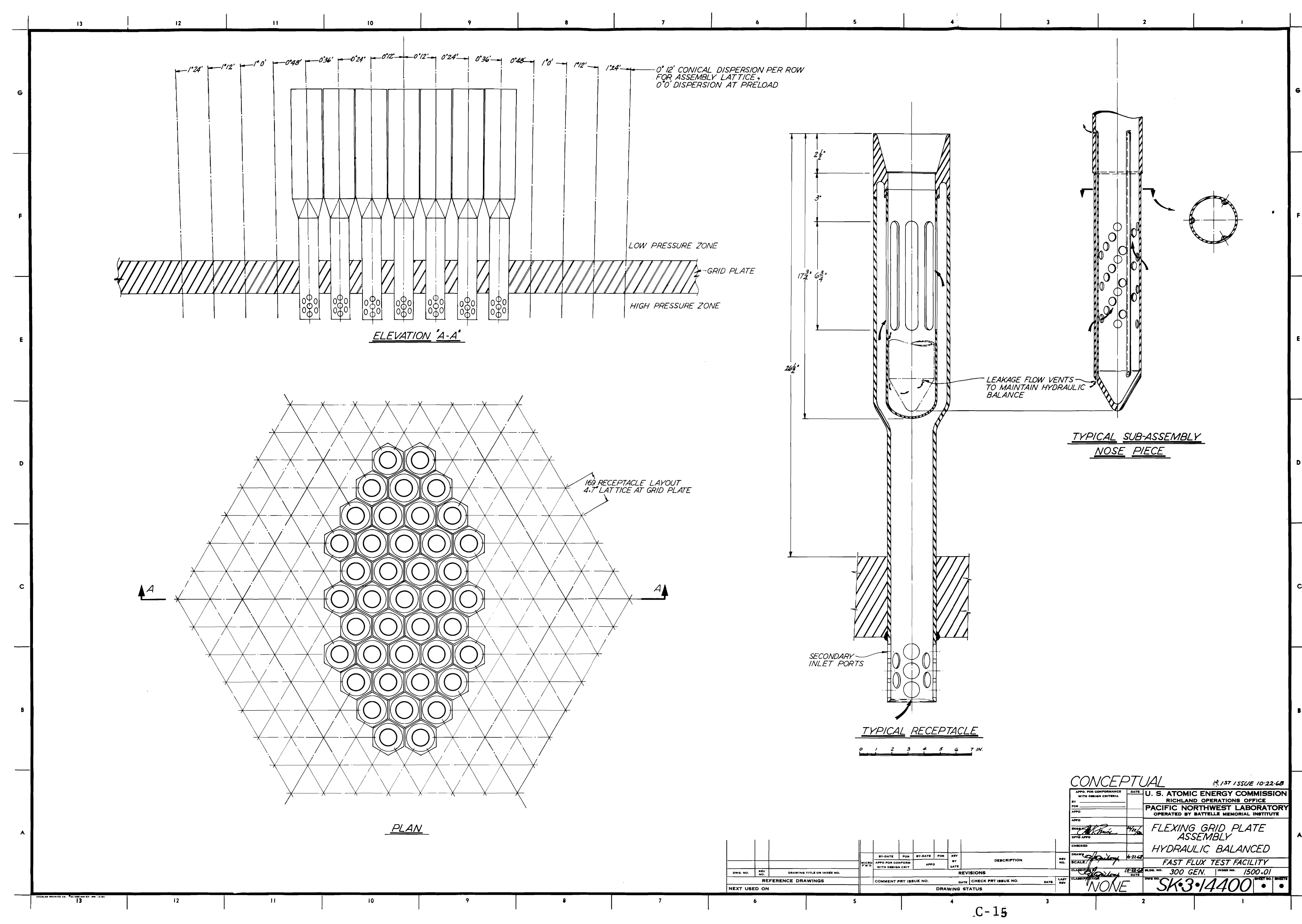




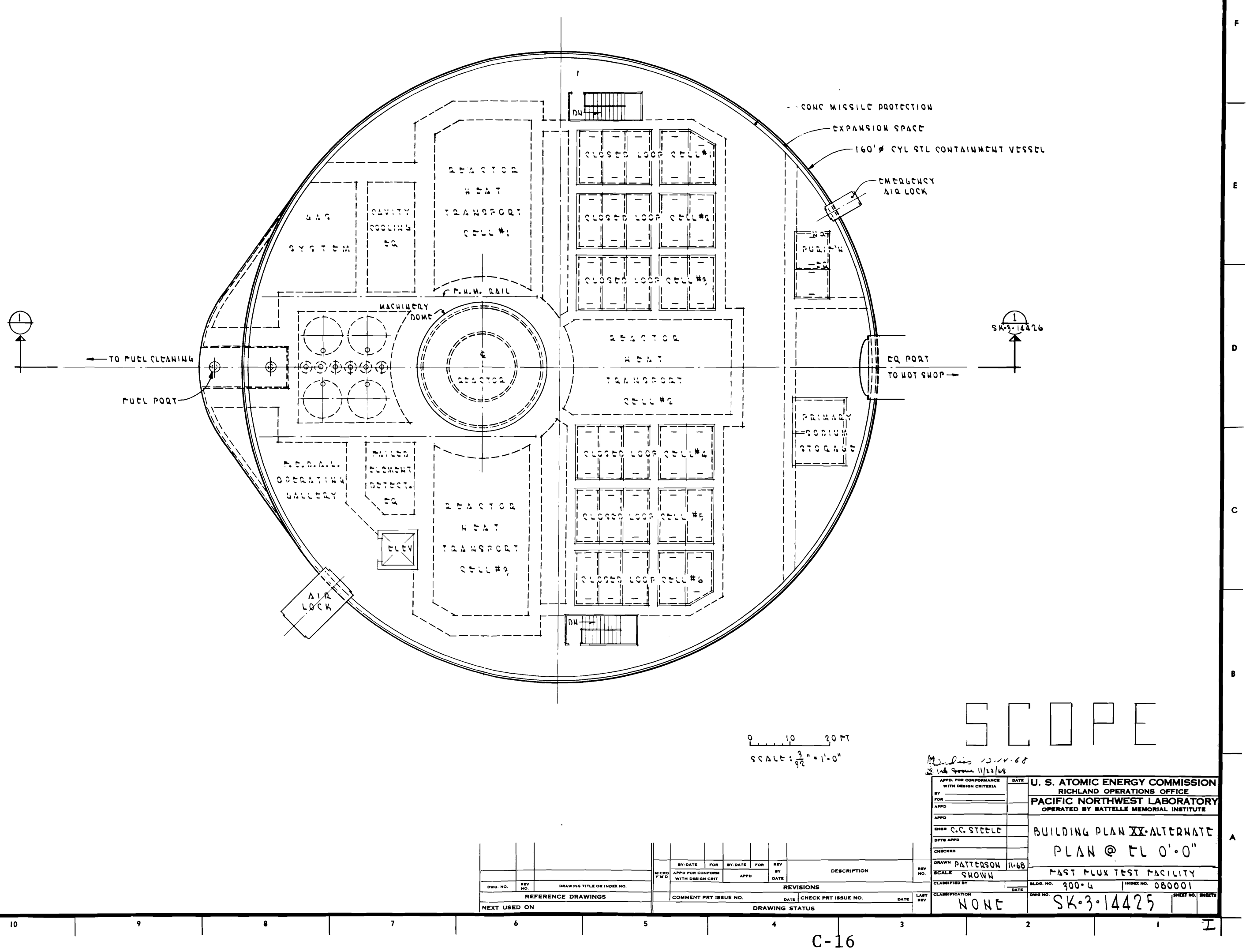




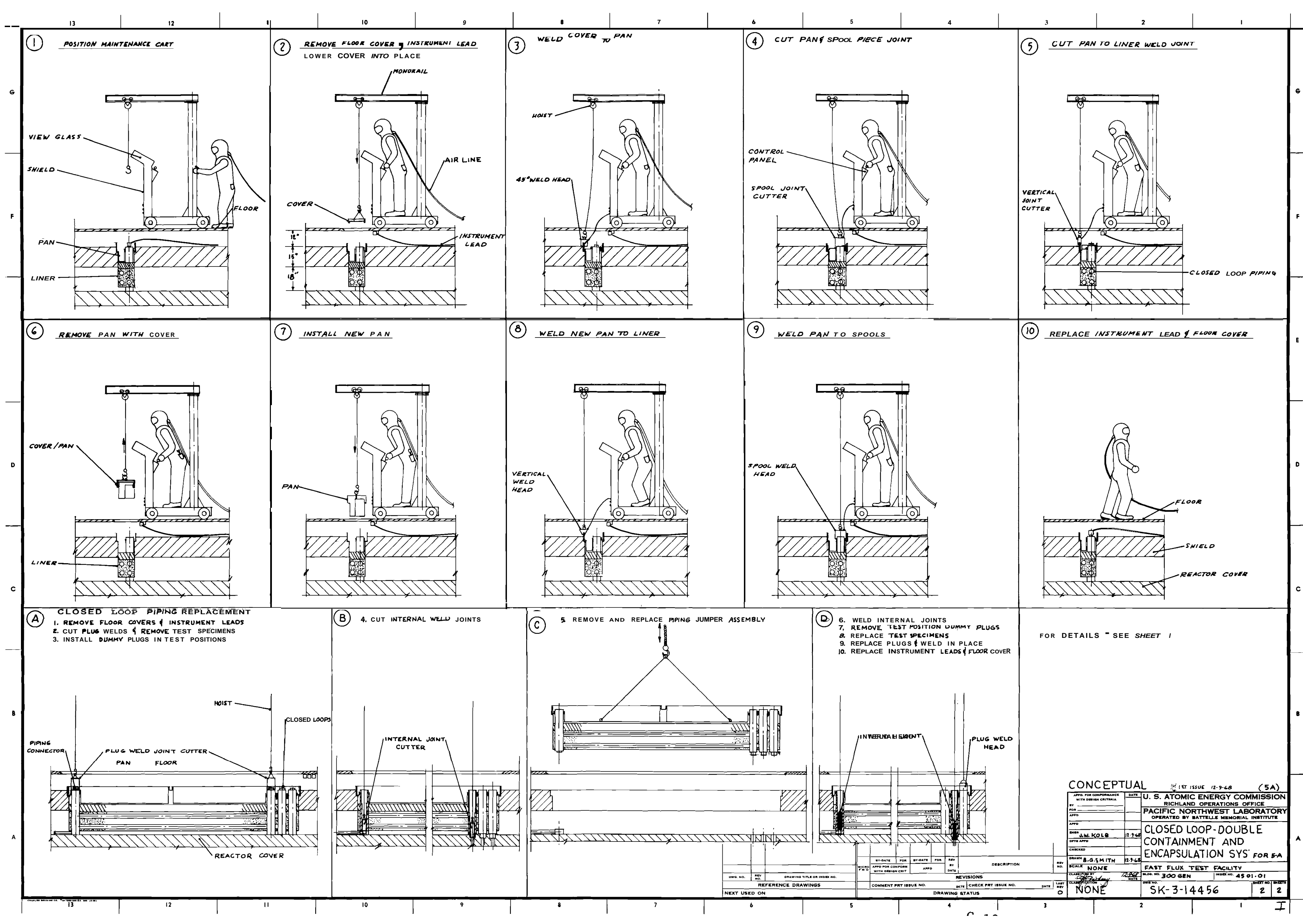




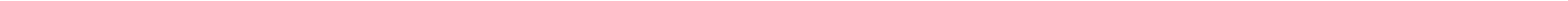




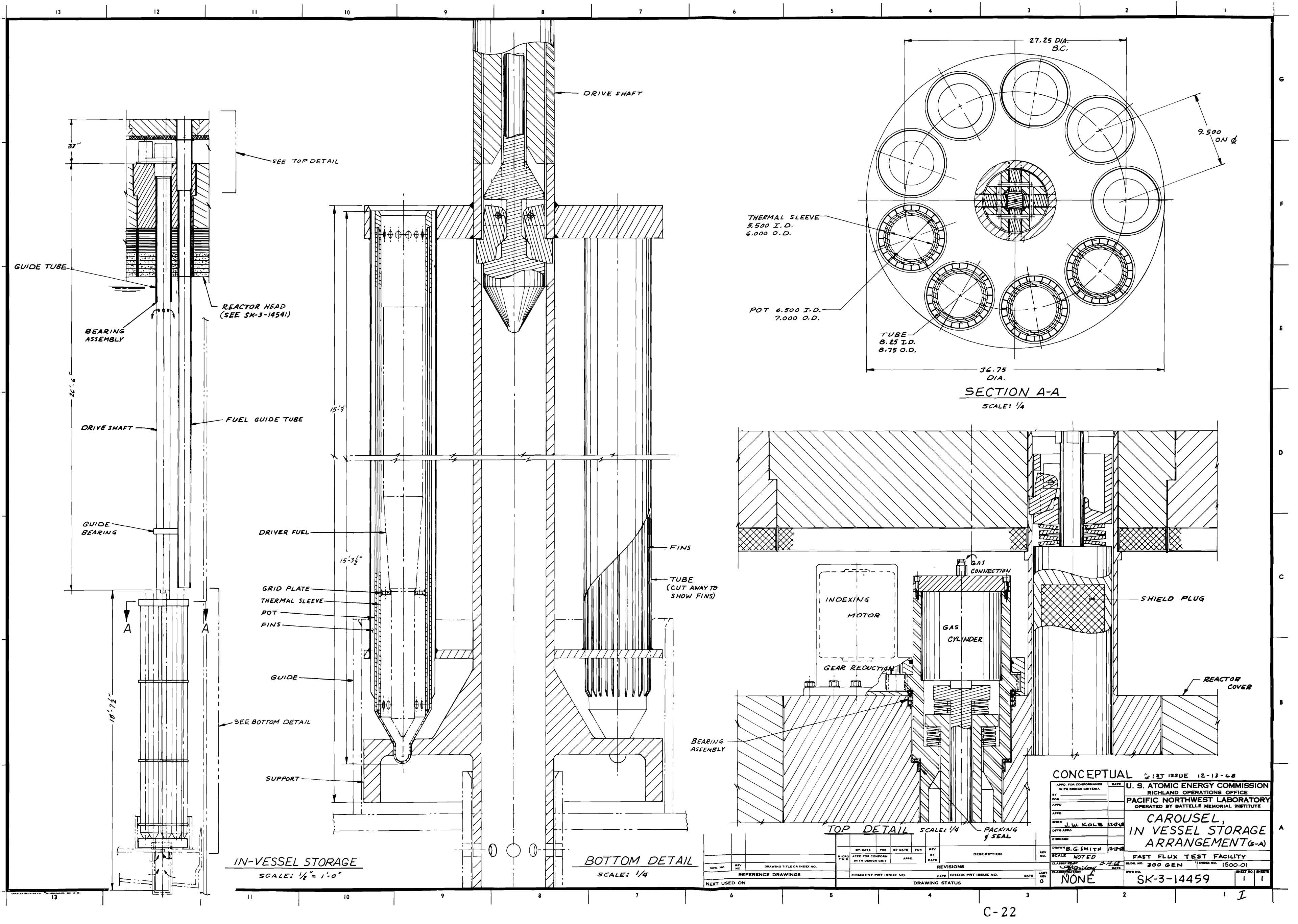




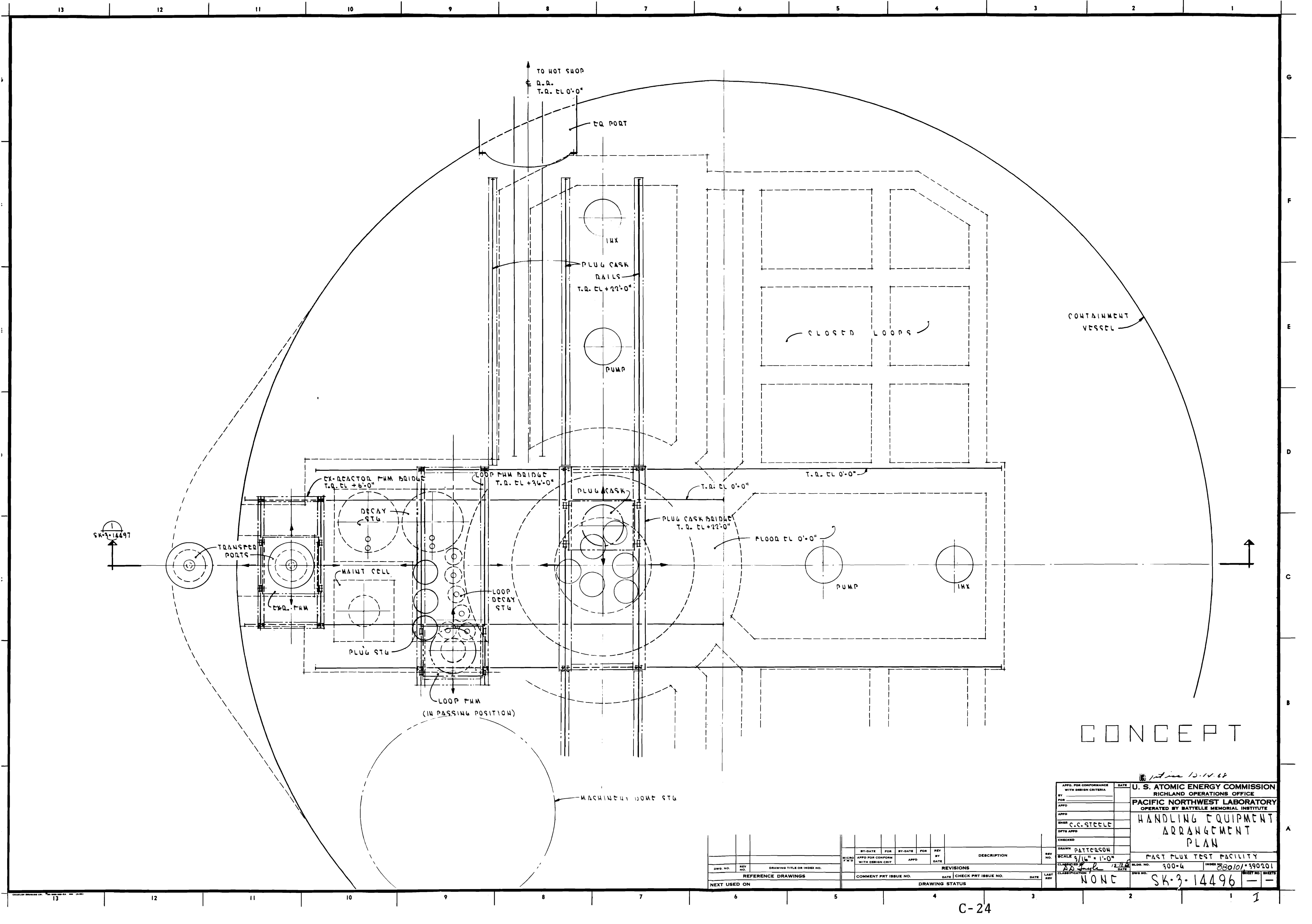




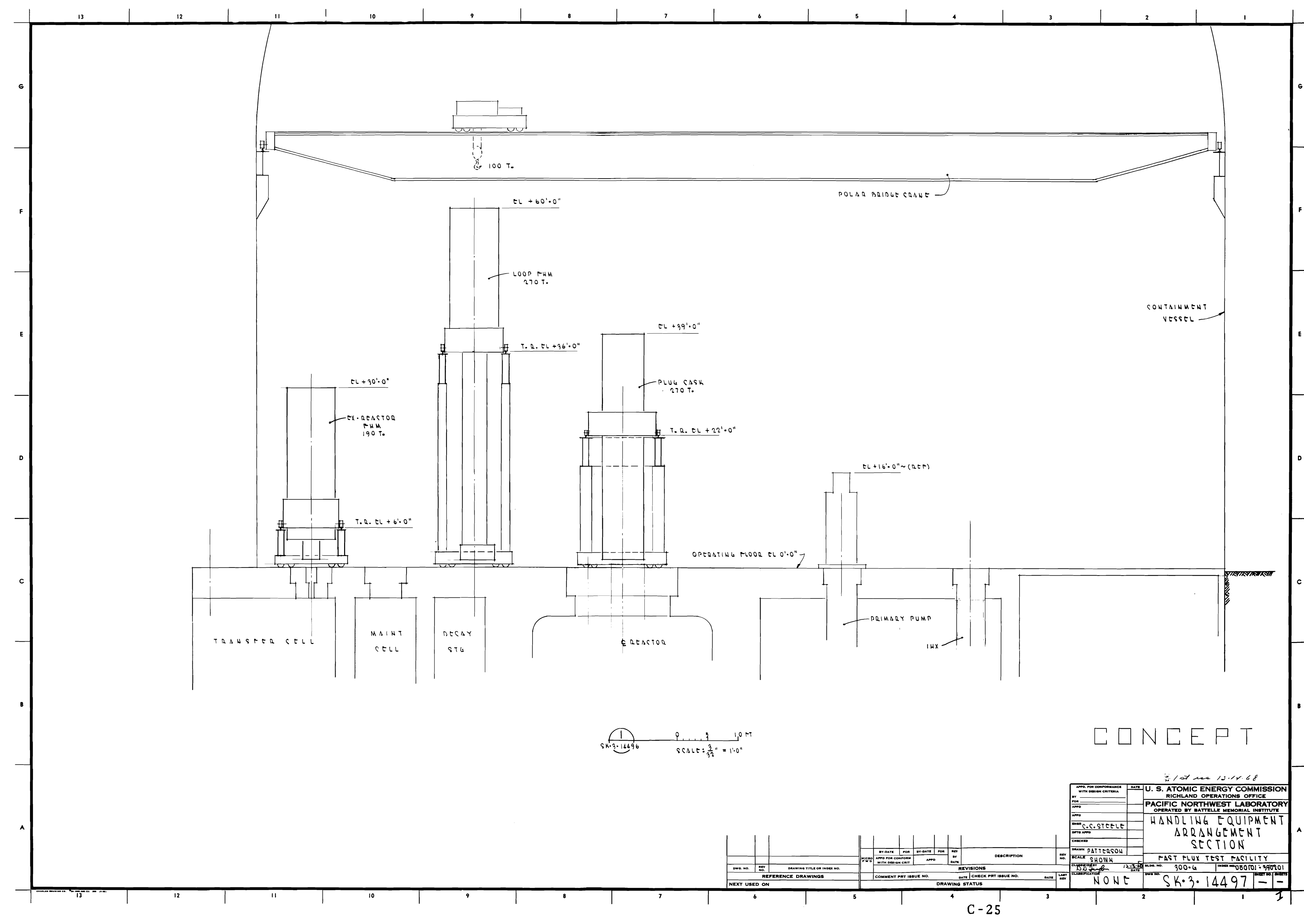




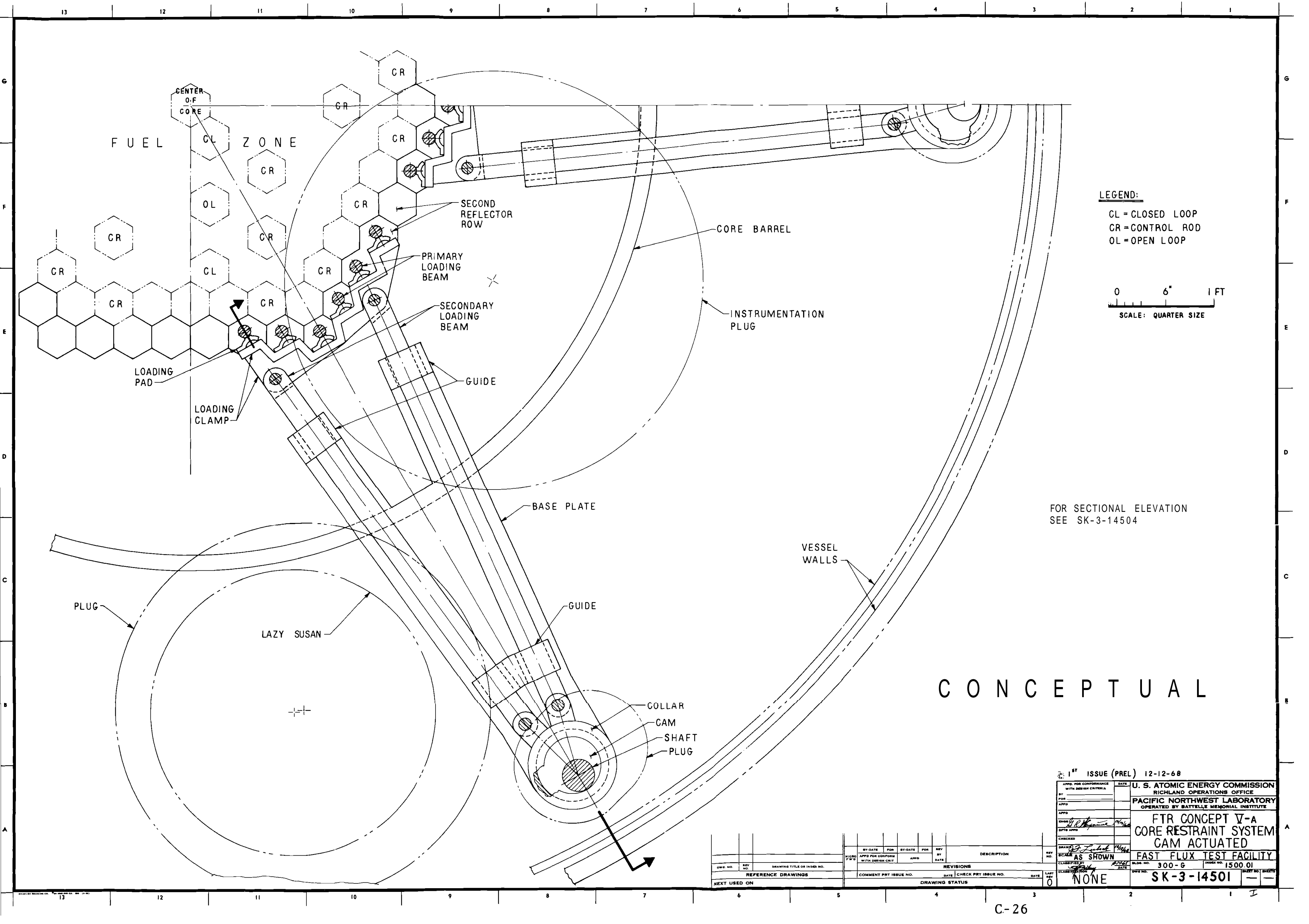




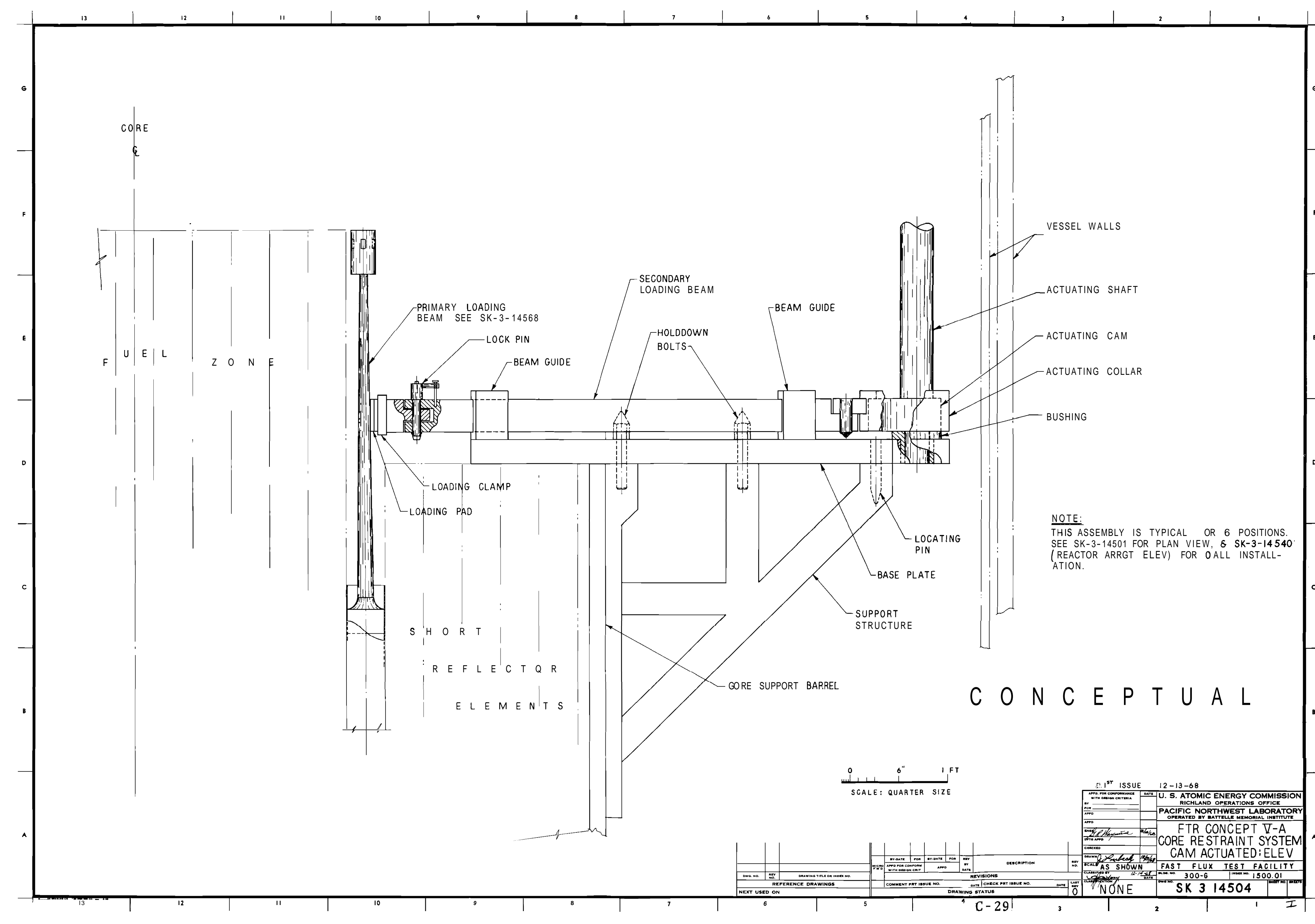




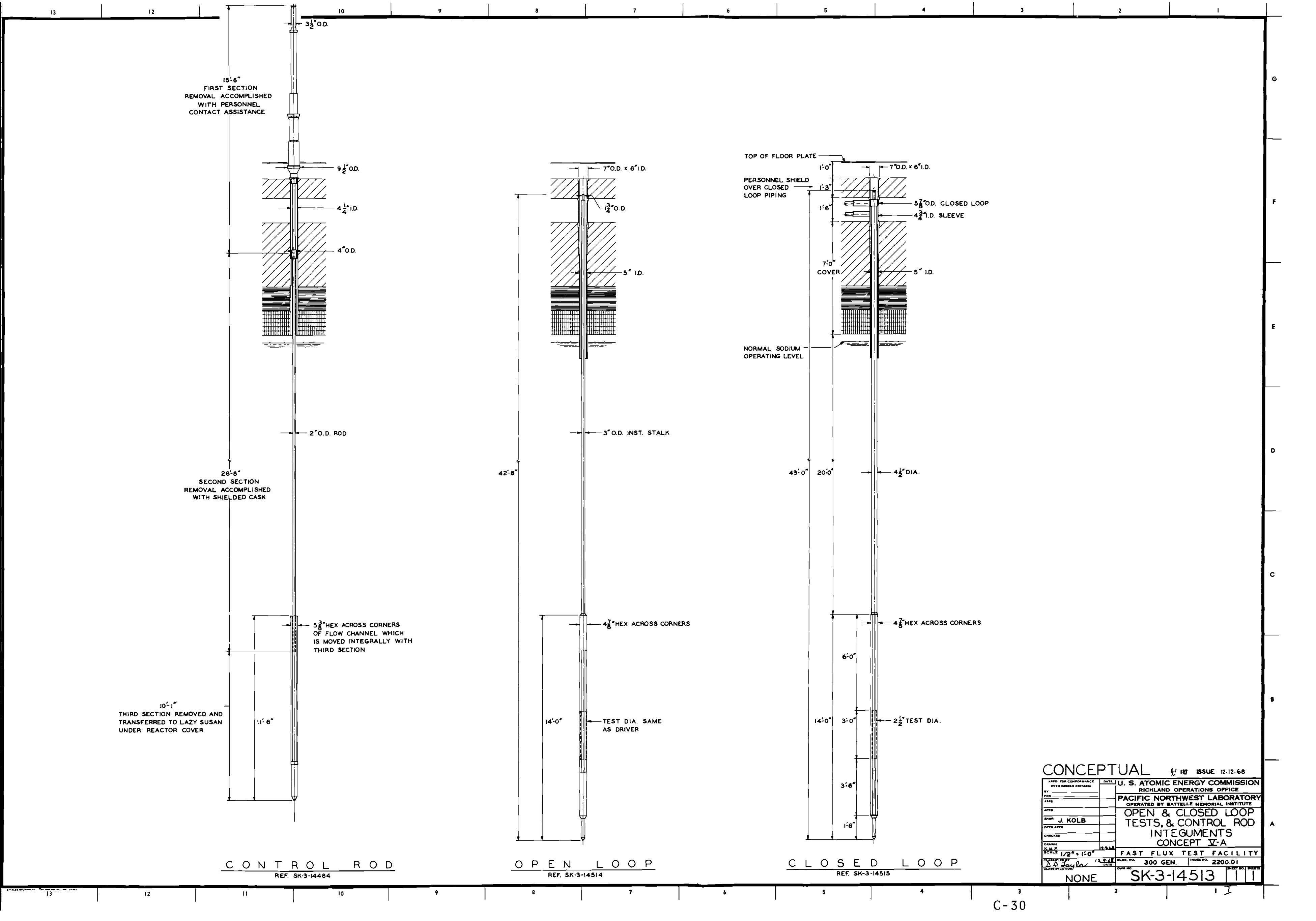




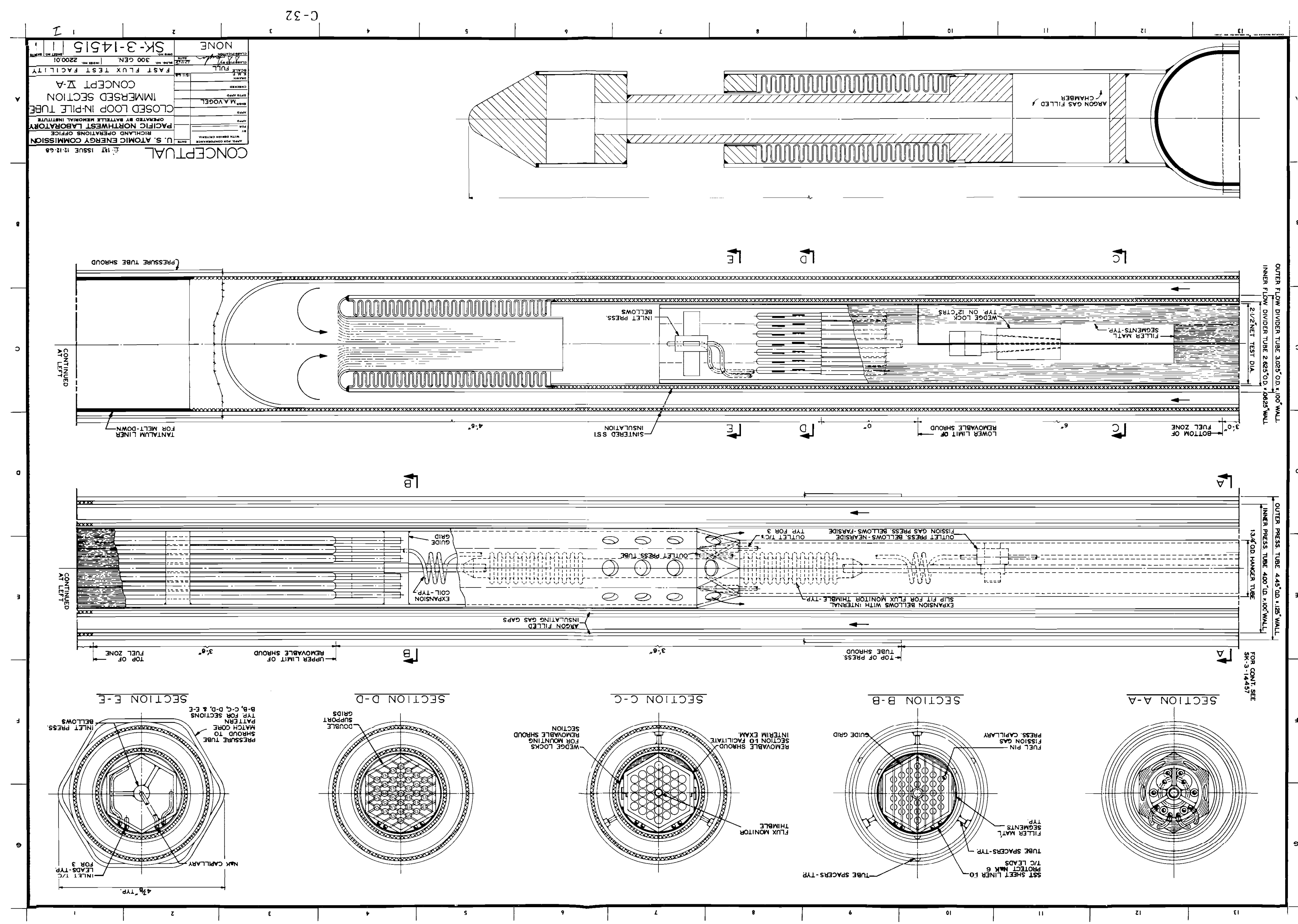




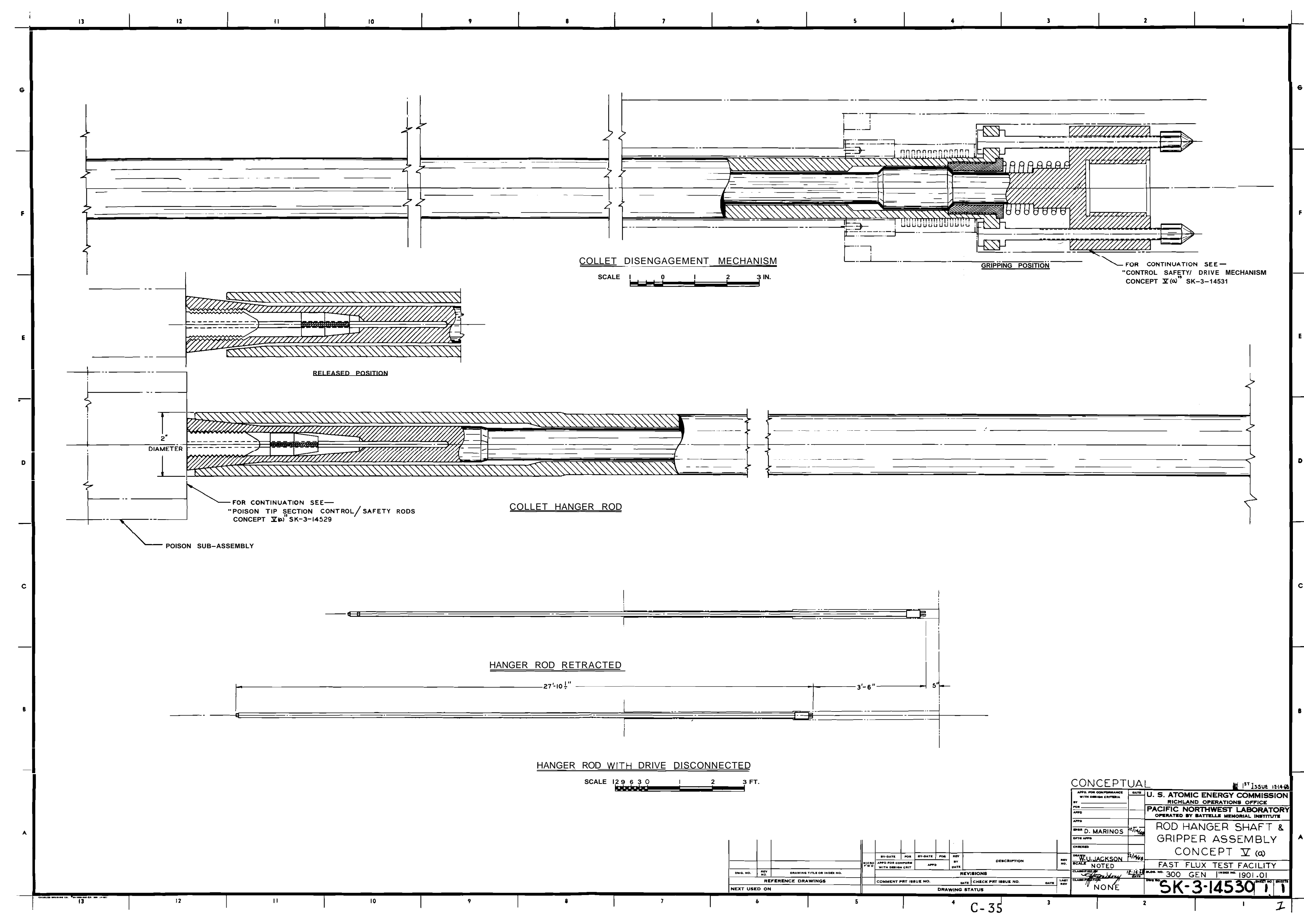




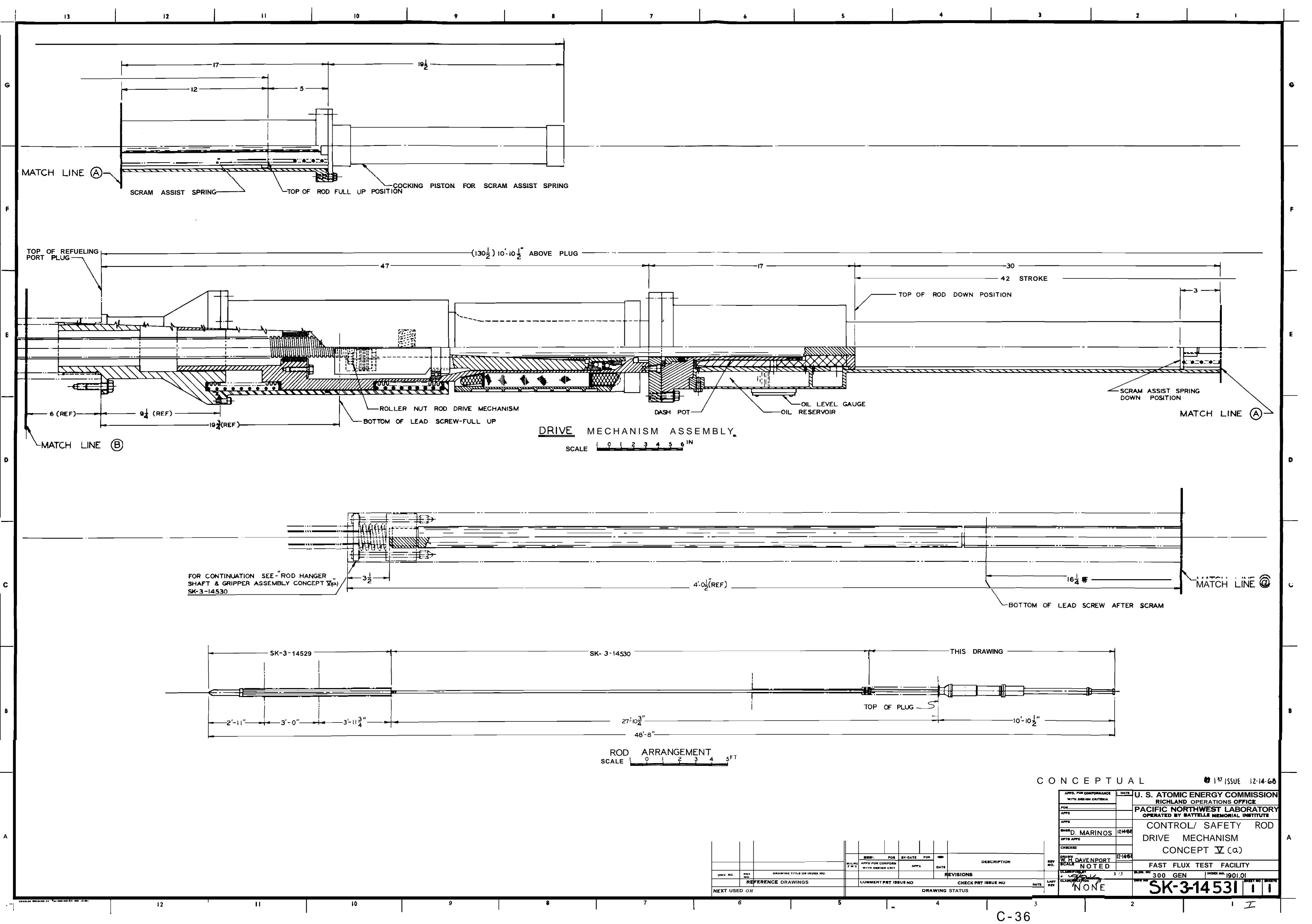




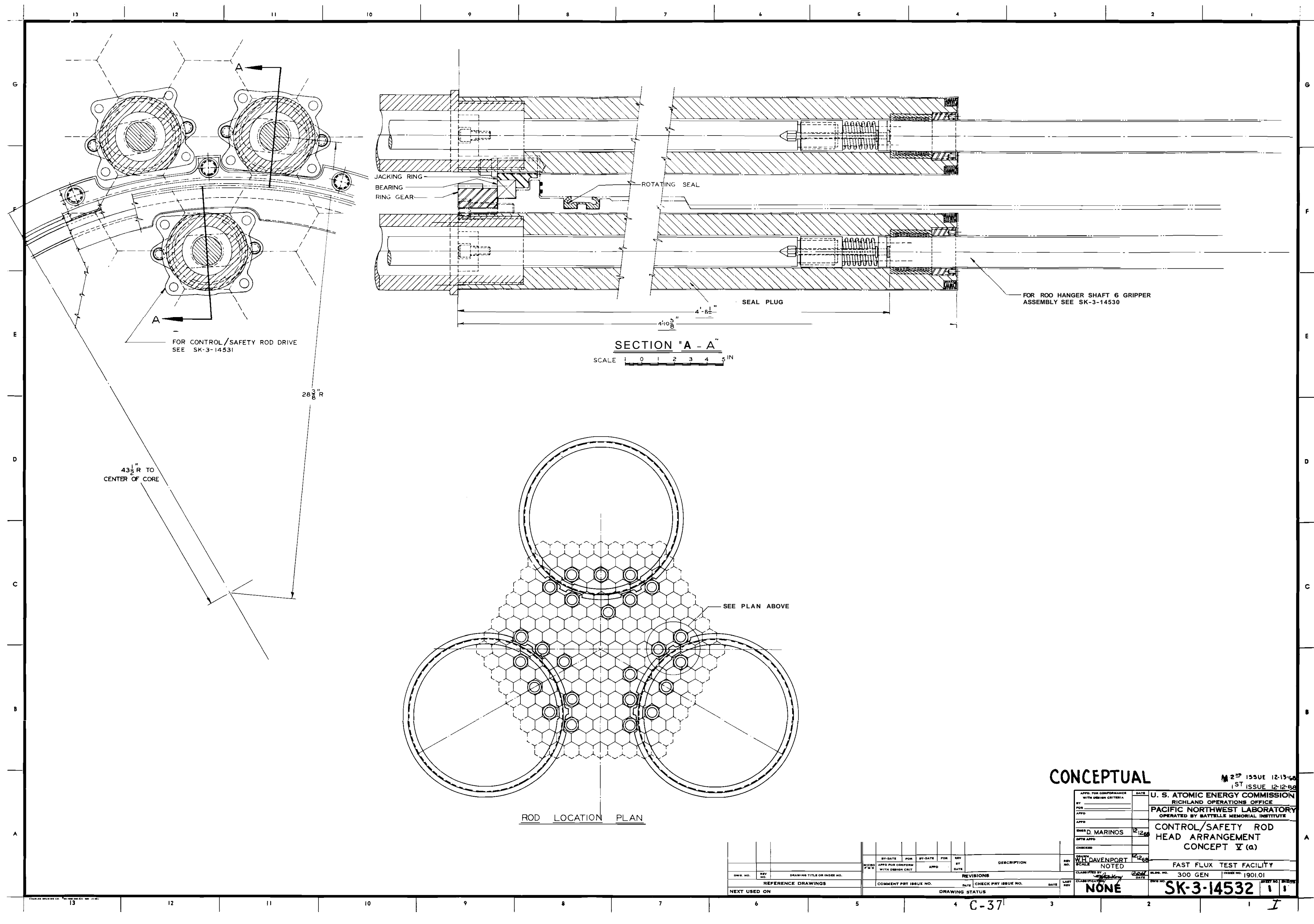




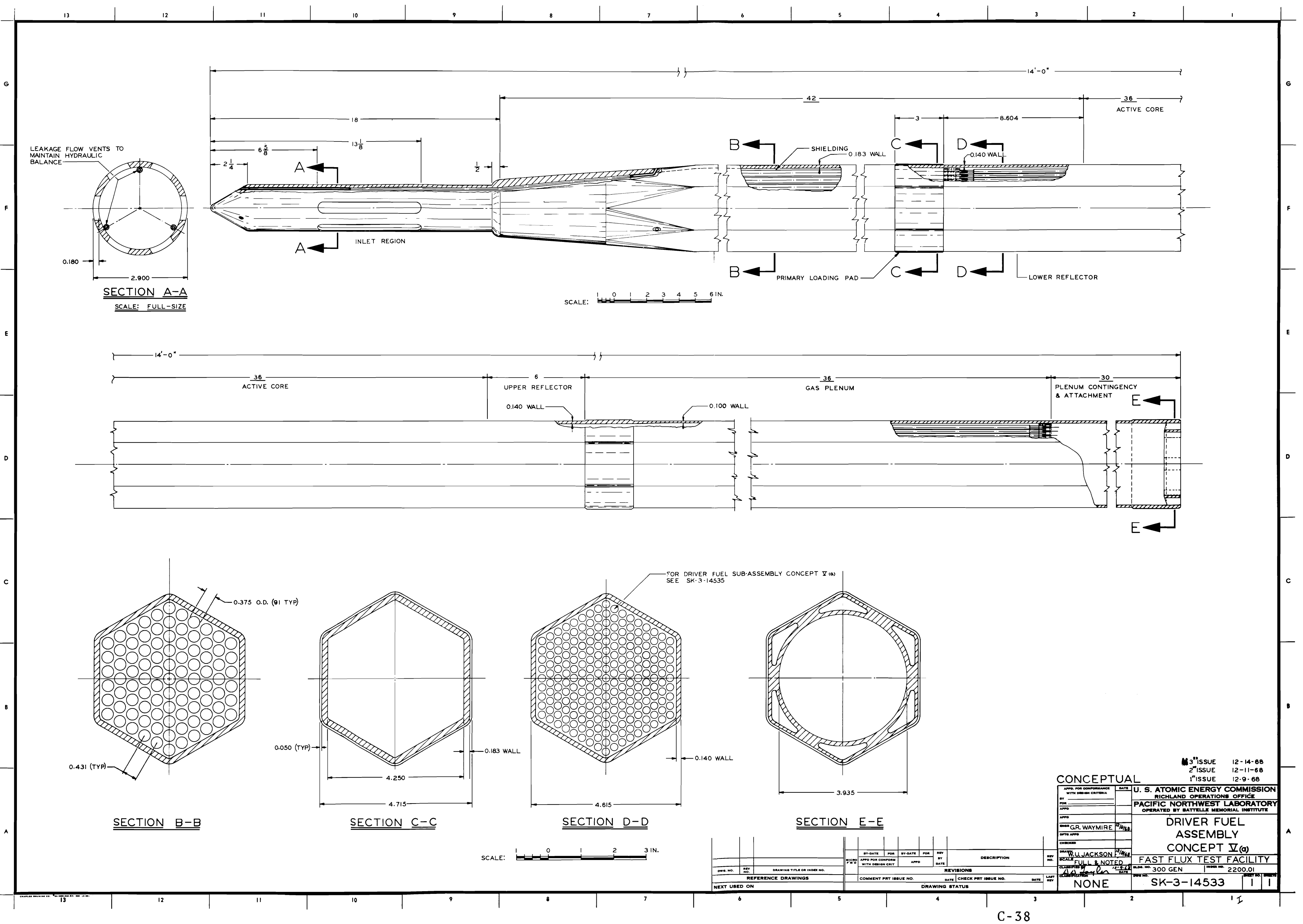




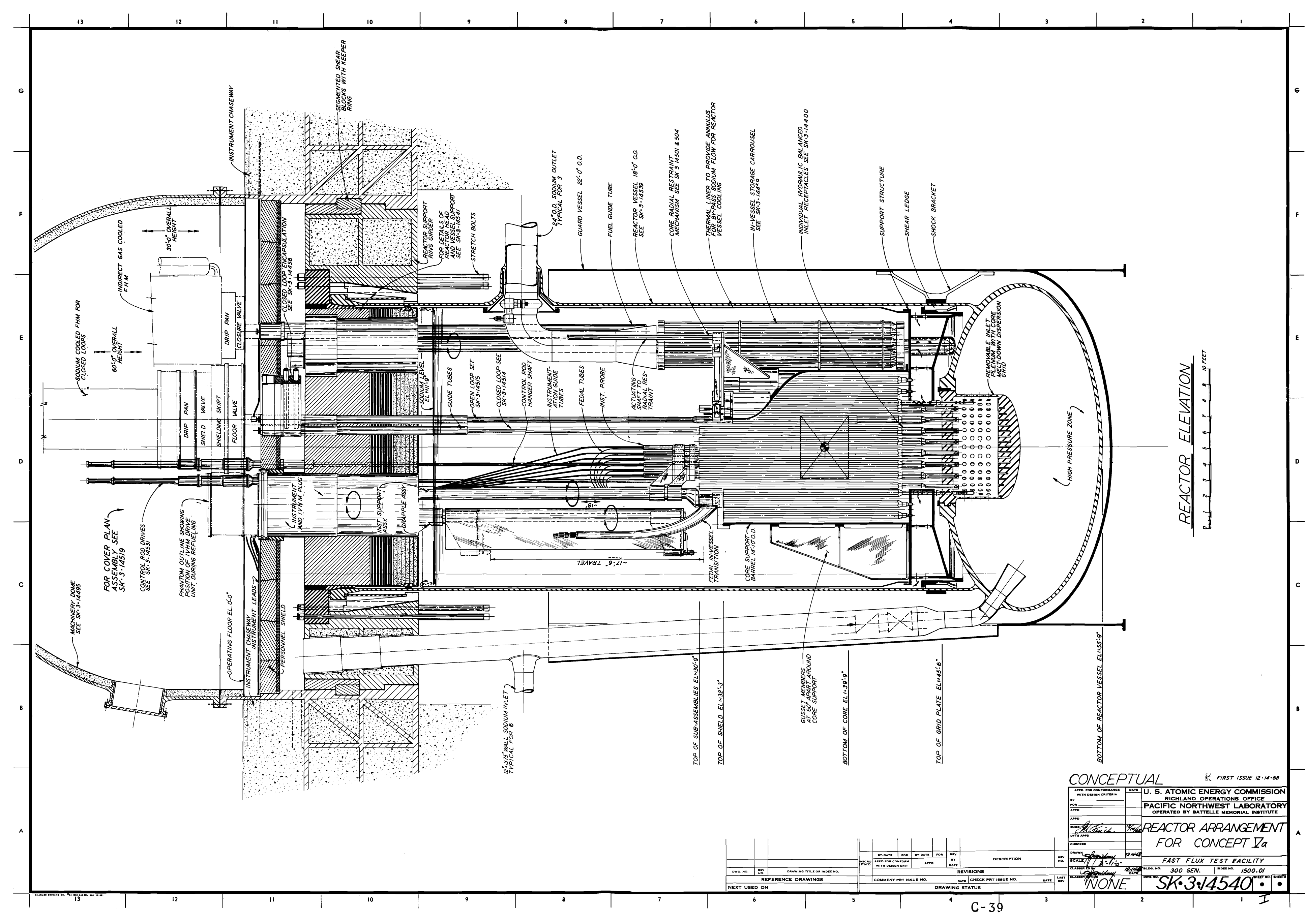




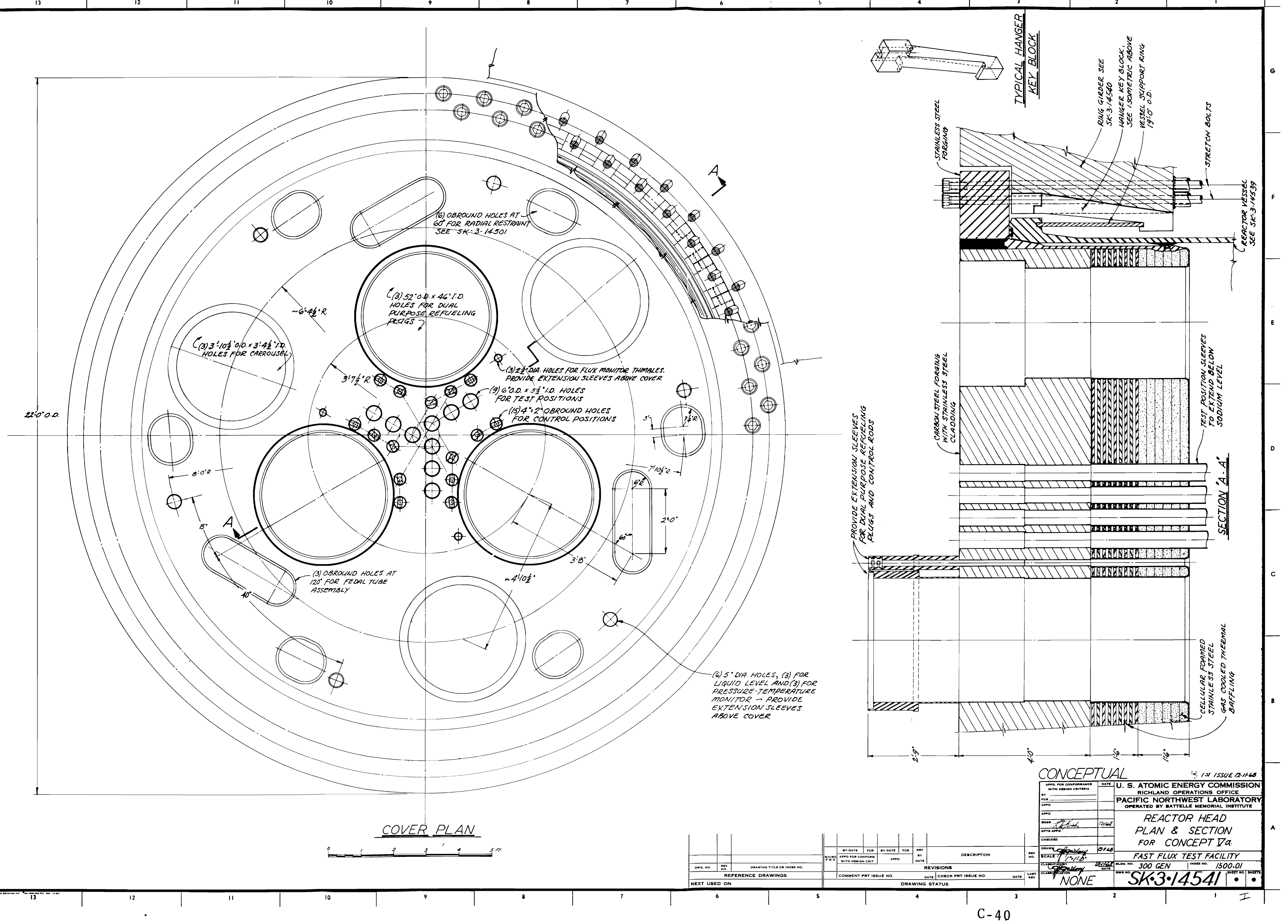




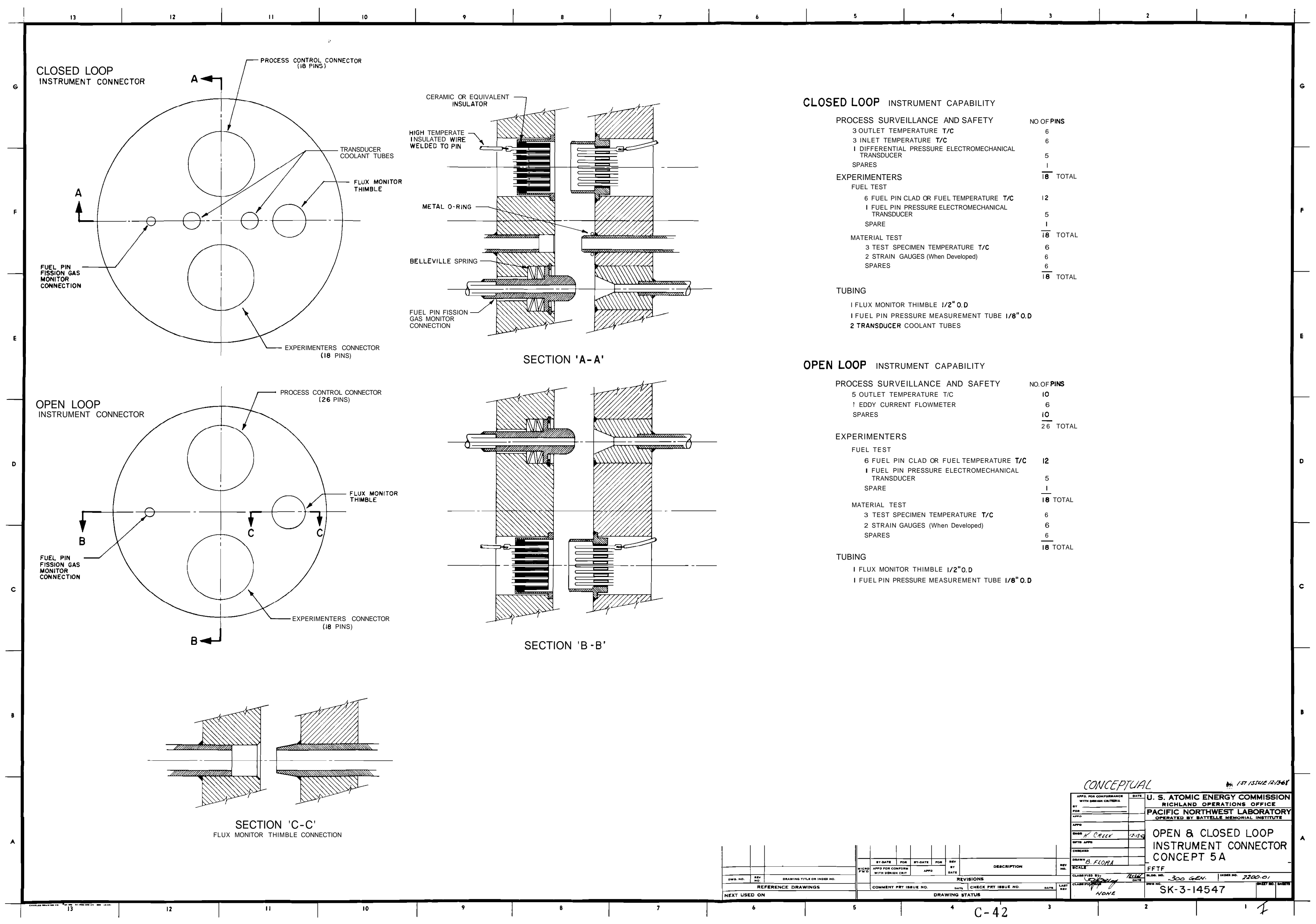




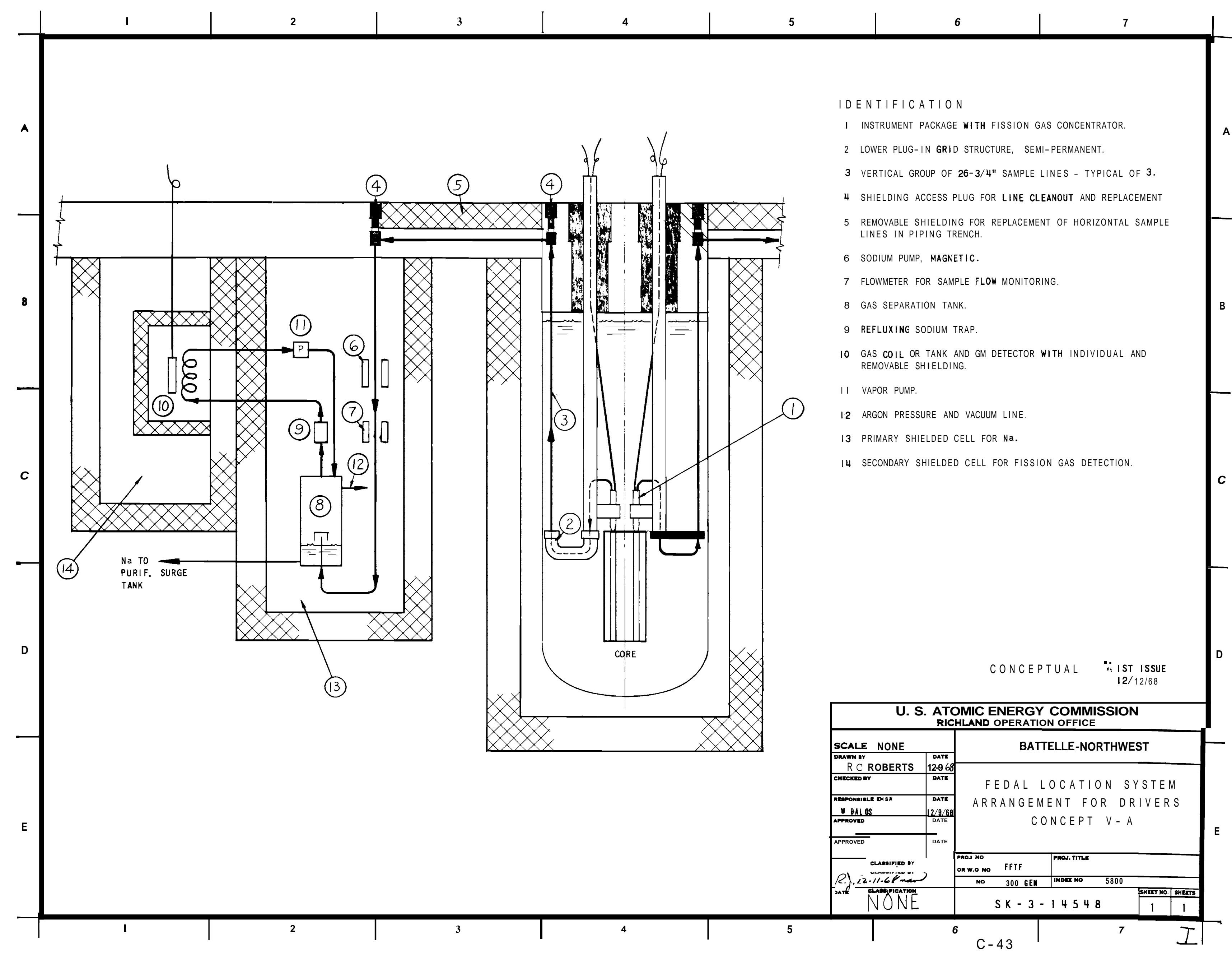




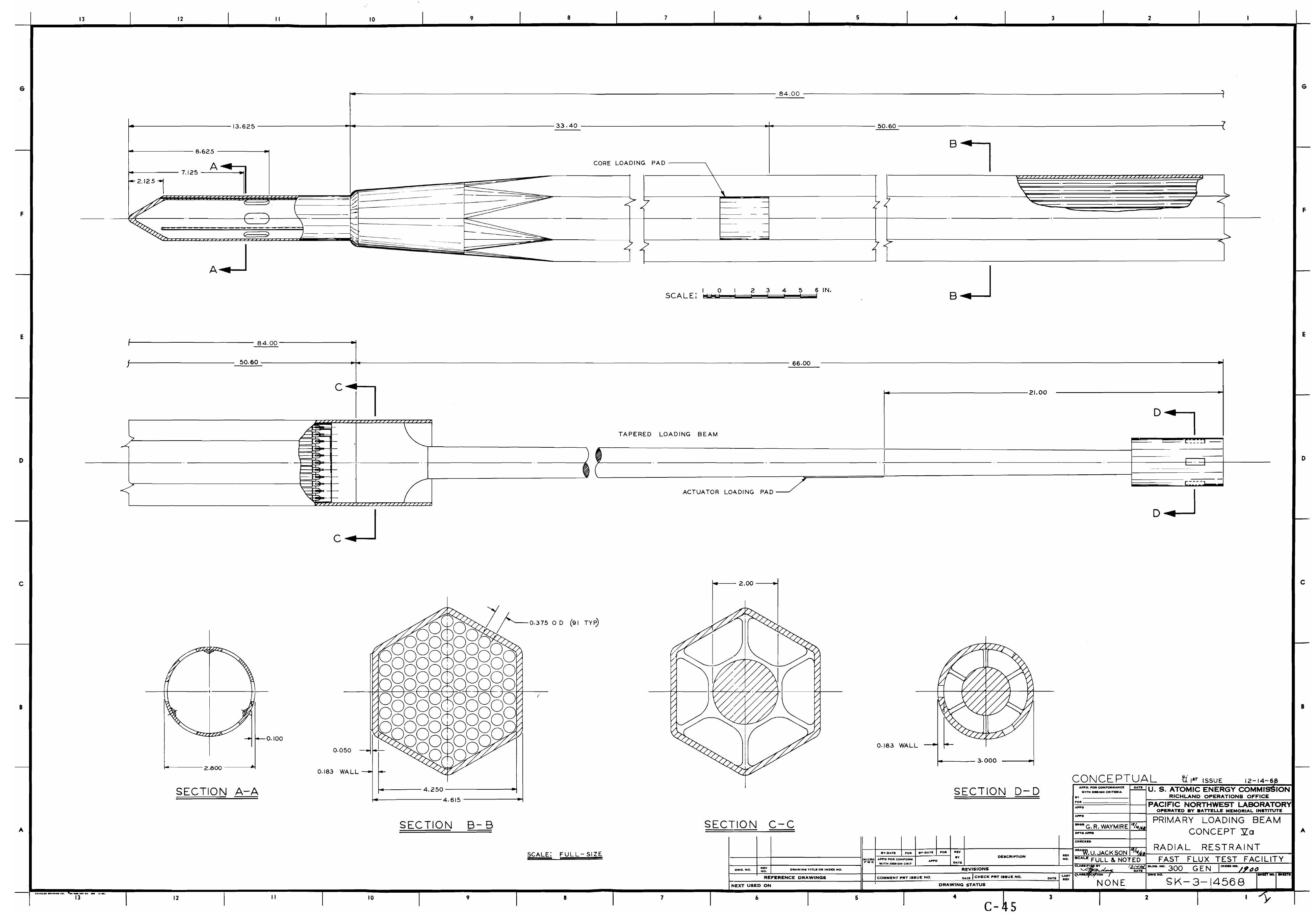


BNWL -1165

\section{SECTION 4. REACTOR CORE DESCRIPTION}

\section{A. CORE ARRANGEMENT}

The reactor core arrangement for this concept is composed of a 91-element vertical hexagonal array. The test positions are located in a "Y" shaped array with the center of the "Y" at the center of the core and the arms extending to the center of the flats of the overall pattern. The trisected design was selected primarily for compatibility with the refueling approach which utilizes offset refueling arms each of which services a one-third (120-degree segment) section of the core. With this type of refueling scheme, it is desirable to "clear" the region between the top of the fuel ducts and the bottom of the reactor top cover of all obstructions within a section being refueled so that refueling equipment will have free access to the 120-degree segment being serviced. Since it is desirable to be able ta leave the open test positions and closed loops in place during refueling, the test positions should be placed along the radial divisions separating the three refueling zones.

Another consideration in determining the placement of the test positions is the routing of the closed-loop piping away from the upper nozzles. The ideal routing is a straight corridor extending radially outward from the center of the reactor. To prevent interferences with the in-core control rods and the closed and open test nozzles, it was found through studies of various alternative layouts that the most efficient arrangement placed the closed loops on one side of the corridor (actually one row off of a true radial pattern) with the piping corridor extending down one side of the test positions. This arrangement leaves a driver position in the center of the core. 
With this type of arrangement, each piping trench will accommodate one closed loop located at the edge of the core with piping running radially outward and one closed loop position located either near the center of the core or in a midcore position with the piping extending along one side of the outboard positions. An individual corridor will not accept two closed loops at inner positions unless branch arm piping is stacked because of the width of the closed loop chaseway.

For in-core and peripheral controls the main requirement from a core arrangement standpoint is to maintain adequate control and a symmetrical geometry. Because of the requirement for nine in-core control positions with 8-in. drive mechanism envelopes and the prior test loop position arrangement, control rod positions appear to be restricted to those shown on SK-3-14567; however, one additional position per sector might be available.

Outboard of the active core there are three rows of reflector and four to six rows of shielding. The first reflector row contains the peripheral control rods and selected test assemblies. The second row contains the radial restraint actuators, and the third row is utilized for reflectors or uninstrumented material test. The first two reflector rows are totally accessible with the fuel handling machine. Nine positions in the third row and a number of shielding positions will require special maintenance procedures for removal. The shielding shown, along with the core barrel and sodium annulus, provides sufficient shielding to predict a vessel 1 ife of 20 years utilizing present damage criteria.

\section{B. FUEL ASSEMBLY}

The fuel assembly is shown on SK-3-14533. The assembly is made up of a hexagonal duct of varying wall thickness which contains axial shielding, the driver fuel pin bundle, an inlet 
for primary sodium and an upper outlet region. The upper outlet region adapts to the instrumentation lance and incorporates attachment slots for the interface with the fuel handling machine.

In order to provide a structure compatible with the radial restraint system the driver fuel duct has 0.050-in. thick contact pads located just above and below the active core region. The duct wall thickness below the core is approximately 0.183 -in. thick, the in-core duct wall is 0.140 -in. thick and, above the core, the duct wall is reduced to $0.100 \mathrm{in}$. The thicker section below the core stiffens the lower region of the duct to provide the proper deflection loading by the radial restraint system. The reduction in thickness of the in-core and upper walls provides flexibility while maintaining its pressure containment function.

The outside across flats dimension is 4.615 in. Maximum dimension across flats at the pads is 4.715 in. The 0.050-in. clearance on each side allows for thermal bow and tolerance buildup. The duct contains a 217-pin hexagonal array of 0.230-in. OD fuel pins on a 0.286-in. triangular lattice. With the shielding pin array of $0.375-i n$. OD stainless steel pins shown, projected tube sheet 1 ife is 10 years with a $500{ }^{\circ} \mathrm{F}$ bulk inlet temperature.

Height increments for the various positions of the core are outlined below.

$\underline{\text { Tabulation of Fuel Assembly Lenath Increments }}$

\begin{tabular}{|c|c|c|}
\hline Increment & $\begin{array}{l}\text { Value, } \\
\text { in. }\end{array}$ & Comment \\
\hline Inlet Section & 18 & $\begin{array}{l}\text { Length for nose, upper and } \\
\text { lower seal, and inlet slots }\end{array}$ \\
\hline Tube Sheet to Active Core & 42 & $\begin{array}{l}\text { Provide shielding to pre- } \\
\text { vent tube sheet damage. } \\
\text { Includes shielding and } \\
6 \text {-in. lower reflector. }\end{array}$ \\
\hline
\end{tabular}


(contd)

\begin{tabular}{lrl}
\multicolumn{1}{c}{ Increment } & $\begin{array}{c}\text { Value, } \\
\text { in. }\end{array}$ & Comment \\
\hline Active Core & 36 & \\
Upper Reflector & 6 & \\
Initial Gas Plenum & 36 & \\
Gas Plenum Contingency & 24 & $\begin{array}{l}\text { Provides additional plenum } \\
\text { space for high burnup fuels }\end{array}$ \\
$\begin{array}{l}\text { Grapple and Instrumentation } \\
\text { Interface }\end{array}$ & $6 \begin{array}{l}\text { Connection point for the } \\
\text { FHM and instrument lance }\end{array}$
\end{tabular}

Total Height

$$
\overline{168}=14 \mathrm{ft}
$$

C. CORE RESTRAINT AND HOLD-DOWN

1. Axial Hold-down

\section{a. Criteria}

The hold-down system for the in-core assemblies must ensure that axial motion results in a net negative reactivity effect. To ensure that the above criteria can be accomplished, a primary hold-down system with a backup minimum travel system is required. The desired design should minimize the number of in-sodium mechanical devices required. The probability of a single failure causing total core lifting should also be minimized.

\section{b. Description of Design}

Primary hold-down for this concept utilized a combination of fuel assembly weight and hydraulic balance. The hydraulic balance system chosen is shown in SK-3-14400. A low-pressure region is created below the locating nose of the fuel assembly by small bypass tubes located adjacent to the fuel assembly duct walls which connect into the low-pressure plenum area (see SK-3-14533). Failure by plugging the vent holes would be

$$
\text { C- } 50
$$


BNWL-1165

limited to a single channel with this concept. This design also introduces an additional compliant member between the tube sheet and the duct.

The hydraulic balance leaves the assembly in a floating mode. The assembly is then held in position by its own weight which also provides a contingency hold-down effect to offset pressure surges.

Backup hold-down is afforded by stops on the instrument lances. The positioning of the stop is based on allowances required for tolerance buildup, thermal expansion, and radiation-induced and expansion effects.

2. Radial Restraint

a. General

Radial, like axial restraint, must provide a predictable method for determining core motion during all phases of FTR operation. Initial restraint studies performed on both vertical and dispersed cores has considered the effect only of thermal camber. Recent analysis of radiation-induced effects have shown that the thermal camber effect is almost a second order phenomenon in comparison with radiation induced effects with advanced core.

Effects considered for the initial core will be limited to the thermal bow phenomenon and, possibly, primary radiation induced creep by limiting the bulk outlet temperature to $800^{\circ} \mathrm{F}$ and a burnup consistent with acceptable irradiation distortion.

\section{b. Description of Desien}

The radial restraint design is shown on SK-3-14501 and SK-3-14504. The design utilizes the second reflector row for applying a compliant load, utilizing beam deflection, to the outer periphery of the core. Initial positioning and alignment of the top of the ducts is provided by the instrument tree 
which sequentially positions each row of ducts. During reactor refueling each row of ducts may be deflected a maximum of 0.1 in. per row. The tree must, therefore, be capable of deflecting the top of the outer fuel row a maximum of 0.5 in.

Once the assemblies are in position, the beams noted above (see SK-3-14586) are deflected inward loading the assemblies at a pad located just below the active core. An additional pad located just above the active core provides an additional contact point on the fuel assemblies. The loading is applied preferentially by variable rate flat springs located on the loading clamp. By utilizing a stiffer spring for the central position on each clamp, the core would initially be loaded across the points of the overall core map. As deflection continues, the next row away from the points begins to load and so on to create a triangular loading pattern.

Two secondary loading beams attached to a rotary cam provide the actuating mode for the backing plate. The cam actuator is driven by a pneumatic cylinder. The cam device is removable for maintenance through a special port in the reactor cover. Six actuators are required for the total core.

c. Alternative Designs

Alternative actuation systems as well as different duct designs have been investigated.

For advanced cores, flexible ducts with multiple loading points may be required. This would require replacement of the loading beams only.

Actuation systems investigated included:

- Hydraulic

- Thermal

- Mechanical. 
The hydraulic and thermal designs were found to be unacceptable because of their potential for feedback and problems with applying loads at low power.

Several alternative mechanical designs were also investigated. These include a pantograph-actuated device shown on SK-3-14502. This design is similar to the selected design and incorporates approximately the same features.

A second alternative utilizes a multiple leaf spring loading design. This system would be actuated by the fuel handling machine grapple as shown on SK-3-14503. The principal advantage of this design is that additional cover penetrations are not required. The time required to actuate this number of devices, however, may be unacceptable. 


\section{SECTION 5 REACTOR VESSEL AND HEAD DESCRIPTION}

\section{A. VESSEL}

The reference reactor vessel and arrangement of internals for this concept is shown on drawing SK-3-14540. The material of fabrication of the wall and structural components of the assembly are of solid Type 304 SS. Nominal vessel dimensions are as follows:

$\begin{array}{ll}\text { Barrel, thickness } & 2 \mathrm{in} . \\ \text { Barrel, diameter } & 18 \mathrm{ft} \\ \text { Height } & 51 \mathrm{ft} \\ \begin{array}{l}\text { Outlet Nozzles (3), } \\ \text { diam }\end{array} & 26 \mathrm{in} . \\ \begin{array}{l}\text { Inlet Nozzles (6), } \\ \text { diam }\end{array} & 12 \mathrm{in} .\end{array}$

The vessel configuration shown is suitable for a mixed mean coolant discharge temperature of $1200^{\circ} \mathrm{F}$ at the outlet nozzles. Nominal design pressure is $30 \mathrm{lb} / \mathrm{in} .^{2}-\mathrm{g}$ although operating vessel cover gas pressure will normally be close to 15 1b/in. ${ }^{2}$-a. The 2 -in. thickness has been determined to be sufficient to apply standard shape fabrication techniques in maintaining normal tolerances and to withstand primary piping end forces and moments.

The coolant enters the vessel through six 12-in. inlet lines which contain removable check valves. The inlet lines serve as inspection entry ports for TV cameras to observe pressure boundary surfaces and for weld examination. The inlet flow is mixed in the large plenum below the core from whence it passes through a flow distribution cup which shreds large vortices and delivers a smooth flow of coolant to the hydraulic hold-down stems which are fixed in a stiff grid plate structure. This arrangement makes it virtually impossible to starve any channel of coolant flow because of foreign objects in the primary system. 
It is not considered feasible to operate the vessel wall uncooled at a temperature of $1200^{\circ} \mathrm{F}$. Accordingly, the reference arrangement utilizes approximately a $10 \%$ bypass flow to cool the barrel and outlet nozzles. At this flow, the nozzle region is approximately $950^{\circ} \mathrm{F}$ maximum and the upper barrel approximately $1000^{\circ} \mathrm{F}$ at the point where the bypass flow is returned to the discharge plenum. The bypass baffle is set some $3 \mathrm{in}$. away from the pressure boundary to permit its inspection for most surveillance purposes without baffle removal. The radial distance allows ready removal and replacement of the baffle should this prove necessary.

The fluence limit for all structural components (these being solid, Type 304 SS) must be sufficiently low to ensure predictable behavior at EOL; i.e., sufficient ductility to exhibit a residual total elongation of $10 \%$. Data presently available indicate that the total neutron fluence corresponding to this $1 \mathrm{imit}$ is $10^{21} \mathrm{nvt}$ at the temperature under consideration for the vessel wall and other 20-year life structural components. For this concept, assuming a central total flux of $10^{16} \mathrm{n} / \mathrm{cm}^{2}-\mathrm{sec}$, three rows of reflectors and five rows of Type 304 SS shielding bars are required for an 18-ft diameter vessel. The $18-\mathrm{ft}$ diameter permits the use of readily removable, rotating, fuel storage racks.

The vessel is top-mounted by suspension from an upper ring flange. The ring flange rests on a support skirt which sets in hangers supported by ring girders mounted in the building structure. The support skirt arrangement accommodates radial ring flange expansion and allows the heavy section to operate in a relatively low temperature $\left(\sim 450{ }^{\circ} \mathrm{F}\right)$ isothermal region. The primary seal is by metallic " 0 " rings in the top face of the ring flange. The temperature disparity between the ring flange and the upper vessel wall (450 to $\left.1000^{\circ} \mathrm{F}\right)$ is taken without overstress along the approximate $7-f t$ length between the sodium level and the flange. 
The complete assembly is surrounded by a closely coupled Type 304 SS guard vessel. The latter is mounted from the cavity floor by a bottom support skirt and has no penetrations, its purpose being to provide reserve coolant drawdown in event of primary piping failure.

Currently under consideration is an alternative cooledwall vessel concept. In this alternative concept, the inlet coolant enters the vessel at the same elevation as the outlet and flows downward through an annulus to the lower plenum. Some of the inlet coolant also flows upward in the annulus for cooling the upper vessel wall. Although no firm decision has been made relative to the alternative vessel concept, it is presently judged that both are basically feasible and that either could be designed to be compatible with the basic, overa 11 reactor concept.

It may also be possible to move the periphery of the lazy susans into the radial shield. Such a move would require the interposing of boron carbide shadow shielding and additional cooling of the storage component, but this innovation would decrease the vessel radius as much as $\mathbf{1} \mathrm{ft}$. For a vessel diameter of $16 \mathrm{ft}$, however, the shielding requirement increases to seven courses of radial shielding. For an 18-ft vessel, shadow shielding would be required between the lazy susans and the vessel wall.

\section{B. VESSEL HEAD}

The reference head for this Concept is shown on Drawing SK-3-14541 in plan and section; partial plans of the head are shown on SK-3-14519. The basic structural material is lowalloy steel which is clad with Type 304 SS. Nominal head dimensions are as follows: 


$\begin{array}{lr}\text { Diameter, overall } & 22 \mathrm{ft} \\ \text { Diameter, in-vessel } & 18 \mathrm{ft} \\ \text { Depth, overall with plugs } & 10 \mathrm{ft} \\ \text { Depth, without plugs } & 7 \mathrm{ft} \\ \text { Depth, structural } & 4 \mathrm{ft} \\ \text { Diameter, refueling ports } & \sim 4 \mathrm{ft} \\ \text { Weight, assembled } & \sim 300 \mathrm{ton}\end{array}$

The primary purpose of the reactor head is to complete the pressure vessel boundary, provide positioning and support for reactor instrumentation, and provide refueling access to the core. The head also ensures the following secondary requirements:

- Gamma shielding and load support

- Thermal barrier

- Sodium vapor deposition barrier. 


\section{SECTION 6 REACTOR NUCLEAR CONTROL DESCRIPTION}

AND OPERATION

\section{A. DESCRIPTION}

For simplicity, all drawings in this report show the roller nut drive mechanism as a standard drive. The adaptation of this drive to this concept requires a hanger rod which is detachable at the drive and poison subassembly ends. The refueling mode for this concept requires that the top head be cleared of protuberances to permit change out of test assemblies and drivers. The proposed design permits removal of the drive mechanism under air-contact maintenance modes.

Release of the poison subassembly is accomplished from the top of the reactor (see SK-3-14530). -Removal of the hanger rod must be accomplished with a sealed machine which can withdraw the sodium-wetted shaft and install a plug in the vessel cover.

The drive mechanism is mounted on the reactor vessel cover. The mechanism drive shaft connects with a hanger rod by use of a breach lock mechanism. The hanger rod passes through a seal system in the bottom of the vessel cover and extends to the poison section. A collet mechanism is located at the bottom of the hanger rod and is used to connect to the poison section. The collet can be operated from the area of the breach lock after the drive has been removed.

The use of a separable hanger rod and drive mechanism makes location of the deceleration device above the reactor vessel mandatory. If the decelerator were located beneath either the breach lock or collet, deceleration loads on these joints would be unacceptable. The decelerator selected for this concept consists of a hydraulic snubber, using oil as a working fluid, which is integral with the drive mechanism. 
In this concept, a scram-assist mechanism is also mounted on the top of the drive mechanism. The scram-assist is provided by a spring, although pneumatic pistons could be used. Mounting the scram-assist mechanism on top the reactor cover permits the mechanism to be cocked by a separate pneumatic cylinder, thus reducing the load on the drive mechanism. Pneumatic pressure is only required during the cocking operation.

Scram-assist devices for obtaining initial accelerations of $2 \mathrm{~g}$ on the scramble rods will impose a buckling load on the hanger rod. The arrangement in this concept differs from that of Concept $V$ in that the hanger rod was guided by the instrument tree to a distance of 4 to $5 \mathrm{ft}$ from the top of the core. In this concept, the hanger rods are unsupported, except for possible short bearings in the instrument plate. Preliminary calculations indicate that the buckling limit for the hanger rod is in excess of $40001 \mathrm{~b}$. Previous investigations into the forces required for achieving $2 \mathrm{~g}$ acceleration indicate that the force required would be on the order of 1000 to $20001 \mathrm{~b}$.

The drive mechanism with attached spring-assist mechanism and decelerator is shown on SK-3-14531. The poison subassembly for a typical safety rod is shown on SK-3-14529 and shows a 61 -pin $\mathrm{B}_{4} \mathrm{C}$ bundle.

The interface between the refueling plug and the control rods located at the corners of the hex pattern is of critical nature because of possible interference, and must be very closely monitored during design. The task force has investigated the cases for conceptual feasibility and this interface is shown on SK-3-14532. As the plug diameter is increased, the peripheral rod located outboard of the plug becomes limit ing and as the diameter decreases, the in-core control rod located near the plug becomes limiting. 


\section{B. OPERATING PHILOSOPHY AND PROBLEM AREAS}

A 11 drives and hanger rods are designed to be removed prior to each refueling operation. The drive mechanism along with the lead screw is removed by unbolting the flange from the top cover and rotating the entire mechanism to release the breach lock mechanism. Release of the poison subassembly is then accomplished by a special tool that is inserted into the lead screw cavity. The hanger rod can now be removed by the casks used to remove driver fuel instrumentation modules. Complete removal is required for a 11 sectors that will require refueling. It may be possible to leave the hanger rods in place in sectors that are not to be refueled. The capability to leave selected hanger rods in place during refueling will depend upon final configuration of the core clamping system.

The current refueling machine concept does not envision changeout of grapple heads on the refueling arm. Therefore, poison sections will be removed with the same grapple head used for driver fuel. Removal and replacement of poison subassemblies by use of a common grapple head will require an interlock to prevent errors in refueling. One such method suggested would be to install the pickup point for the poison subassembly deeper in the duct than that for the fuel subassembly. In this way, an "over travel" permissive switch must be unlocked to permit the fuel handling arm to lower far enough to pick up a poison subassembly. 


\section{SECTION 7 REACTOR REFUELING SYSTEM DESCRIPTION}

\section{A. DRIVER FUEL AND CORE COMPONENT HANDLING}

\section{Refueling Plug}

Three refueling plugs provide access for removable instrumentation to each driver fuel subassembly and provide access for refueling the reactor. Each refueling plug services a onethird sector of the core. The plugs are removable for maintenance and require rotation for positioning the instrumentation probes and for operating the reference in-vessel fuel handling machine. (See SK-3-14567 and SK-3-14540.)

The plug supports the instrumentation and hold-down plate assembly and the in-vessel fuel handling machine (IVHM). The IVHM can be removed from the refueling plug for maintenance. The refueling plug must be removed for maintaining the instrumentation hold-down plates for other than individual thermocouple and flow meter instrumentation maintenance. The IVHM must be removed before the refueling plug can be removed.

\section{Instrumentation and Hold-Down Plate Assembly}

The instrumentation and hold-down plate provides instrumentation probes to each fuel subassembly in a sector, serves to compact the fuel subassemblies toward the center of the core, provides back-up fuel subassembly hold-down, and guides the control rod driveline assemblies. The column supports and positions the instrumentation plate and the hold-down plate. The lower end of the support column is offset and is supported laterally by a bearing and structure.

To prepare for fuel handling, the control rod drivelines are removed, and the instrument plate raised until all probes 
are above the top of the fuel assemblies. The support column is raised until it is removed from and is above the lateral bearing. The hold-down plate ensures that the instrument probes withdraw from the ends of the subassemblies without lifting any adjacent subassemblies out of the core. The instrument tree, in the raised position, is rotated away from the core by a dual rotation of the instrument tree support column and the shield plug.

A 11 actions of the instrument tree are powered by electric motors located in the shield plug. The motors are controlled from a console located remotely from the shield plug.

\section{In-Vessel Lazy Susan Storage Facility}

A lazy susan is located adjacent to the shielding outboard of each sector of the core as shown in Drawing SK-3-14540.

Each rotor has nine positions; each position being capable of accepting a finned pot containing a driver subassembly or other core component. Fuel or core components are transferred from the core to the storage position in the lazy susan via the IVHM. The lazy susan may be indexed as required by electric motors geared to the centrally located drive shaft. To transfer a driver subassembly or other core component out of the reactor, the storage position containing the desired finned pot is oriented under the transfer port. The subassembly or core component may then be withdrawn through the transfer port into the ex-vessel handling machine.

\section{Ex-Vessel Handling Machine}

The ex-vessel handling machine (EVHM), transports driver fuel subassemblies and core components from in-vessel storage through the transfer port to either interim storage or the transfer cell. The EVHM returns new driver fuel subassemblies and core components to the in-vessel storage positions. 
The EVHM is shielded and carries the subassemblies in sodium-filled finned pots; the EVHM can handle and cool up to three subassemblies. The decay heat from the subassemblies is transferred by conduction and convection through the sodium to the finned pots. The pots are cooled by forced convection and radiation to the cask walls. Argon is used as the coolant media for the pots. The gas flows out of the machine main body through the shielded sodium vapor trap, the circulator, the air blast heat exchanger, the heater for preheat and temperature control, and back to the machine. High pressure gas storage tanks provide emergency cooling (blowdown) in case a pot sticks in the reactor head, or shield. Redundancy of cooling systems provides emergency cooling of the fuel.

The machine uses one grapple and drive assembly, and a three-position rotating barrel. Three pots are contained in the rotating barrel. A grapple-operated guide sleeve is used to protect the machine drip pan valve and closure valve and the reactor floor valve from sodium drippage during pot transfers.

\section{Plug Handling Cask}

The plug handling cask is a shielded machine capable of transporting a shield plug containing an instrument tree. It has the capability of handling the IVHM, the lazy susan shield plug, and the lazy susan storage rotor. The plug handling cask may be the same maintenance cask used to handle the primary pumps and the IHXs.

The plug handling cask is comprised of a lower closure valve (which mates with the floor valve), the drip pan, the main barrel, the hoisting and guiding system, and the environmental control system for maintaining an inert atomsphere at the required temperature. 


\section{Control Rod Driveline and Instrument Cask}

The control rod driveline and instrument cask is a dual purpose cask used to replace the control rod driveline and guide from the reactor and the fuel assembly instrumentation tree. The cask is used to remove the control rod driveline from the reactor after the driveline has been disengaged from the absorber section. After removal of the control rod driveline, a seal and shield plug are inserted into the reactor opening prior to removing the cask.

When used for instrument maintenance, the cask is positioned over the instrument probe to be removed and the selected probe is withdrawn. A new probe is inserted into the vacant hole. Glove ports and lead glass windows are provided at the top and bottom of the cask to assist in the instrument probe exchange. The lower glove ports are provided with shielding for the actual pulling of driveline or instrument probes.

B. OPEN AND CLOSED LOOP HANDLING

\section{Loop Preparation Cask}

The loop preparation cask, is used to prepare both open and closed loops for test removal from the reactor. The instrumentation connector plug and leads are removed by hand prior to the use of the loop preparation cask.

A shielded floor valve is placed over the loop experiment after the instrumentation leads have been removed. The loop preparation cask is placed on the floor valve. The loop preparation cask is a shielded machine containing: (1) a weld cutter and a vacuum cleaning system to pick up chips formed during cutting, (2) a grapple for removing the top loop shield seal-plug, and (3) a weld head for rewelding the seal-plug to the loop nozzle. 


\section{Loop Handling Machine}

The loop handling machine (LHM) is a shielded sodiumcooled machine for handling open loop test assemblies, closed loop test assemblies, and the in-reactor assembly of the test loops. The LHM is used to remove these assemblies from and insert them into the reactor, and to transport them from the reactor to either interim storage or the transfer cell. The sodium coolant is obtained from the reactor bulk coolant system if handling open loop tests, and from the closed loop system if handling closed loop tests. The LHM secondary cooling system uses $\mathrm{NaK}$ as coolant.

A snorkel, attached to the wet valve, is socketed into the test position nozzle to seal the machine to the port or nozzle and to prevent sodium leakage when the sodium is raised. Sodium coolant is retained in the internal assembly of the LHM by a wet valve located at the bottom of the internal assembly. The primary mode of sealing the wet valve is metal-tometal contact. The secondary or backup mode of sealing is freezing the sodium between the valve and valve seat. After the test assembly is inside the machine, the wet valve is closed and the sodium in the snorkel drains back to its source. The residual sodium on the inside wall of the snorkel is frozen to control drippage. The snorkel is then withdrawn into the LHM, a drip pan is positioned under the snorkel, and the shield valve seals the internals of the machine from the atmosphere.

C. FUEL HANDLING EQUIPMENT ARRANGEMENT

Preliminary layouts of the ex-reactor fuel and test handling equipment are shown on SK-3-14497. 


\section{SECTION 8 IRRADIATION TEST FACILITIES}

A. TEST FACILITY LOCATION AND TYPE

The reference core provides space for nine test facilities along the 120-degree trisecting axis of the core. One of the three positions adjacent to the central driver location can only have proximity instrumentation in order to provide refueling access to the central position.

The remaining eight positions can accommodate six closed loops and two open tests using contact or proximity instrumentation, eight open tests with contact or proximity instrumentation, or any combination thereof.

A 11 nine experiment locations-are instrumented through independent ports penetrating the vessel cover. However, any test position can be reached by the driver fuel handling machine and, thus, all proximity instrumented open tests can be changed out using the driver handling sequence.

The core map does not prescribe a position for a shortterm facility (trail cable). It appears that a trail cable may be located in any one of the three peripheral experiment locations (next to first) reflector row). Task force effort did not examine the vessel head routing for the access tube and associated changeout mechanism for this facility.

\section{B. CLOSED LOOP DESCRIPTION}

1. Closed Loop Branch Arm Piping Drawing SK-3-14456, Sht. 1

The design provides for 2 -in. OD Sch. 40 coolant piping enclosed by a 4-in. ID insulation envelope. Insulation consists of an argon gas gap, reflective metal wrap, and 5/8 in. of Mini-K fiber insulation. Further optimization may be achieved by providing multiple layers of stainless foil with fiber insulation between layers all contained inside an evacuated space. 
Up to 15 in. of high density radiation shielding can be applied above the coolant piping. The instrument cable is routed along the coolant piping above the shielding but below the operating deck.

The branch arm piping has been doubly encapsulated to permit decontamination (by replacement) of sodium spills into the branch arm pipe chaseway and to contain sodium from a fractured branch arm pipe. Handling sequences for changeout and replacement are illustrated on Drawing SK-3-14456, Sheet 2.

\section{Closed Loop Nozzle Detail - Drawing SK-3-14457}

The design provides a spool piece and closure arrangement utilizing welds as the final seal between reactor cover gas and containment a ir atmosphere and between loop sodium and containment air atmosphere. K-gaskets are used as primary seals between the tube inlet and outlet coolant and as an initial barrier between loop sodium and reactor cover gas and between loop sodium and the containment air atmosphere. The closure design permits routine removal of the experiment separate from the outer tube and nonroutine removal of the experiment and outer tube together.

\section{Closed Loop In-Core Tube - Drawing SK-3-14515}

The tube provides double walled inner and outer tubes with argon in the gas gap. Along the in-core portion of the test, sintered stainless steel replaces the gas gap because it is a more conductive surface for decay heat removal. The circular cross section of the outer tube is adapted to fit the hexagonal core array. The test space can accommodate 37 pins of 0.25 -in. diameter or 19 pins of larger diameter.

This drawing and other test positions drawings are based on a 7-in. OD spool piece assembly for open and closed loops. This dictates a 5-in. ID clearance hole in the reactor cover and spool piece which limits the diameter across the hex of 
open loop ducts to less than 5-in. OD. This would limit the experiment to less than full driver size.

Further study of the problem indicated that the spool assemblies could be increased to approximately $75 / 8$-in. OD which provides a clearance hole of $51 / 2-i n$. ID. This is compatible with driver duct dimensions. Principles of operation and maintenance appear to be essentially unchanged. Because of the limited time available the drawings were not revised.

C. OPEN TEST POSITION (With Contact Instrumentation)

1. Open Test Position Nozzle Detail - Drawing SK-3-14458

This nozzle utilizes the same welded closure configuration as that used for the closed loop and, therefore, the same welding and cutting equipment may be utilized. The opening through the nozzle allows withdrawal of an adapted driver-size open test assembly similar to the closed loop. An extension is provided between the nozzle and the reactor sodium pool to permit wet withdrawal of a test utilizing the closed loop handling machine.

\section{Open Test In-Pile Section - Drawing SK-3-14514}

The design provides for a driver-size test assembly. As previously noted, eight positions can accommodate contact instrumentation. Standard instrumentation includes thermocouples, pressure sensors, gas sampling line, flux thimble, and a FEDAL sampling system. The latter involves a vortex generator and sodium sampling line to detect fission gas in the test channel.

3. Open Test, Closed Loop and Control Rod Integuments Drawing SK-3-14513

The drawings show envelopes to define handling methods. 
BNWL -1165

D. DESIGN OPTIONS FOR IRRADIATION TEST FACILITIES

The reference closure designs for both closed loops and open test positions involve remote welding and cutting operations. This choice is based on the great incentive for providing ensured no-leakage boundaries. If development efforts now planned and in progress on mechanical seals result in proven designs, then an availability advantage may result from the use of mechanical clamps on closed loops and open tests. 


\section{SECTION 9 REACTOR INSTRUMENTATION}

\section{A. INSTRUMENT SUPPORT ASSEMBLY}

The primary functions of the instrument plug(s) are to:

- Provide access to the driver assemblies so that they may be instrumented for flow, temperature, and fuel failure location.

- Provide backup mechanical hold-down for the core.

- Provide a method for assembling the core prior to applying radial restraint.

Each of the three instrument plugs provides access to approximately one-third of the core and consists of:

- An instrument plate that supports the driver instrument packages, the core assembly pieces, and the mechanical hold-down foot.

- The driver shaft which permits translation and rotation of the instrument plate.

- The FEDAL line plug-in connection grid.

- The guide tubes which permit replacement of the flow and temperature sensors with the plug in or out of the reactor.

- The shielding needed in the top head region.

- All hardware required for the function of the instrument plug such as drives, bearings and seals.

B. FEDAL ARRANGEMENT

1. Basic Concept Description and Rationale

The technical basis document $(1)$ for FEDAL indicates that fuel failure detection must be accomplished rapidly so that

1. J.J. Regimbal, Technical Bases for FFTF Driver Fuel Instrumentation, BNWL-916, pp. 6-8. Battelle-Northwest, Richland, Washington. October 1968, 
action can be taken to prevent continuation of the damage sequence which is not fully understood. This reasoning and other considerations dictate the following guidelines for the FEDAL detection-location system:

- In the early stages of FTR operation, the reactor will not be operated intentionally with failed fuel.

- The fuel failure must be detected rapidly; the detection time has not been established.

- Fuel will be considered to be failed if the cladding has been violated at any location including the gas plenum region.

- Failed fuel location should be possible within the refueling time period for the reactor.

Three FEDAL location systems were considered for the location system concept. These were:

- Detection of released fission gases.

- Detection of delayed neutrons.

- Detection of released tag gases.

The detection of released fission gases were selected as the reference concept for the following reasons:

- This system has the potential for locating a failed element from which only gas is released either continuously or in a burst.

- It has the potential for locating an element with the reactor shut down.

- It has the potential for identifying single or multiple elements which may fail at the same time.

To ensure that the sodium sample stream can obtain gas from any fuel pin in the subassembly and that the amount of 
gas in the sample stream be maximized, a fission gas concentrator is required. The concentrator (also known as a vortex generator, or a fission gas separator) is located above the fuel pins in the subassembly outlet coolant flow. Gas bubbles are forced to the center of the concentrator by centrifuge action where a perforated tube serves as a collector and the starting point for the sodium sample line.

These sodium samples are removed from the reactor vessel to shielded cells by means of pumps located in the rupture detection cell. Here the gas is separated from the sodium by means of stilling chambers. The sodium is returned to the sodium purification surge tank and the separated gas is delivered to a monitoring location-shielded from the sodium where the GM detectors monitor for an increase in gas activity.

A conceptual arrangement for the driver location system is shown in Drawing SK-3-14548. Other details of the conceptual FEDAL system are shown on the following drawings:

- N-68181251 FEDAL Tube Configuration at Stationary Top Shield*

- N-68181255 Instrument Support Assembly

- N-68181256 Instrumentation Assembly and Driver Fuel Alignment

- SK-3-14519 Reactor Cover Assembly

- SK-3-14540 Reactor Elevation

- SK-3-14541 Reactor Head Plan and Section

2. FEDAL for Open and Closed Loops

Detection of closed loop test section failure will be accomplished by monitoring in the closed loop cell. For the open loops with fuel tests, the sodium sample line will exit

\footnotetext{
* Requests for these drawings must be sent to Atomics International, a Division of North American-Rockwell, Canoga Park, California.
} 
near the top of the open loop stalk where the sample is transferred from the stalk to exit tubing in the reactor cover shield (see SK-3-14458). This is accomplished by means of a plug-in socket on a shoulder of the open loop. This connection is broken when the open loop is withdrawn. The exit tubing in the shield must be accessible for unplugging or replacement.

The exit method for open loops is not ideal. A leak at the transfer point during operation will cause loss of flow. During each removal of the open loop, both ends of the line (the end in the stalk and the end of the line in the shield) are potentially exposed to oxygen which could result in oxide plugs when the open loop is re-installed. Therefore, alternatives such as locating this connection under the sodium pool must be considered during preliminary design. Two ways of doing this are to remove the sample line from the bottom of the open loop (bottom of the core) or provide egress through a gland located beneath the shield and under the sodium.

C. DRIVER FUEL SUBASSEMBLY INSTRUMENT PACKAGE

The driver fuel instrumentation consists of four main assemblies:

- The removable sensor assembly which consists of an eddy current flowmeter, five thermocouples, the lead wires associated with the sensors, a push-pull support rod, and the male half of a ring type electrical connector.

- The flow conditioner-neutron shield assembly and the fission gas concentrator. These are located in a flow duct. A lead out-guide is welded into the top of flow duct.

- The maintenance access assembly, including the female half of the ring type electrical connector (mentioned in the first bullet), several plug type electrical connectors, the necessary seals, and the mechanical support structure required. 
- The FEDAL system including in-vessel and out-of-vessel equipment. This system is discussed separately in Section 9B.

Each of these will be discussed in sufficient detail to supplement the material presented in the drawings.

The total pressure drop across the instrumentation package is estimated to be between 10 and 15 1b/in. 2

\section{Sensor Assembly}

The removable sensor package provides for the monitoring of subassembly coolant flow and temperature. Provision has been made for five thermocouples, assuming a 2-of-4 temperature safety trip plus one used for-data gathering and/or control functions. With the neutron shielding presently envisioned, the thermocouple expected 1 ife is three years.

The flowmeter should provide acceptable $<<20 \%$ of the full flow as the error) flow measurement over a 20 to $120 \%$ flow range. Readings will be available at lower flows but the accuracy may be questionable.

The leads (two conductor) are mineral insulated and sheathed. These leads are 0.125-in. nominal OD and are attached to the push-pull support rod by the spherical balls. The spherical balls are included to provide guidance and support and to prevent galling or fretting of the wires with the guide tube.

The male half of the electrical connector begins immediately above the radiation shield. A transition piece is provided for each sheathed lead to allow the use of flexible, comparatively larger wires from his point to the rear of the connector. The connector proper consists of a hollow cylinder which has electrically conductive surfaces separated by insulator material and has the lead terminations attached to these 
conductive surfaces from the inside of the cylinder. This type of connector has been successfully used in hot cell operations.

There is a structural piece with a grapple ring below the connector proper to provide for attachment of the device which will be used to insert or remove the sensor assembly. The push-pull support rod is attached to this structure through the solid radiation shield piece. This assembly minimizes the force exerted on the electrical leads during insertion.

The removable sensors package is to be completely bench assembled using hands-on assembly procedures. The entire assembly is to be inserted into the guide tube. This procedure provides a more reliable and economical assembly than a procedure which involves making up connectors after insertion.

2. Flow Conditioner - Neutron Shield Assembly

The mechanical support and flow conditioner-neutron shield serves to reduce the physical or radiation damage to the active sensors. The flow guide tube serves to channel the flow from a single assembly past its instrumentation, provides the structural support for all of the instrumentation, and serves as part of the core gathering agency. The leadout guide tube provides the continuous path for the sensor package to follow during insertion and withdrawal. The bends in the leadout guide tubes are sized to allow relatively easy passage of the sensor package.

The neutron shield is included to 'reduce the fluence in such a manner that a 3-year lifetime goal for the thermocouples is considered reasonable. The flow straightener provides a flow profile to enhance the accuracy of the eddy current flowmeter. 


\section{Maintenance Access Assembly}

The design of the maintenance access port provides the capability for replacing the removable sensor packages at periodic intervals. Four plug-type connectors are provided to permit easy removal of the electrical jumper leads when required by the fuel handling procedures. The lower half of the plug type connector and the female half of the ring connector are attached to a structural plate which includes a depleted uranium shielding structure. Removal of this connector assembly can be performed using hands-on access techniques. The male halves of the ring type connector are a 11 exposed after the connector assembly is removed.

The hold-down plate restrains-the sensor packages from motion induced by loading at the lower end. This hold-down plate is removed when sensor packages are to be replaced. After the hold-down is removed, the double seals on each sensor package are still maintained.

D. EXPERIMENTAL FACILITY INSTRUMENTATION

1. Open Test Facility Instrumentation - Drawing SK-3-14514

The open test facility process instrumentation is similar to the driver fuel instrumentation and consists of the following:

- One eddy current flowmeter.

- Five outlet coolant thermocouples

- One vortex generator and sodium sample line. The sodium sample line exits through a connection in the nozzle area.

- Provision for 0.50-in. OD thimble for flux mapping during startup testing. 
BNWL -1165

\section{Experimenter's Instrumentation}

Drawing SK-3-14514 shows the capability for making the following measurements which are in addition to the process instrumentation requirements:

- Two fuel pin heat thermocouples

- Four fuel pin cladding thermocouples

- One fission gas pressure measurement using a NaK capillary to electromechanical transducer

- One fission gas pressure measurement using a null balance pressure transducer

- Many other combinations of instruments or test arrangements are possible.

Nozzle connector and instrument leadout details are shown on SK-3-14546 and SK-3-14547.

2. Closed Loop Instrumentation

Instrumentation has two major parts, process surveillance and experimenter instrumentation. Reference Drawing SK-3-14515.

\section{a. Process Surveillance}

- Inlet coolant temperature - three thermocouples mounted below the test section.

- Outlet coolant temperature - three thermocouples mounted above the test section before bypass coolant is introduced.

- Coolant flow is measured in closed loop piping external to the reactor.

- Failed fuel detection is performed outside the reactor. Failed fuel location is, of course, not required.

- Differential pressure across the test section is measured by two bellows-NaK capillaries. One is installed below the test section and the other above the test section. 
The two capillaries are led to a differential pressure electromagnetic transducer located in the nozzle.

- Flux monitor thimble - a 0.25-in. OD thimble is shown penetrating to the bottom of the test section. Installation of the thimble and its size depends upon the needs of the experimenter. Space for a 0.5-in. diameter thimble is shown through the nozzle connector (Reference Drawing SK-3-14547). The thimble may also be used separately during early startup for flux mapping.

\section{b. Experimenters Instrumentation}

For a fuel test, Drawing SK-3-14515 represents the manner of connecting experimenters lines. The following instrumentation capability, in addition to surveillance instrumentation, is possible. Alternative combinations of instruments are possible at the experimenters discretion.

- Fuel pin internal temperature - 2 thermocouples

- Fuel pin cladding temperature - 4 thermocouples

- Fuel pin internal pressure - using the pressure balance method, a tube is led to the nozzle connector from a diaphragm in the fuel pin.

For an alternative material test, instrument lines are available for the following representative tests:

$$
\text { Specimen temperature - } 3 \text { thermocouples }
$$$$
\text { Strain gages (when developed) - } 2
$$

Nozzle connector and instrument leadout details are shown on Drawings SK-3-14546 and SK-3-14547.

\section{E. CABLE ROUTING - REACTOR COVER ASSEMBLY}

The connectors that pick up the instrumentation leads as they emerge at the top of the reactor cover shield are shown on SK-3-14547 for open and closed test loops. 
The location of each connector and cable routing over the reactor cover shield is shown on Drawing SK-3-14519.

The cable is assembled into harnesses which have a quick disconnect at each end. The driver fuel element instrument harnesses are stored below the reactor cover floor plate during fuel handling. The test loop harnesses are also stored under the floor plate but would be removed during closed loop pipe handling.

The harness assemblies connect to junction boxes located on the circumference of the reactor top shield assembly.

F. LOW LEVEL NEUTRON MONITORS

1. Basic Requirements and Rationale

The flux monitor system is required to monitor the neutron flux level at all times. The most difficult situation to monitor occurs several minutes after the reactor has been shutdown from full power operation. The Low Level Neutron Monitor (LLNM) must be capable of monitoring the shutdown flux, which may be as low as a factor of $2 \times 10^{11} \mathrm{n} / \mathrm{cm}^{2}-\mathrm{sec}$ below full power flux. A minimum acceptable count rate for a low level neutron monitor has been established at 5 to 10 counts/sec.

\section{Detector Location}

Recently established fluence limits on the vessel wall were used to calculate the reaction rates of candidate sensors materials, boron and ${ }^{235} \mathrm{U}$, located in the neutron shield external to the vessel. These reaction rates indicate that the minimum count rate values cannot be established with stateof-the-art sensors located in the external shield and circuitry when the reactor is in its most subcritical state.

For this reason, an acceptable location for a low level neutron sensor was sought within the reactor vessel. Studies indicate that an acceptable detector location would be at approximately the interface of the nickel reflector and the in-vessel shield.

$$
\text { C - } 82
$$




\section{Detector Response}

The estimated neutron shutdown count rate for a commercial 2 -in. diameter fission chamber containing about $1.8 \mathrm{~g}$ of ${ }^{235} \mathrm{U}\left(2 \mathrm{mg} / \mathrm{cm}^{2}\right)$ when operating in a gamma field of $10^{5} \mathrm{R} / \mathrm{hr}$ is about 10 counts/sec. This estimate takes into consideration a decrease of $2 \times 10^{11} \mathrm{n} / \mathrm{cm}^{2}-\mathrm{sec}$ in reactor power, and the local effect induced by the insertion of the peripheral rods.

The background gamma immediately after shutdown will be about 1 to $2 \times 10^{6} \mathrm{R} / \mathrm{hr}$ because of the decay gammas, predominately from manganese, in the stainless steel. This will reduce the available neutron count rate to values below 10 counts/sec for a period of 8 to 10 hours after shutdown.

4. Mechanical Features

Drawing SK-3-14519 shows the location selected for the shutdown monitor. It is expected that three in-vessel monitors will be required to ensure that two are normally available. A mechanical interference exists between the fuel hand1inginstrument plug and the flux monitor thimble during refueling. For this reason the flux thimble containing the neutron sensor and driver must be removed from one cover sector before refueling in that sector can be accomplished. The removal procedure for the chamber drive and the thimble will be similar to that for the control rods driveline.

The flux monitor assembly will consist of the protective thimble which contains the fission chamber, some inorganic moderator, the driver extension, a gas cooling system, and shielding. The chamber positioning mechanism will be similar to a rod drive and will be capable of raising the chamber approximately $42 \mathrm{in}$. above its fully inserted position. The neutron flux in the retracted position will be sufficiently low to permit a chamber life of several years if based only on this consideration. 
The chamber cooling system must maintain a chamber environment of about $600^{\circ} \mathrm{F}$ or less. However, the cooling system need not be operative during reactor shutdown.

A supplementary LLNM system located in the shield external to the reactor vessel will be required to obtain the necessary overlap with the intermediate range monitor system.

G. IN-VESSEL OUT-OF-CORE INSTRUMENTATION

\section{Coolant Level}

Coolant level will be sensed through closed thimbles by means of induction coils similar to those used at Hallam. Three vessel cover penetrations of about 5-in. diameter will be required.

Three penetrations are required to provide the necessary redundancy and backup required for scramming and other purposes. The thimble locations are out of the core area, over core shield pieces, and out of the way of fuel handling operations. 2. Inlet, Outlet and Cover Gas Temperature

The inlet coolant temperature will be measured with thermocouples installed through a thimble, which penetrates the vessel cover and a core shield piece and with access to the inlet plenum. This same thimble (perforated) may be used for the thermocouples which measure the temperature of the three outlet coolant streams. The cover gas temperature is measured with thermocouples located between the pool level and the shield. Three locations for these thimbles are necessary to provide redundancy of measurement as well as to provide temperature measurements at the points necessary due to the arrangement of the inlet and outlet streams. 


\section{Inlet Pressure}

Inlet coolant plenum pressure will be measured with a bellows, a NaK-filled capillary, and an electromechanical transducer located out of the high-temperature region. The bellows will be mounted on a long stalk inserted in a thimble which penetrates the vessel cover and vessel shield piece to be exposed to the inlet pressure.

\section{Cover Gas Pressure}

Because the cover gas pressure will be low (near atmospheric) a large diaphragm is required to obtain adequate sensitivity. It is probably impossible to find enough space inside the vessel or in the top shield for this sensor. Therefore, the cover gas pressure will probably be measured out of the vessel by means of such a large sensor connected to a large (about 2-in. diameter) pipe connected to the reactor cover gas space.

In summary the overall plan for making these in-vessel bulk measurements requires six 5-in. diameter penetrations of the vessel cover and shield. Refer to SK-3-14540 and SK-3-14541 for the proposed location of the top shield penetrations. 


\section{SECTION 10 CONTAINMENT}

\section{A. $\quad$ CONCEPT}

The overall containment concept is shown in SK-3-14425 and SK-3-14426 and utilizes a double barrier to maintain radionuclide leakage to the atmosphere to concentrations specified by 10CFR100 criteria for a Design Basis Accident. The outer and final barrier to the environs is a steel pressure vessel either cylindrical or spherical in shape with a leakage rate of less than 1 vol\%/day at design pressure. For the diameters required, a cylindrical vessel is limited to about $20 \mathrm{lb} / \mathrm{in}^{2}{ }^{2}-\mathrm{g}$ and a spherical vessel to about $35 \mathrm{lb} / \mathrm{in}^{2}{ }^{2}-\mathrm{g}$ before stress relieving in the field is required. The vessel is designed in accordance with Section III of the Nuclear Pressure Vessel Code as a Class B vessel and is to be tested, initially, to determine its leak rate and, at periodic intervals thereafter, to ensure its containment capability.

Personnel and equipment access through the containment vessel is normally via air locks. A large equipment access door, normally sealed, is available during special controlled shutdown conditions. Penetrations for piping and wiring are sealed in a positive manner to prevent leakage. Ventilation and piping are provided with double valves.

The inner containment barrier is the reactor machinery dome (see SK-3-14495). The steel liner of the reactor cavity vault and the heat transport system cells offer protection from accidents which may originate in the reactor core and primary sodium system. Accidents in a closed loop cell are isolated to that particular cell.

The reactor machinery dome is a steel pressure vessel which is positioned over the top face of the reactor during reactor operation which has an air atmosphere. Its purpose is to contain energy released from the reactor vessel via the 
vessel head as a result of an accident and to contain sodium air reactions which may result from sodium injection through the head. It also provides missile protection to the outer containment vessel with its energy absorbing materials inside the dome. The reactor machinery dome is hemispherical in shape and about $33 \mathrm{ft}$ in diameter. It is removed during shutdown for maintenance and refueling operations. A manhole access provides entry to the reactor top face without removing the structure.

The reactor cavity vault is a cylindrical concrete structure which houses the reactor vessel. It is steel lined to prevent leakage and designed for high pressure, similar to the reactor dome. The reactor cavity vault is common to the three heat transport system cells; temperature and pressure originating in the vault equalize with these adjoining cells. The atmosphere in the reactor cavity vault and the HIS cells is normally nitrogen so as to minimize the possibility of a sodium-air reaction. The concrete is thermally insulated and will have embedded cooling coils to supplement the inert gas cooling and limit temperatures within the structural concrete.

B. INSTRUMENTATION AND CONTROL REQUIREMENTS

Instrumentation and Controls for the containment system shall operate as follows:

- They shall monitor the temperatures and pressures within the containment vessel and the radionuclide concentration in the air leaving the vessel, and provide signals to initiate containment in the event of an abnormal energy or radioactivity release.

- Containment shall be initiated as either ventilation containment or total containment. 
- A reactor shutdown shall be initiated by either the ventilation containment actuation signal or the total containment actuation signal, whichever occurs first.

- Exhaust and supply ventilation valves shall close simultaneously upon indication of radionuclide concentrations in the exhaust air which exceed a preset $1 \mathrm{imit}$.

- All containment valves not essential for safe reactor operation shall close automatically upon an increase in pressure or temperature beyond a preset limit.

- Individual cells within the containment vessel, in which a potential for a serious contamination incident exists, shall be isolated and shall be monitored for temperature, pressure, and airborne radionuclide concentration. 


\section{I S TR I B UT ION}

No. of

Copies

OFFSITE

$\underline{\text { AEC Chicago Patent Group } S}$

G. H. Lee

AEC Division of Reactor Development and Technology

Director, RDT

Asst Dir for Nuclear Safety

Analysis E Evaluation Br, RDT:NS

Asst D ir for Plant Engrg, RDT

Facilities Br, RDT:PE

Components $\mathrm{Br}, \mathrm{RDT}: \mathrm{PE}$

Instrumentation \& Control Br, RDT:PE

Liquid Metal Systems Br, RDT:PE

Asst Dir for Program Analysis, RDT

Asst Dir for Project Mgmt, RDT

Liquid Metals Projects Br, RDT:PM

G. J . Mishko

FFTF Project Manager, RDT :PM

Asst D i r for Reactor Engrg, RDT

Control Mechanisms Br, RDT:RE

Core Design $\mathrm{Br}, \mathrm{RDT}: \mathrm{RE}$ (2)

Fuel Engineering $B r$, RDT:RE

Fuel Handling Br, RDT': RE

Reactor vessels Br, RDT:RE

Coolant Chemistry Br, RDT:RT

Fuel Recycle Br, RDT:RT

Fuels \& Materials Br, RDT:RT

Reactor Physics Br, RDT:RE

Special Technology Br, RDT:RT

Asst Dir for Engrg Standards, RDT

LMFBR Program Manager, RDT:PM

215 AEC Division of Technical Information Extension

1 AEC Idaho Operations Office

Nuclear Technology Division

C. W. Bills, Director

1 ABC San Francisco Operations Office

Director, Reactor Division

$5 \quad$ AEC Site Representatives

Argonne National Laboratory-CH

Argonne National Laboratory-ID

Atomics International

General Electric Company

Westinghouse Electric Company 
No. of

Copies

3

5

2

5

1

Combustion Engineering

1000 MWe Follow-On Study

W. P. Staker, Project Manager

1 Combustion Engineering

911 West Main Street

Chattanooga, Tennessee 37401

Mrs. Ne11 Holder, Librarian

3 General Electric Company

Advanced Products Operation

K. Cohen (3)

1 General Electric Company

Nucleonics Laboratory

Pleasanton, Calif.

Dr. H. W. Alter

2

Gulf General Atomic Incorporated

General Atomic Division

D. Coburn 
No. of

Copies

1

Idaho Nuclear Corporation

J. A. Buckham

1 Liquid Metal Engineering Center

R. W. Dickinson

2

Liquid Metal Informaticn Center

A. E. Miller

1

Oak Ridge National Laboratory

W. 0. Harms

1 Stanford University

Nuclear Division

Division of Mechanical Engineering

R. Sher

1 United Nuclear Corporation

Research and Engineering Center

R. F. DeAngelis

10 Westinghouse Electric Corporation

Atomic Power Division

Advanced Reactor Systems

D. C. Spencer

ONS ITE-HANFORD

1

$\frac{\text { AEC Chicago Patent Group }}{\text { R. K Sharp (Richland) }}$ S

2

AEC Richland Operations Office

J. M. Shively

3

Battelle Memorial Institute

1 Bechtel Corporation

W. A. Smith (Richland)

2

0. C. Schroeder

C. W. Kuhlman

\section{Distr-3}


No. of

Copies

3

RDT Assistant Director

WADCO Corporation

G. J. Alkire

H. J. Anderson

S. O. Arneson

J. M. Atwood

J. M. Batch

R. A. Bennett (2)

K. L. Berrett

C. L. Boyd

D. C. Boyd

W. L. Bunch

C. A. Burgess

C. P. Cabe11

J. R. Carrel1

J. C. Cochran

D. L. Condotta

R. R. Cone

J . H. Cox

W. Dalos

L. J. Defferding

D. R. Doman

R. V. Du1in

J. F. Erben

W. H. Esselman

E. A. Evans

L. E. Fort

W. M. Gajewski

E. E. Garrett

J. W. Hagan

J. P. Hale

J . E. Hanson

K. M. Harmon

R. A. Harvey

E. N. Heck

R. E. Heineman

J. W. Helm

R. J . Hennig

C. W. Higby

P. L. Hofmann

B. M. Johnson

H. G. Johnson

E. M. Johnston

J . N. Judy
F. J . Kempf

J . W. Kolb

G. A. Last

F. J. Leitz

H. D. Lenkersdorfer

W. W. Little, Jr.

C. E. Love

M. K. Mahaffey

D. E. Mahag in

W. B. McDonald

J . S. McMahon

D. Marinos

J . E. Mills

W. A. Muller

C. A. Munro

C. R. Nash

J. M. Norris

D. J. Oakley

R. E. Peterson

O. W. Priebe

B. G. Rieck

W. E. Roake

G. J. Rogers

E. J. Ruane

D. P. Schively

J . M. Seehuus

F. H. Shade 1

D. W. Shannon

W. F. Sheely

D. E. Simpson

C. R. F. Smith

D. D. Stepnewski

G. H. Strong

C. D. Swanson

J. C. Tobin

K. G. Toyoda

L. D. Turner

R. C. Walker

G. R. Waymire

J. H. Westsik

J. F. Wett

T. W. Withers 
No. of

Copies

WADCO Corporation (Contd)

B. Wolfe

M. R. Wood

W. R. Wykoff

WADCO Document Control (15)

WADCO Tech Pubs. (703 Bldg.)

18 Battelle-Northwest

F. W. Albaugh

E. R. Astley

A. L. Bement, Jr.

P. D. Cohn

D. R. de Halas

J. M. Davidson

L. M. Finch

H. Harty

N. G. Wittenbrock

F. W. Woodfield

Technical Information (5)

Technical Publications (2)

Legal - ROB, 221 A. 